\title{
Compositional Variations of Titan's Impact Craters Indicates Active Surface Erosion
}

Alyssa Werynski, The University of Western Ontario

Supervisor: Neish, Catherine D., The University of Western Ontario

A thesis submitted in partial fulfillment of the requirements for the Master of Science degree in Geophysics

(C) Alyssa Werynski 2018

Follow this and additional works at: https://ir.lib.uwo.ca/etd

Part of the Geology Commons

\section{Recommended Citation}

Werynski, Alyssa, "Compositional Variations of Titan's Impact Craters Indicates Active Surface Erosion" (2018). Electronic Thesis and Dissertation Repository. 5585.

https://ir.lib.uwo.ca/etd/5585

This Dissertation/Thesis is brought to you for free and open access by Scholarship@Western. It has been accepted for inclusion in Electronic Thesis and Dissertation Repository by an authorized administrator of Scholarship@Western. For more information, please contact wlswadmin@uwo.ca. 


\begin{abstract}
Impact craters on Titan are relatively scarce but provide ample information about the subsurface properties and modification processes present there. This study utilizes impact craters to examine compositional variations across Titan's surface and their subsequent modification. Fifteen craters and their ejecta blankets were studied. Subsurface composition was inferred from emissivity data from Cassini’s RADAR instrument, and surficial composition from Cassini's Visible and Infrared Mapping Spectrometer (VIMS). Results show subsurface composition of these craters is controlled by their degradation state and local environment. Older craters are more infilled with organics than younger, and dunes craters show more organic enrichment than plains craters. Surficial composition is only controlled by the local environment (i.e. dunes or plains regions). Since degraded craters show organic rich subsurfaces, but varying surface compositions, it is likely there is an active surface process clearing the surface of sediments and infilling the craters' subsurface fractures.

\section{Keywords}

Titan, impact processes, cratering, surface processes, radar, infrared observations 


\section{Co-Authorship Statement}

Chapter 3 is a version of a manuscript for publication submission titled "Compositional Variations in Titan's Impact Craters Indicates Active Surface Erosion”. Co-authors are Dr. Catherine Neish, Dr. Alice Le Gall, Dr. Michael Janssen, and the Cassini RADAR team. Mapping techniques and the first method of analysis was completed by A. Werynski. The second method of analysis was completed by Dr. Le Gall. Interpretations and suggestions were contributed by Dr. Catherine Neish and Dr. Alice Le Gall. 


\section{Acknowledgments}

Thank you to Dr. Catherine Neish for not only providing me with a thesis topic I thoroughly enjoyed but also for the unconditional and helpful guidance in this work. Thank you especially for understanding the delicate balance and intricate relationship between work and personal life. Thank you for pushing me, supporting me, and reminding me that I can do it! Thank you for sending me to so many different conferences - these were all truly enjoyable and of course, educational. An additional thank you to Dr. Alice Le Gall for all of her helpful insights and feedback in this work.

Thank you to my friends near and far who helped me through the last year whether it was with my research, field work, or enjoying my time in London. Thanks to Lindsay especially for kicking my writing into gear. Thanks to Jordan and Sarah (and Lindsay) for keeping me sane and introducing me to a lot of new things. Thanks to Liam for sharing a love of sports. And of course, thanks to Josh for his helpful MATLAB guidance whenever Mathematica failed me.

Finally, thank you to my parents. Thank you for unconditionally supporting me in everything I want to do - whether it be moving to a new state or country, deciding to go back to school, or wanting to travel the world. Thank you for putting up with me and thank you for always helping me out, no matter what. 


\section{Table of Contents}

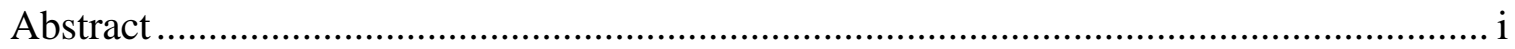

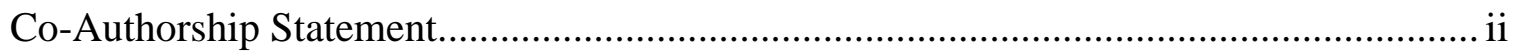

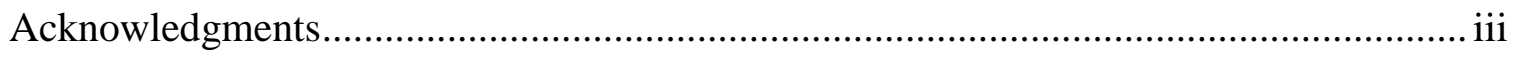

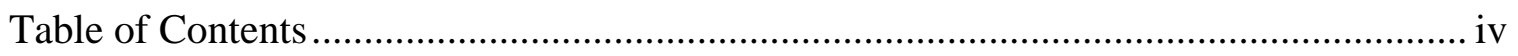

List of Tables …................................................................................................ vi

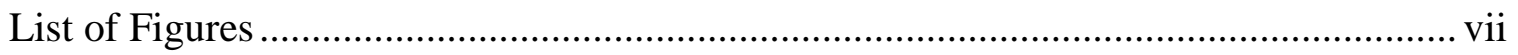

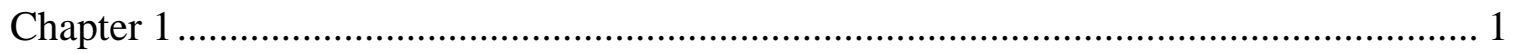

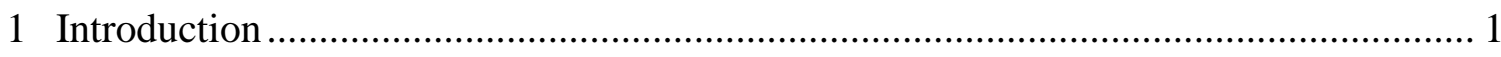

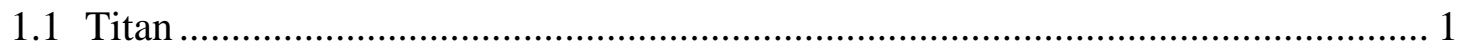

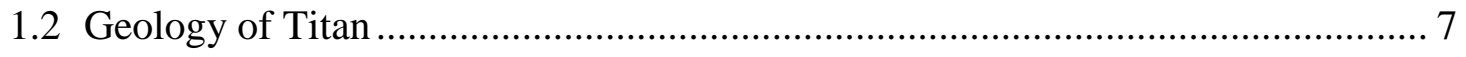

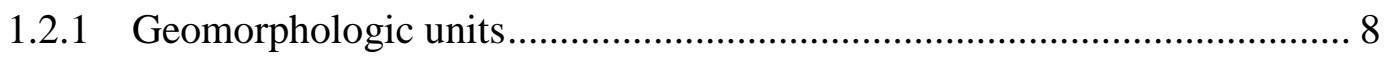

1.3 Impact crater formation......................................................................... 14

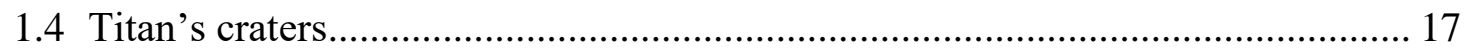

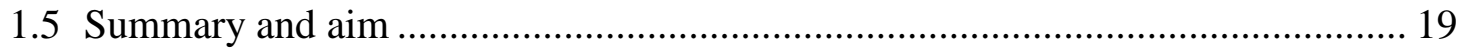

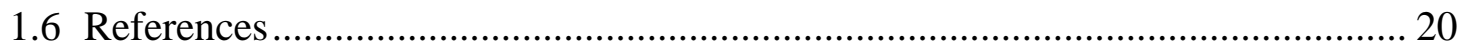

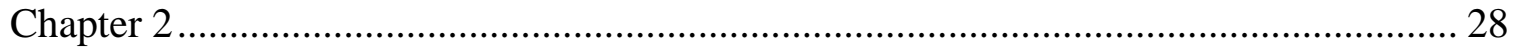

2 Remote Sensing Datasets and Methodology ................................................... 28

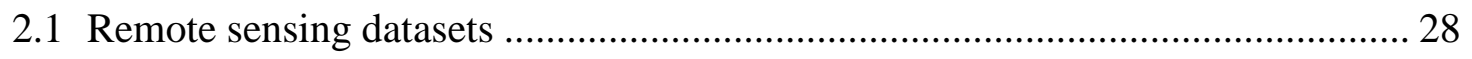

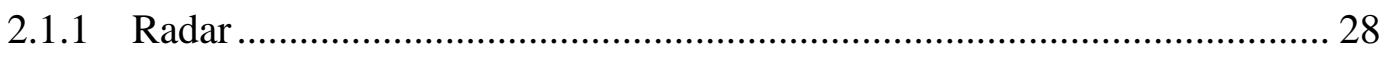

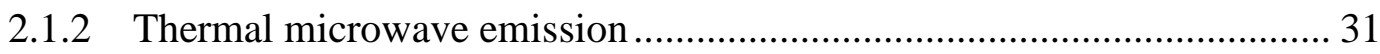

2.1.3 Visible and Infrared Mapping Spectrometer (VIMS) ............................ 35

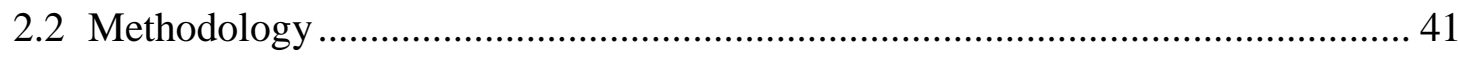

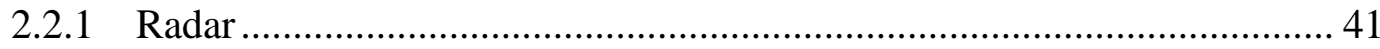

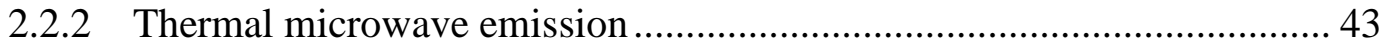


2.2.3 Visible and Infrared Mapping Spectrometer (VIMS) ........................... 46

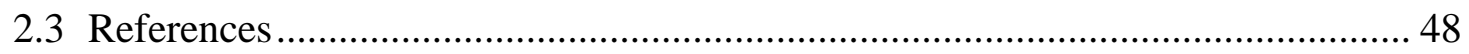

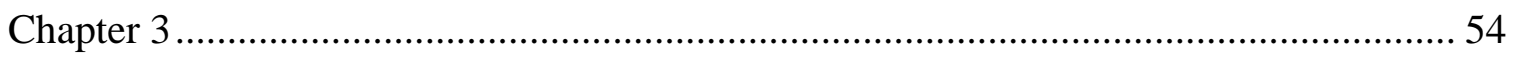

3 Compositional Variations of Titan's Impact Craters Indicates Active Surface Erosion 54

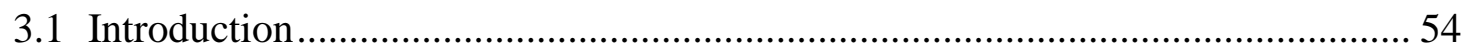

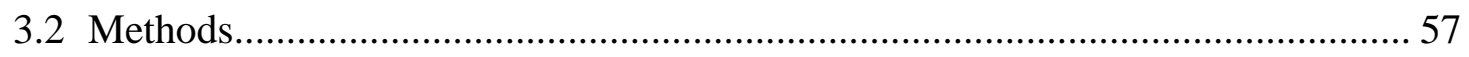

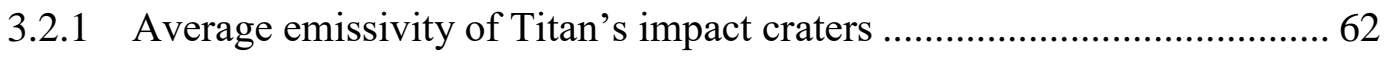

3.2.2 Filling factor emissivity of Titan's impact craters ............................... 65

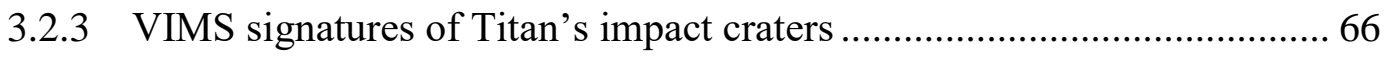

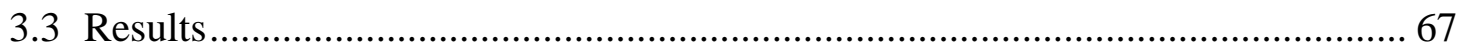

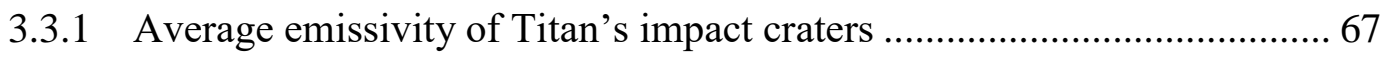

3.3.2 Filling factor emissivity of Titan's impact craters .............................. 71

3.3.3 Infrared spectra of Titan's impact craters ........................................ 74

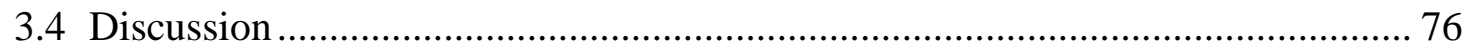

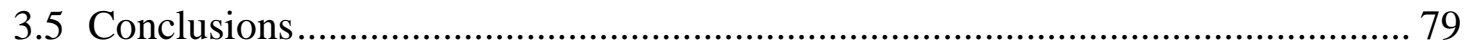

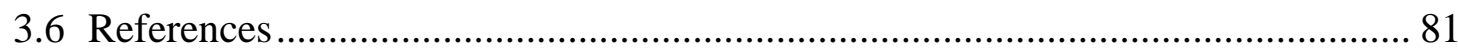

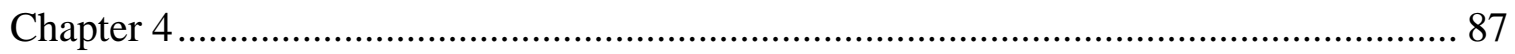

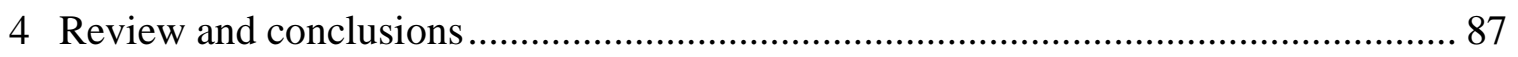

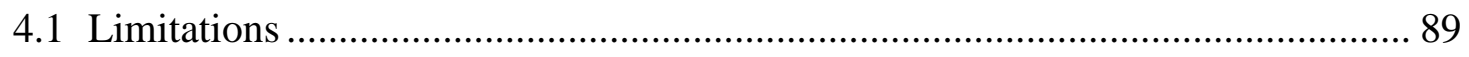

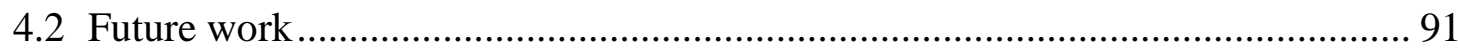

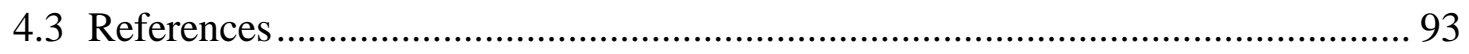

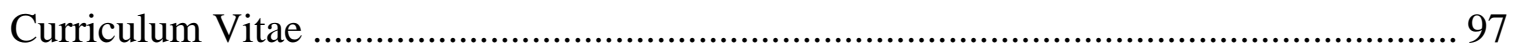




\section{List of Tables}

Table 1: Instrument suite for the Huygens probe........................................................... 5

Table 2: Payload suite onboard the Cassini spacecraft....................................................... 6

Table 3: Environmental Conditions on Titan.............................................................. 7

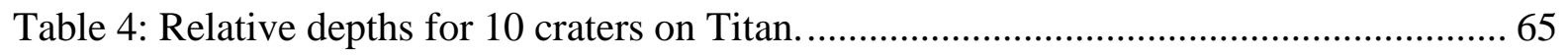

Table 5: Calculated high and low resolution mean emissivity for 15 craters on Titan ......... 67

Table 6: Characteristics of 15 impact craters on Titan ................................................. 76 


\section{List of Figures}

Figure 1: Size comparison of Mercury, Titan, and Earth's Moon. Approximate diameters $(\mathrm{km})$ for each body listed here. Image created from NASA's image archive. 2

Figure 2: a) Hypothesized interior structures of the icy Galilean satellites, Europa, Ganymede, and Callisto in comparison to Titan. Figure 2a from Sotin et al., 2009. b) Modeled interior structure of Titan, which likely has a silicate, or mix of ice and rock, core, surrounded by high pressure ices. Beneath the icy crust there is likely a liquid water ocean.

Figure $2 b$ from Tobie et al., 2005. 3

Figure 3: Spectral plot obtained from VIMS image v1525115629_1 centered at $\sim 32^{\circ} \mathrm{N}$, $12^{\circ} \mathrm{W}$. The atmospheric windows are illustrated by the wavelength peaks.......................... 7

Figure 4: Titan in different wavelengths of light. The left image shows what Titan would look like to the human eye. The right image shows a near-infrared wavelength image $(0.938$ $\mu \mathrm{m}$ ), capable of viewing the surface (NASA, 2018). Both images were acquired by Cassini's Imaging Science Subsystem (ISS).

Figure 5: Map of major geomorphologic units on Titan. Labyrinth terrain represented in red, undifferentiated plains in green, hummocky/mountainous terrain in yellow, and sand dunes in purple. Cassini ISS map underneath available RADAR image swaths to provide context. Image from Lopes et al., 2016.

Figure 6: Radar image of potential cryovolcanic feature called Sotra Facula. Here, North is up. A $1450 \mathrm{~m}$ high mountain, Dooms Mons is to the west of Sotra Patera, a $1700 \mathrm{~m}$ deep pit. The associated lobate flows are outlined in red, flowing in a NE direction.

Figure 7: Cat scratch features $\left(\sim 16^{\circ} \mathrm{N}, 93^{\circ} \mathrm{W}\right)$ shown by the radar as dark streaks flanking the western and eastern sides of the image. These were later determined to be longitudinal dune features. Image from NASA's image archive.

Figure 8: a) Visible images taken by the Huygens probe DISR showing dark, dendritic fluvial channels (modified from Lunine and Lorenz, 2009). b) Radar image of a lake, large enough 
to be classified as a sea, named Ligeia Mare. These images are in polar projection (modified from Lopes et al., 2010).

Figure 9: Series of schematic cross-sections depicting the three main stages in the formation of simple (left) and complex (right) craters. Modified from Osinski et al., 2011.

Figure 10: Radar map of Titan with the 90 craters circled in red. The size of the circle is proportional to the crater's diameter. Note the lack of craters near the poles. Image from Hedgepeth et al., 2018.

Figure 11: a) Schematic showing how a surface will scatter the radar energy in certain directions based on the wavelength-scale roughness of its surface. b) Radar backscatter also depends on the incidence angle of the beam. Smoother surfaces can have strong returns when the incidence angle is close to the surface slope angle, but have very weak returns at incidence angles greater than $30^{\circ}$. Image from Neish and Carter, 2014, adapted from Farr, 1993

Figure 12: Cassini RADAR image of Santorini crater located at $2.2^{\circ} \mathrm{N}, 147.7^{\circ} \mathrm{W}$. Radar bright regions correspond with the rough crater rim and ejecta blanket. Radar dark regions correspond with the smooth surrounding sand dunes and sediment infill in the crater interior. Sand dunes appear smooth in radar because grain size is only a few hundred microns and the radar senses surface roughness at centimeter scales. 30

Figure 13: The Sun's spectrum (black) in relation to a perfect emitter, or blackbody (green), at the same temperature. The Sun is considered a blackbody but note how the Sun's spectrum does not match up evenly with a laboratory spectrum of a similar temperature blackbody. In nature, nothing is 'perfect', therefore objects in nature will have emissivity values less than 1. Image from Physics Stack Exchange.

Figure 14: Global emissivity map of Titan from Janssen et al., 2016. Higher emissivities are represented by warmer colors and indicate organic enrichment. Lower emissivity values are represented by cooler colors and are interpreted as water-ice enrichment.

Figure 15: An example of volume scattering of sunlight on a tree top. Leaves, as well as branches, can scatter the incoming light in different directions. 
Figure 16: Global VIMS mosaic of Titan from Cassini observations by Barnes et al., 2007. Colors are mapped with red as 4.8-5.2 $\mu \mathrm{m}$, green as $2.0 \mu \mathrm{m}$, and blue as $1.28 \mu \mathrm{m}$. Reds are either clouds or evaporites, blue represents water-ice, browns are sand dunes, and green is an unknown unit, likely a mix of organics and water-ice. Figure modified from Neish et al., 2015 36

Figure 17: Spectra of pure water-ice shown from a wavelength range of 0.8-3.0 microns. Note the large absorption bands at $\sim 1.5$ and 2.0 microns (Kokaly et al., 2017).

Figure 18: VIMS spectra from 3 distinct units on Titan. a) VIMS brown spectra, indicative of organics. b) VIMS blue spectra, indicative of a water-ice enrichment. c) VIMS green spectra, an unknown unit, potentially a mix of water-ice and organics.

Figure 19: VIMS spectra for Sinlap crater and the surrounding region on Titan. The RGB image shown is a band ratio image ( $\mathrm{R}: 1.59 / 1.27$, G: 2.03/1.27, and $\mathrm{B}: 1.27 / 1.08)$. Blue regions and spectra correspond with a proposed water-ice unit, brown regions and purple spectra are likely organic, white regions and red and black spectra represent an unknown unit. The green spectra is derived from a single pixel and could be affected by a cosmic ray, however, this pixel has been captured in previous images and likely represents a surface heterogeneity. I/F is the observed spectral radiance divided by the solar irradiance (Le Mouelic et al., 2007).

Figure 20: VIMS-IR images of the same area of Titan at 3 different wavelengths. As the wavelength gets shorter, there are more scattering effects caused by the haze in the atmosphere (McCord et al., 2006).

Figure 21: Surface mass to charge ratios acquired from the GCMS on board the Huygens probe. Data was taken starting upon impact until signal was lost (Niemann et al., 2005)... 41

Figure 22: Cassini RADAR basemap comprised of all available radar images. 42

Figure 23: Interpolated global elevation map of Titan obtained from Corlies et al., 2017.

High elevation areas are shown in red, low elevation in blue. 43 
Figure 24: Image showing process of creating the high resolution emissivity mosaic. a) The global, low resolution, emissivity dataset for Titan. b) All high resolution, BIBQI-, radar images of Titan. These images were acquired at the same time as the highest resolution emissivity swatches and therefore match up with each other. c) The radar swatches shown in b) were used to extract the emissivity data from a) to create the high resolution data product shown here.

Figure 25: Three VIMS images with the color scheme outlined in Barnes et al., 2007 showing Sinlap crater. The highest resolution image is placed on top. The lowest resolution is placed on the bottom, providing more context to the region.

Figure 26: Cassini RADAR map of Titan. All 15 craters in this study are shown in red and labeled.

Figure 27: Cassini RADAR images of the 15 craters (outlined in red) studied in this work, in order of size. North points up in all images. a) Menrva, D $425 \mathrm{~km}$. b) Forseti, D $139 \mathrm{~km}$. c) Paxsi, D 120 km. d) Afekan, D 115 km. e) Hano, D 100 km. f) Sinlap, D 82 km. g) Selk, D 80 km. h) Soi, D 78 km. i) Guabonito, D 68 km. j) Nath, D 58 km. k) Unnamed crater discovered in flyby T104, D $57 \mathrm{~km}$. 1) Momoy, D $40 \mathrm{~km}$. m) Ksa, D 39 km. n) Shikoku, D 35 km. o) Santorini, D $\sim 33$ km.

Figure 28: $2.18 \mathrm{~cm}$ emissivity data overlain on Cassini RADAR images of the 15 craters of interest on Titan (outlined in red), in order of size. North points up in all images. a) Menrva, D 425 km. b) Forseti, D 139 km. c) Paxsi, D 120 km. d) Afekan, D 115 km. e) Hano, D 100 km. f) Sinlap, D 82 km. g) Selk, D 80 km. h) Soi, D 78 km. i) Guabonito, D 68 km. j) Nath, D 58 km. k) Unnamed crater discovered with flyby T104, D 57 km. 1) Momoy, D 40 km. m) Ksa, D 39 km. n) Shikoku, D 35 km. o) Santorini, D $\sim 33 \mathrm{~km}$. 60

Figure 29: Available VIMS data overlain on Cassini RADAR images for 12 of the 15 craters, outlined in red. VIMS spectra colors: blue is $1.28 \mu \mathrm{m}$, green is $2 \mu \mathrm{m}$, and red is $4.8-5.2 \mu \mathrm{m}$. Blue units are water-ice, green units are an unknown unit potentially organics and water-ice, and brown units are sand dunes. a) Menrva crater, b) Forseti, c) Paxsi (larger) and unnamed 
crater discovered with flyby T104 (smaller), d) Afekan, e) Sinlap, f) Selk, g) Soi, h) Guabonito, i) Nath, j) Ksa, and k) Santorini.

Figure 30: Cassini RADAR image of Forseti crater. Radar bright regions here correlate with the crater's rough rim and ejecta blanket, outlined in red. The radar dark material in the crater floor may be smooth sediments deposited there by aeolian or/and fluvial activity. A possible central uplift as inferred from crater diameter and radar imagery is observed on the floor as well

Figure 31: Cassini RADAR image of Forseti crater with global emissivity data overlain. The NE segment of the crater shows the higher resolution emissivity data available whereas the SW segment of the crater is covered by the lower resolution data set.

Figure 32: Left: Outlines of the Forseti crater (black) and radiometry footprints (blue) over the crater region. Right: Emissivity of the crater area as a function of the areal filling factor by the crater rim and ejecta of each radiometry footprint and associated linear fit (solid line).

Figure 33: Mean emissivity versus (a) crater longitude $\left({ }^{\circ} \mathrm{W}\right)$, (b) crater latitude and (c) crater elevation. The dashed lines represent average global background values for the high resolution data set in addition to the low resolution data set. Blue boxes correspond to the low resolution data set, black circles represent the high resolution data set.

Figure 34: Mean emissivity for crater rim and ejecta blankets on Titan versus relative crater depth. Craters with larger relative depths (more degraded) have higher emissivity than craters with smaller relative depths (less degraded). However, composition also depends on location. Here we see Santorini and Shikoku (dunes craters) with higher emissivities than Soi, the most degraded crater. This will be discussed further in section 3.3.2. The arrow indicates that this is an upper limit to Forseti's relative depth.

Figure 35: Filling factor emissivity of the ejecta blanket + rim and the floor of 12 craters on Titan. Cooler colors correspond with lower emissivities and warmer colors represent higher emissivities. The crater ejecta blanket + rim and floor emissivities were obtained by extrapolation of the emissivity for a filling factor of $100 \%$ (see section 3.2 .2 ). There is a larger uncertainty on the emissivity of the crater floors of Sinlap, Momoy, Soi, Afekan and 
Santorini which have been observed with radiometry footprints including more than $50 \%$ of other terrains. Note that, except for Sinlap, the crater floors are always more emissive than the crater ejecta blankets + rims, most likely because these are sinks for organics.

Figure 36: Emissivity difference between crater floor and crater ejecta blanket + rim versus relative depth. The dashed line represents an equivalent emissivity for the crater interior and exterior. The solid blue line shows the general trend of the craters. Sinlap is the only crater with a lower emissivity value in the interior, implying extreme youth. As craters degrade toward intermediate ages, this difference increases. As craters become heavily degraded, this difference becomes minimal again.

Figure 37: Top images show radar images, center images show VIMS data, bottom images show 2.18-cm emissivity data of Sinlap, Santorini, and Soi. The ejecta of Sinlap, a dunes region crater, exhibits a bright green VIMS spectra, potentially a mix of organics and waterice. The emissivity data shows a blue signature, indicative of a lower value that is interpreted as water-ice. Santorini, a relatively degraded dunes crater, but less degraded than Soi, shows a VIMS green spectra on its ejecta blanket. The emissivity data shows a heavily organic region, represented by the dark red hue. The ejecta of Soi crater, a degraded plains crater, shows VIMS dark blue unit, suggestive of water-ice. The emissivity data shows a reddish hue, indicating a higher value or an organic-rich composition.

Figure 38: Hypothesis for the evolution of a crater in the dunes region. In the pre-impact stage, the surface shows a brown spectra, indicative of sand dunes, and a high emissivity, indicative of an organic-rich substrate. Immediately post-impact, a well-preserved crater is formed. The ejecta blanket and rim shows a surficial VIMS green spectra, likely a mix of organics and water-ice. The ejecta blanket and rim shows a water-ice rich subsurface. Over time, as this crater degrades, the VIMS signature of the ejecta blanket remains the same due to active surface processes, but the subsurface becomes more organic-rich as the fractures are infilled by sediment. A similar process happens in the plains regions: the VIMS spectra remains the same over time, with an increase in the emissivity of the subsurface. 


\section{Chapter 1}

\section{Introduction}

Impact cratering affects virtually all solid rocky and icy surfaces in the solar system. By studying the cratering processes on different planetary bodies, more can be learned about the process as a whole, as well as provide clues about the characteristics and exogenic processes on the target body. Since this process affects a wide range of planetary surfaces with various differing geologic characteristics, it is possible to learn how different factors control the process. For instance, the effects of an atmospheric component on the cratering process could be studied. Additionally, impact cratering reveals valuable information about the target subsurface and its composition, something that would otherwise remain hidden from study. Researching this process is especially important for bodies at great distances from Earth - it is difficult and costly for missions to reach these locations, so we must be as prepared as possible for what environments will be encountered. For example, Saturn's moon Titan is in the outer solar system, and by studying its craters, we are learning that it is a dynamic place. We do not, however, understand how craters on Titan are modified over time and what that implies about its modification processes.

\subsection{Titan}

Titan was discovered by Dutch astronomer Christiaan Huygens on March 25, 1655. It was the first Saturnian moon discovered and is the largest of Saturn's 62 known satellites, as well as the second largest satellite in the entire solar system. It has a mean radius of $2,576 \mathrm{~km}$ and is larger than the smallest planet, Mercury, which has a radius of 2,440 km (Figure 1). The sheer grandness of Titan inspired its name, suggested by John Herschel. Titan is tidally locked to Saturn, therefore its rotational period and orbital period are equivalent, completing a full orbit or rotation during a period of 15.945 days (Coustenis, 2014). Saturn is 9 AU away from the Sun at its closest point and 10.1 AU at its farthest. 


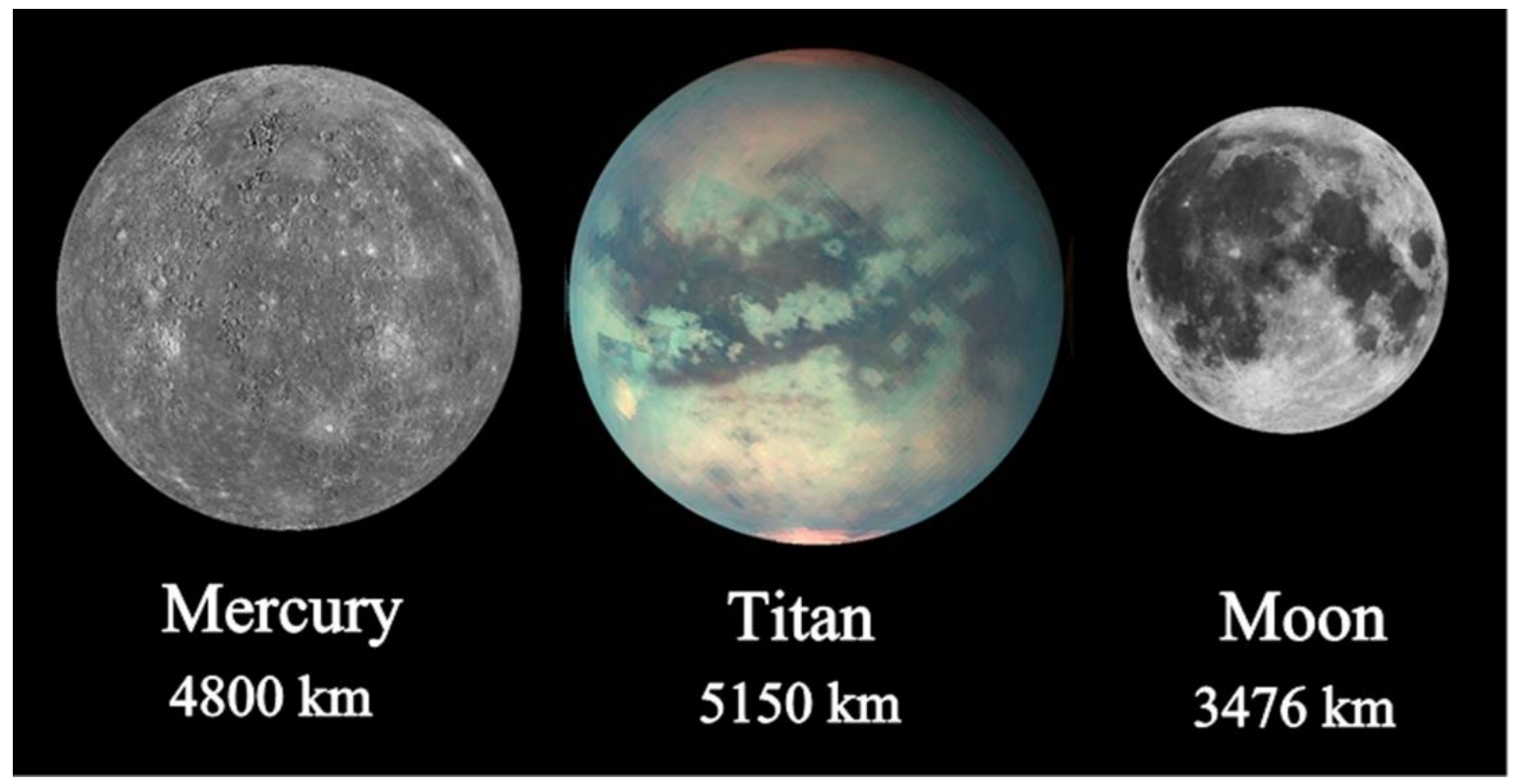

Figure 1: Size comparison of Mercury, Titan, and Earth's Moon. Approximate diameters $(\mathrm{km})$ for each body listed here. Image created from NASA's image archive.

The interior structure of Titan is believed to be somewhat similar to the icy Galilean satellites of Jupiter (Figure 2). Callisto likely has a rocky core, surrounded by alternating layers of ice and liquid oceans, whereas Europa likely has an iron core, a rocky shell surrounding the core, followed by a liquid ocean layer entrapped by a shell of ice (Sotin and Tobie, 2004). The interior of Ganymede is thought to be similar to Europa's interior, with the exception of an icy layer between the liquid ocean and the rock surrounding the iron core. Titan most closely resembles the interior of Ganymede, however with differing core compositions (Figure 2b). Titan's core is thought to be rocky, or perhaps an ice-rock mix, different than Ganymede's iron core (Tobie et al., 2005). Overall, the internal structure of Titan is poorly understood, however, recent studies (e.g. Nimmo and Bills, 2010; Iess et al., 2012; Mitri et al., 2014) provide explanation for the likelihood of a subsurface liquid ocean through modeling and observations of gravity anomalies, tidal stresses, etc. 

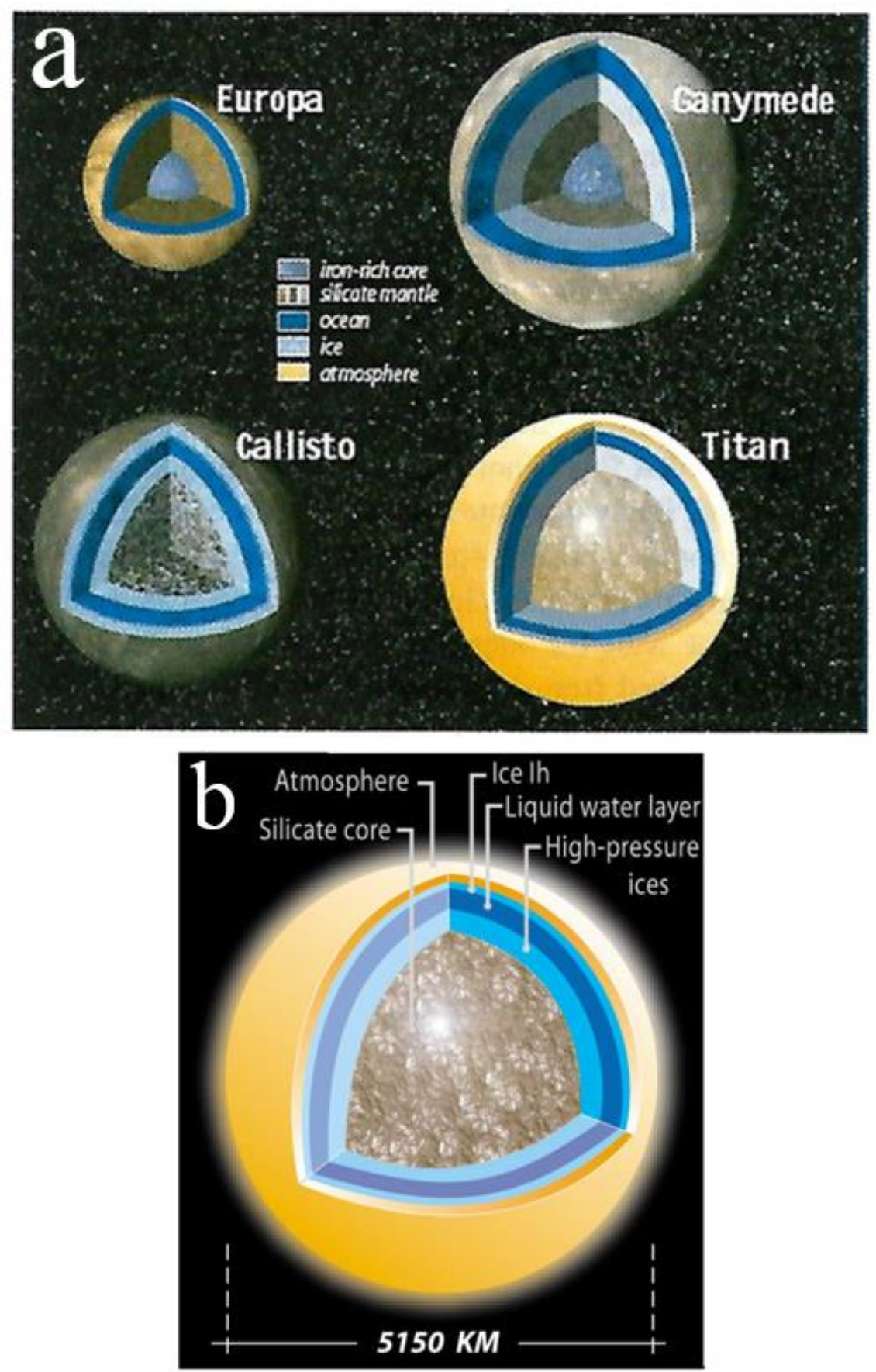

Figure 2: a) Hypothesized interior structures of the icy Galilean satellites, Europa, Ganymede, and Callisto in comparison to Titan. Figure 2a from Sotin et al., 2009. b) Modeled interior structure of Titan, which likely has a silicate, or mix of ice and rock, core, surrounded by high pressure ices. Beneath the icy crust there is likely a liquid water ocean. Figure 2b from Tobie et al., 2005. 
Titan's average surface temperature is quite cold $\left(93.7 \mathrm{~K}\right.$ or $\left.-179.5^{\circ} \mathrm{C}\right)$ because of its extreme distance from the Sun at $~ 9-10$ AU. It does experience some heating from its atmosphere due to the greenhouse effect, although this is largely offset by the antigreenhouse effect caused by its atmospheric haze (Fulchignoni et al., 2005). Titan's substantial atmosphere is a unique characteristic amongst the entirety of the solar system satellites. It is this which caused some astronomers prior to the 1970s to miscalculate and believe Titan to be larger than Jupiter's moon, Ganymede, thus being mistakenly dubbed the largest moon in the solar system (Lorenz and Mitton, 2008). When the Voyager I spacecraft reached the Saturnian system in 1980, radio signals from the spacecraft were used to assess Titan's true diameter (Lorenz and Mitton, 2008). Unfortunately, Voyager 1 and 2 did not have the capabilities to see through Titan's atmosphere, but Earth-based telescopes in conjunction with Voyager 1 revealed that the main atmospheric constituents are $\mathrm{N}_{2}$ and $\mathrm{CH}_{4}$ (Hanel et al., 1981; Kunde et al., 1981). The Voyager missions sparked interest about the elusive moon, and the Cassini-Huygens mission began development in 1989 as a joint effort between the National Aeronautics and Space Administration (NASA) and the European Space Agency (ESA). The Cassini-Huygens mission was launched in 1997 and reached Saturn in 2004. The Huygens probe was designed to learn more about Titan's atmosphere by slowly descending to the surface. It had a six experiment payload suite to complete this objective (Table 1). There were a lot of unknowns about Titan's surface prior to Cassini, so landing on the surface was neither a priority nor requirement for the mission to be successful. However, ESA did design the probe with the possibility in mind (Lorenz and Mitton, 2008). ESA bargained for a maximum of three minutes of imaging and sensing after the probe landed on the surface (Lorenz and Mitton, 2008). Indeed, this extended part of the atmospheric probe mission was successful, and it took place in 2005. As it was descending and even after it landed, Huygens imaged the surface. These images revealed remarkable views of the geology of Titan. In the process of descent, it also recorded the atmospheric wind profile, electrical conductivity, temperature and pressure profiles, etc. (Lebreton et al., 2005). Cassini itself had its own suite of instruments capable of investigating Titan's atmosphere (Table 2). The ion and neutral mass spectrometer (INMS) aboard Cassini determined the atmosphere to be made of molecules comprised of combinations of carbon and hydrogen, 
such as methane, ethane, etc. (Lorenz and Mitton, 2008). The surprising discovery was the abundance of more complex compounds with masses up to 100 Daltons or more, such as benzene (Lorenz and Mitton, 2008).

\section{Table 1: Instrument suite for the Huygens probe}

\begin{tabular}{|c|c|c|}
\hline Instrument & Acronym & Capability \\
\hline $\begin{array}{l}\text { Aerosol } \\
\text { Collector and } \\
\text { Pyrolyser }\end{array}$ & $\mathrm{ACP}$ & $\begin{array}{l}\text { Drew in aerosol particles from the atmosphere to vaporize } \\
\text { volatiles and decompose the complex organic molecules. } \\
\text { Products were then flushed to the GCMS for analysis }\end{array}$ \\
\hline $\begin{array}{l}\text { Descent } \\
\text { Imager/Spectral } \\
\text { Radiometer }\end{array}$ & DISR & $\begin{array}{c}\text { Made a range of imaging and spectral observations using several } \\
\text { sensors and fields of view }\end{array}$ \\
\hline $\begin{array}{l}\text { Doppler Wind } \\
\text { Experiment }\end{array}$ & DWE & $\begin{array}{l}\text { The intent of this instrument was to measure the wind speed } \\
\text { during the descent through Titan's atmosphere, however, due to a } \\
\text { configuration problem, this was accomplished through other } \\
\text { Earth-based means }\end{array}$ \\
\hline $\begin{array}{l}\text { Gas } \\
\text { Chromatograph } \\
\text { Mass } \\
\text { Spectrometer }\end{array}$ & GCMS & $\begin{array}{l}\text { Versatile gas chemical analyzer that identified and measured } \\
\text { chemicals in Titan's atmosphere as well as the surface material } \\
\text { upon impact }\end{array}$ \\
\hline $\begin{array}{l}\text { Huygens } \\
\text { Atmospheric } \\
\text { Structure } \\
\text { Instrument }\end{array}$ & HASI & $\begin{array}{l}\text { Contained a suite of sensors that measured the physical and } \\
\text { electrical properties of Titan's atmosphere }\end{array}$ \\
\hline $\begin{array}{l}\text { Surface- } \\
\text { Science } \\
\text { Package }\end{array}$ & SSP & $\begin{array}{l}\text { Designed to determine the physical properties of Titan's surface } \\
\text { at the point of impact }\end{array}$ \\
\hline
\end{tabular}

Weather is driven on planetary bodies primarily by redistributing the Sun's energy in the atmosphere and subsequently moving the air around. In general, the closer the planetary body is to the Sun, the more intense the received energy will be. Although Titan is on average between 9 and 10 times further away from the Sun than Earth is, there are some surprising similarities in terms of weather. On Earth, there is an active hydrological cycle: water evaporates, condenses into clouds, and produces rain. However, due to the 94 K temperatures on Titan, water is not a liquid, and instead, methane evaporates, condenses, and rains on Titan. There are also thought to be infrequent methane 'monsoons' on Titan, similar to what occurs in terrestrial deserts but much smaller in size and intensity (MacKenzie et al., 2014). These occur at low latitudes typically near the equinox (Jaumann et al., 2008; Schneider et al., 2012). The northern region gets more rainfall than the southern region, though this is also dependent on seasonality (Rannou et al., 2006; Schneider et al., 2012). Like Earth, Titan has seasonal weather patterns as well as wind patterns. Titan is a slower rotator than Earth; Earth completes 16 full rotations in 
the time Titan takes to complete one. The slow rotation of Titan produces a global Hadley cell (Horst, 2017). Titan's Hadley cell redistributes the heat in the atmosphere efficiently and therefore produces small atmospheric temperature differences between equator and pole locations (Jennings et al., 2009; Schinder et al., 2011; Cottini et al., 2012; Schinder et al., 2012). Though the atmospheric temperature is relatively homogenous, seasonal temperature variations in Titan's surface temperature have been observed by Cassini (Jennings et al., 2011). These seasonal temperature variations are likely due to the asymmetries in the amount of solar energy at Titan, caused by Saturn's eccentricity. The similarities between weather on Earth and weather on Titan also extend into the basic geological features on both bodies. A summary of the main environmental conditions on Titan is shown in Table 3.

\section{Table 2: Payload suite onboard the Cassini spacecraft.}

\begin{tabular}{|c|c|c|}
\hline Instrument & Acronym & Capability \\
\hline $\begin{array}{l}\text { Cassini Plasma } \\
\text { Spectrometer }\end{array}$ & CAPS & $\begin{array}{l}\text { Measured the flux of charged particles as a function of direction and } \\
\text { energy. Ion composition was also measured. Plasma, solar wind and } \\
\text { its interaction with Saturn's magnetosphere was also investigated }\end{array}$ \\
\hline $\begin{array}{l}\text { Composite } \\
\text { Infrared } \\
\text { Spectrometer* }\end{array}$ & CIRS & Measured infrared emissions from atmospheres, rings, and surfaces \\
\hline $\begin{array}{l}\text { Cosmic Dust } \\
\text { Analyzer }\end{array}$ & $\mathrm{CDA}$ & Measured the size, speed, and direction of tiny dust grains near Saturn \\
\hline $\begin{array}{c}\text { Imaging Science } \\
\text { Subsystem* }\end{array}$ & ISS & Captured images in visible, infrared and ultraviolet light \\
\hline $\begin{array}{l}\text { Ion and Neutral } \\
\text { Mass } \\
\text { Spectrometer* }\end{array}$ & INMS & $\begin{array}{l}\text { Measured composition of charged and neutral particles near Titan and } \\
\text { Saturn to learn more about their atmospheres }\end{array}$ \\
\hline Magnetometer & MAG & Measured the strength of Saturn's magnetic field \\
\hline $\begin{array}{l}\text { Magnetospheric } \\
\text { Imaging } \\
\text { Instrument }\end{array}$ & MIMI & $\begin{array}{c}\text { Produced images and measured energetic ions and electrons trapped in } \\
\text { Saturn's magnetic field }\end{array}$ \\
\hline RADAR* & & $\begin{array}{l}\text { Produced topography and surface roughness maps of Titan. Passive } \\
\text { radiometry was used to infer composition of surfaces in the Saturn } \\
\text { system }\end{array}$ \\
\hline $\begin{array}{l}\text { Radio and } \\
\text { Plasma Wave } \\
\text { Science }\end{array}$ & RPWS & $\begin{array}{l}\text { Measured the electric and magnetic wave fields in the interplanetary } \\
\text { medium and planetary magnetospheres }\end{array}$ \\
\hline $\begin{array}{l}\text { Radio Science } \\
\text { Subsystem* }\end{array}$ & RSS & $\begin{array}{l}\text { Used radio antennas on Earth to observe the way radio signals from the } \\
\text { spacecraft changes as they were sent through objects in the Saturn } \\
\text { system }\end{array}$ \\
\hline $\begin{array}{l}\text { Ultraviolet } \\
\text { Imaging } \\
\text { Spectrograph }\end{array}$ & UVIS & $\begin{array}{l}\text { Captured images of the ultraviolet light reflected off of an object, such } \\
\text { as the clouds of Saturn }\end{array}$ \\
\hline $\begin{array}{l}\text { Visible and } \\
\text { Infrared Mapping } \\
\text { Spectrometer* }\end{array}$ & VIMS & $\begin{array}{l}\text { Captured images using visible and infrared light to learn more about the } \\
\text { composition of moon surfaces, rings, and the atmospheres of Saturn and } \\
\text { Titan }\end{array}$ \\
\hline
\end{tabular}

\section{*Used to study Titan}


Table 3: Environmental Conditions on Titan

\begin{tabular}{|c|c|c|}
\hline Condition & & Source \\
\hline Surface temperature & $93.7 \mathrm{~K}$ & Fulchignoni et al., 2005 \\
\hline Rain $\left(< \pm 70^{\circ}\right.$ latitude) & $\sim 1 \mathrm{~cm} /$ year & Rannou et al., 2006 \\
\hline Rain (poleward) & $>1 \mathrm{~m} / \mathrm{year}$ & Rannou et al., 2006 \\
\hline Surface wind speeds & $\sim 1 \mathrm{~m} / \mathrm{s}$ & Tomasko et al., 2005 \\
\hline
\end{tabular}

\subsection{Geology of Titan}

Titan's thick atmosphere obstructs most wavelengths of the electromagnetic spectrum from transmitting through, therefore impeding the view of the surface. The wavelengths that can penetrate the atmosphere are found in the visible and near infrared regions and are 0.94, 1.08, 1.28, 1.6, 2.0, 2.7-2.8, and 5.0 microns (Figure 3) (Barnes et al., 2007).

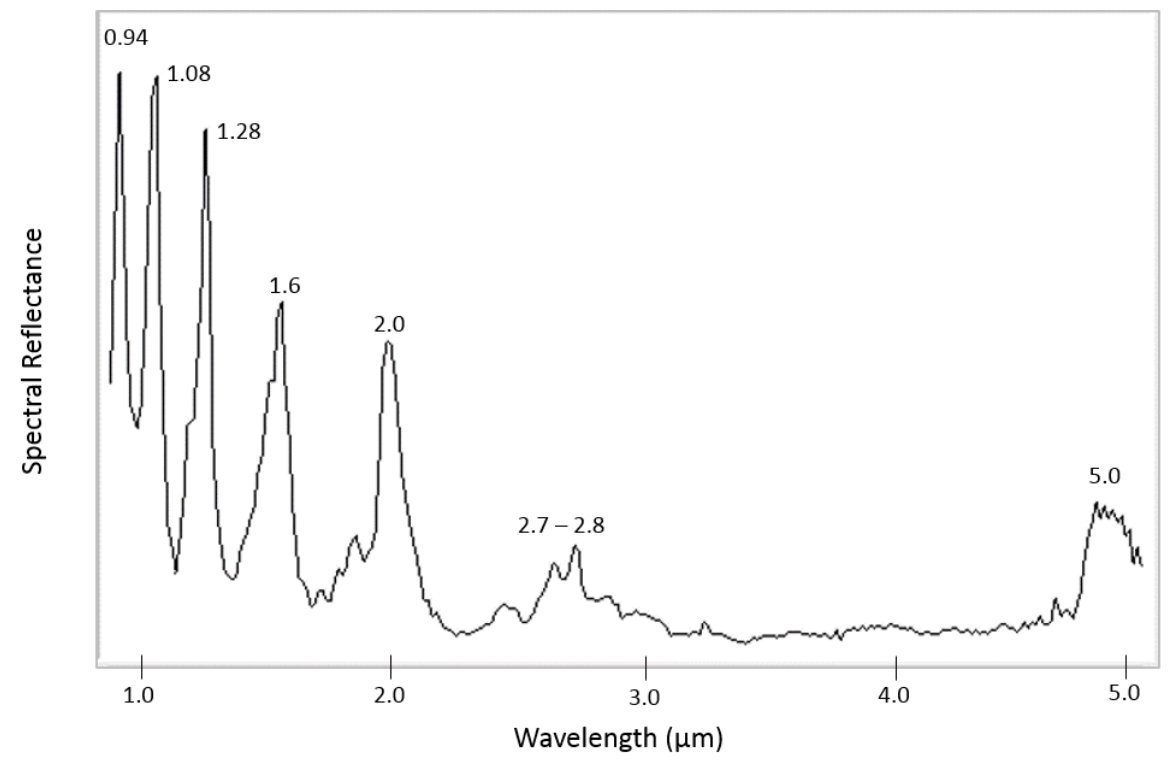

Figure 3: Spectral plot obtained from VIMS image v1525115629_1 centered at $\sim 32^{\circ} \mathrm{N}, 12^{\circ} \mathrm{W}$. The atmospheric windows are illustrated by the wavelength peaks.

Voyager 1 and 2 lacked instruments capable of observing through the atmosphere of Titan and were thus unable to see any detailed surface features. In retrospect, Voyager 1 
barely managed to acquire extremely low resolution images of the surface in the visible range that only showed some large-scale bright and dark regions (Richardson et al., 2004). After Voyager, in the early 1990s, the Hubble Space Telescope imaged Titan. The first few images were unsuccessful at viewing the surface, but in 1994, some distinguishable low resolution surface features were seen (Lorenz and Mitton, 2008). One such feature is now dubbed Xanadu and will be discussed in the next subsection. It was not until Cassini, in the early 2000s, that the first high-resolution images of the surface were taken (Figure 4). Using multiple instruments aboard Cassini (RADAR, VIMS, ISS), an intriguing surface is revealed and major geomorphological units are recognized, some of them quite Earth-like.

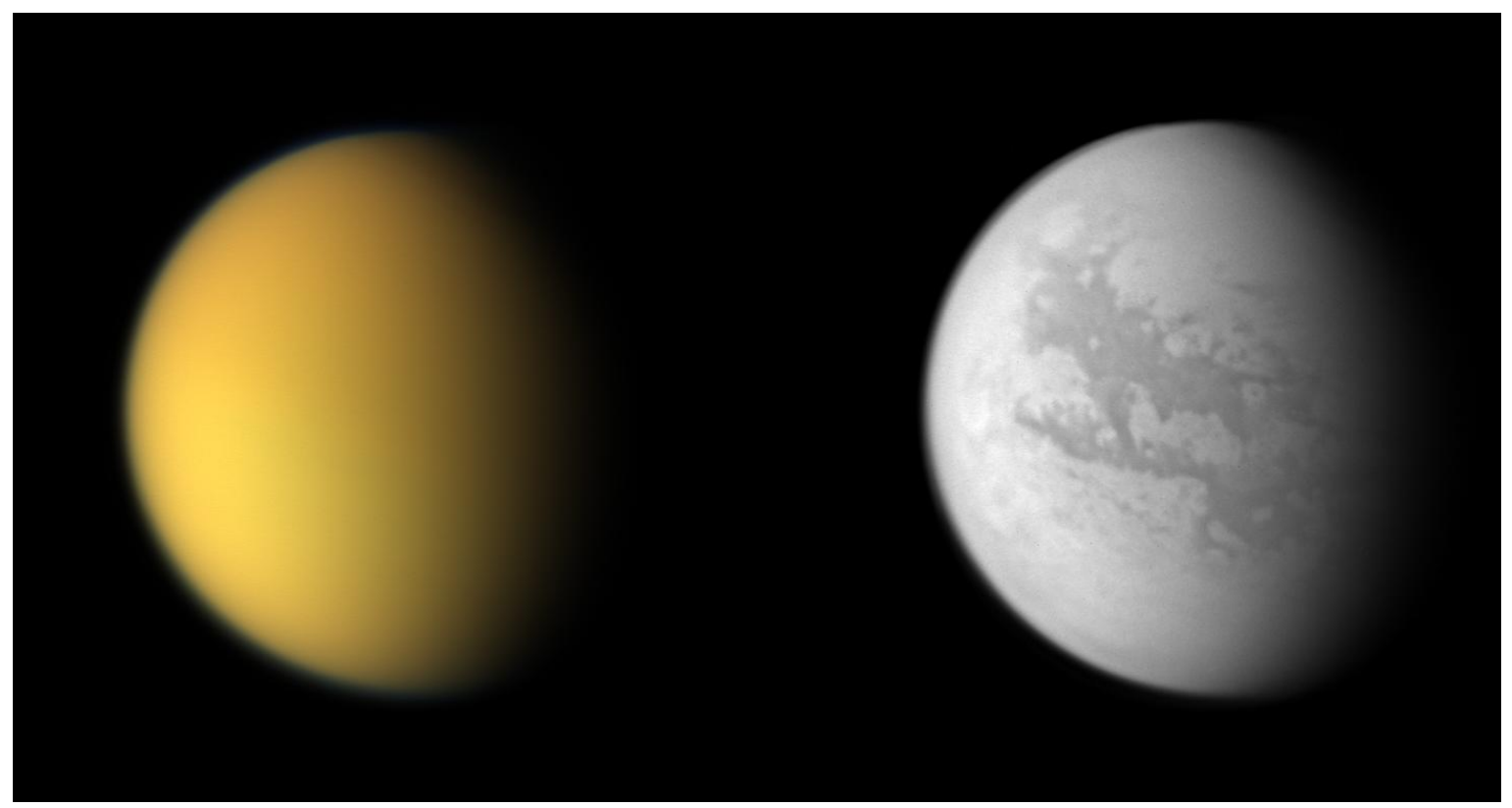

Figure 4: Titan in different wavelengths of light. The left image shows what Titan would look like to the human eye. The right image shows a near-infrared wavelength image $(0.938 \mu \mathrm{m})$, capable of viewing the surface (NASA, 2018). Both images were acquired by Cassini’s Imaging Science Subsystem (ISS).

\subsubsection{Geomorphologic units}

The Cassini RADAR instrument has provided an unprecedented view to the surface geology on Titan. It has revealed a complex surface with modification from major 
geologic processes seen on Earth, such as tectonics, cratering, and fluvial and aeolian activity. These modification processes shape the surface and provide a range of major geomorphologic units. Figure 5 shows a map of four major units across Titan.

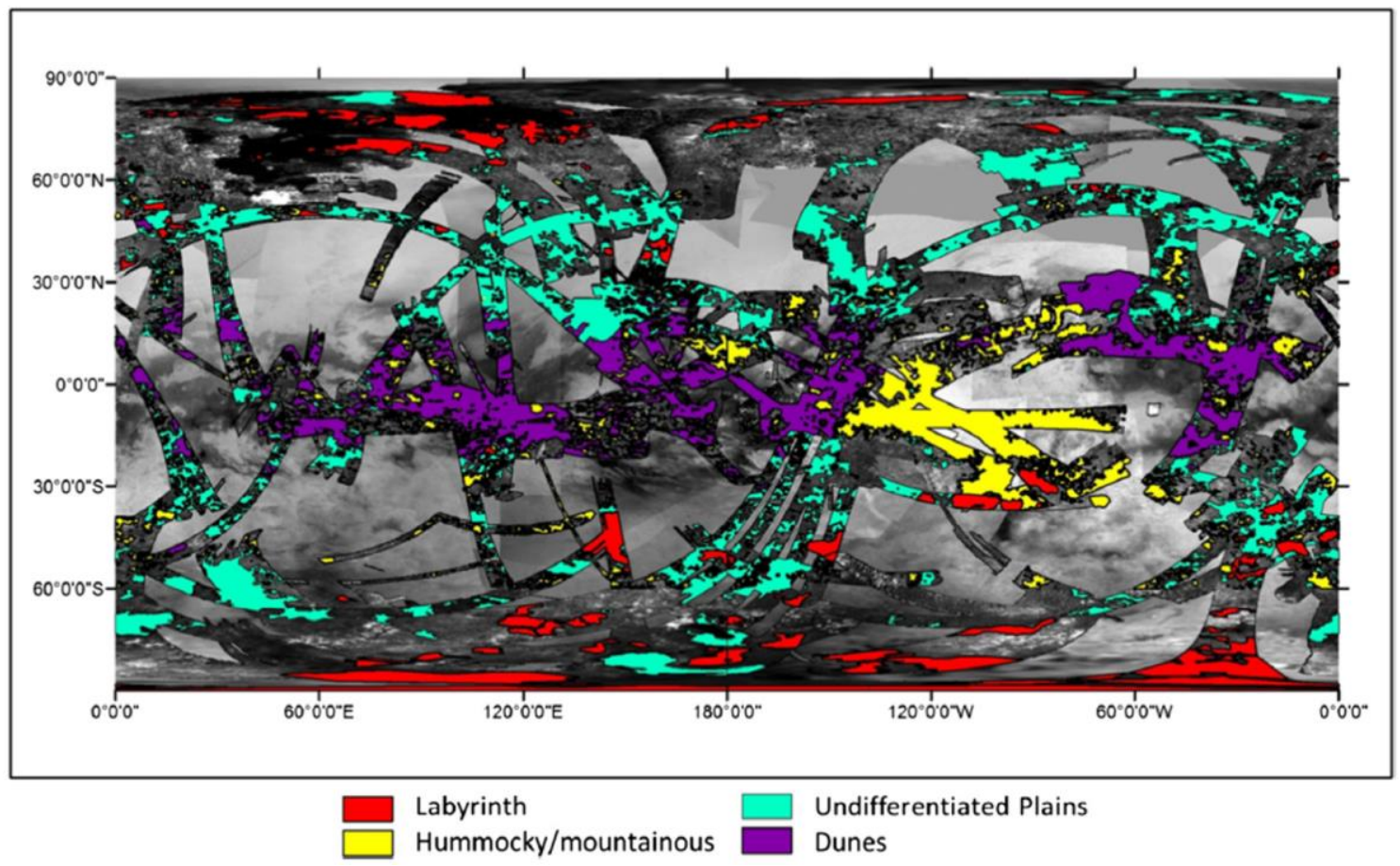

Figure 5: Map of major geomorphologic units on Titan. Labyrinth terrain represented in red, undifferentiated plains in green, hummocky/mountainous terrain in yellow, and sand dunes in purple. Cassini ISS map underneath available RADAR image swaths to provide context. Image from Lopes et al., 2016.

\subsubsection{Xanadu}

Before Cassini, the only surface feature that stood out from observations from Hubble was a large bright region near Titan's equator, centered at $\sim 100^{\circ} \mathrm{W}$, now named Xanadu. Cassini confirmed this to be the largest and brightest region on Titan in multiple wavelengths (Jaumann et al., 2009). Xanadu is roughly $4500 \mathrm{~km}$ across and is distinct from other regions because of its brightness and its low emissivity values (see section 2.1.2) indicative of water-ice (Lopes et al., 2010). It is hypothesized to be amongst the 
oldest terrains on Titan, along with the rest of the bright, hummocky, and mountainous terrains (Jaumann et al., 2009).

\subsubsection{Tectonic features}

The hummocky and mountainous terrains are seen in bright patches throughout the surface of Titan and are relatively small in area, on the order of 10s of kilometers. Xanadu looks similar to these terrains but is expected to be different because it is so much larger than the hummocky and mountainous regions (Radebaugh et al., 2007; Lopes et al., 2010). It is hypothesized that these terrains are tectonic in origin, either extensional or compressional (Radebaugh et al., 2007). It is also considered that some of the blockier patches neighboring craters could be of ejecta origin (Radebaugh et. al., 2007).

\subsubsection{Impact features}

Impact cratering is a common process throughout the solar system and is found on all solid bodies with the exception of Io, a volcanically active Galilean satellite. On Titan, however, there is a relative scarcity of craters on the surface, which is likely due to the

presence of Titan's large and dense atmosphere. The atmosphere shields the surface from smaller impactors (Lorenz et al., 2007), while the reduction in larger craters (> $20 \mathrm{~km}$ in diameter) is likely due to rapid resurfacing from erosion and burial (Lorenz et al., 2007). Titan's impact craters will be discussed in greater detail in section 1.4.

\subsubsection{Cryovolcanic features}

As described in section 1.1, there exists a liquid layer in Titan's interior (e.g. Tobie et al., 2005; Nimmo and Bills, 2010; Iess et al., 2012; Mitri et al., 2014). Therefore, with thermal convection, it is possible for mixtures from the interior to erupt onto the surface (Lopes et al., 2013). One such hypothesis for how cryovolcanism occurs on Titan is proposed by Mitri et al. (2008). They describe the liquid subsurface ocean to be the source, but with an ammonia constituent (Mitri et al., 2008). Adding the ammonia to the pure water has two benefits: 1) it has a lower freezing point than pure water and 2) it 
decreases the density and is close to neutral buoyancy between its liquid and solid phase (Mitri et al, 2008). Neutral buoyancy, in conjunction with large-scale tectonic stresses and cracks in the bottom layer of the ice shell, could enable eruption of the liquid ammonia-water (Mitri et al., 2008). It is difficult to conclusively say if a feature is volcanic in origin (Moore and Pappalardo, 2011), and only a few candidate features have been proposed as such so far (Lopes et al., 2013). One strong candidate revealed by radar images is the Sotra Facula region (Figure 6). Alternate candidates identified on radar images are other apparent volcanic features with associated flows as well as depressions that appear to be calderas (Lopes et al., 2013).

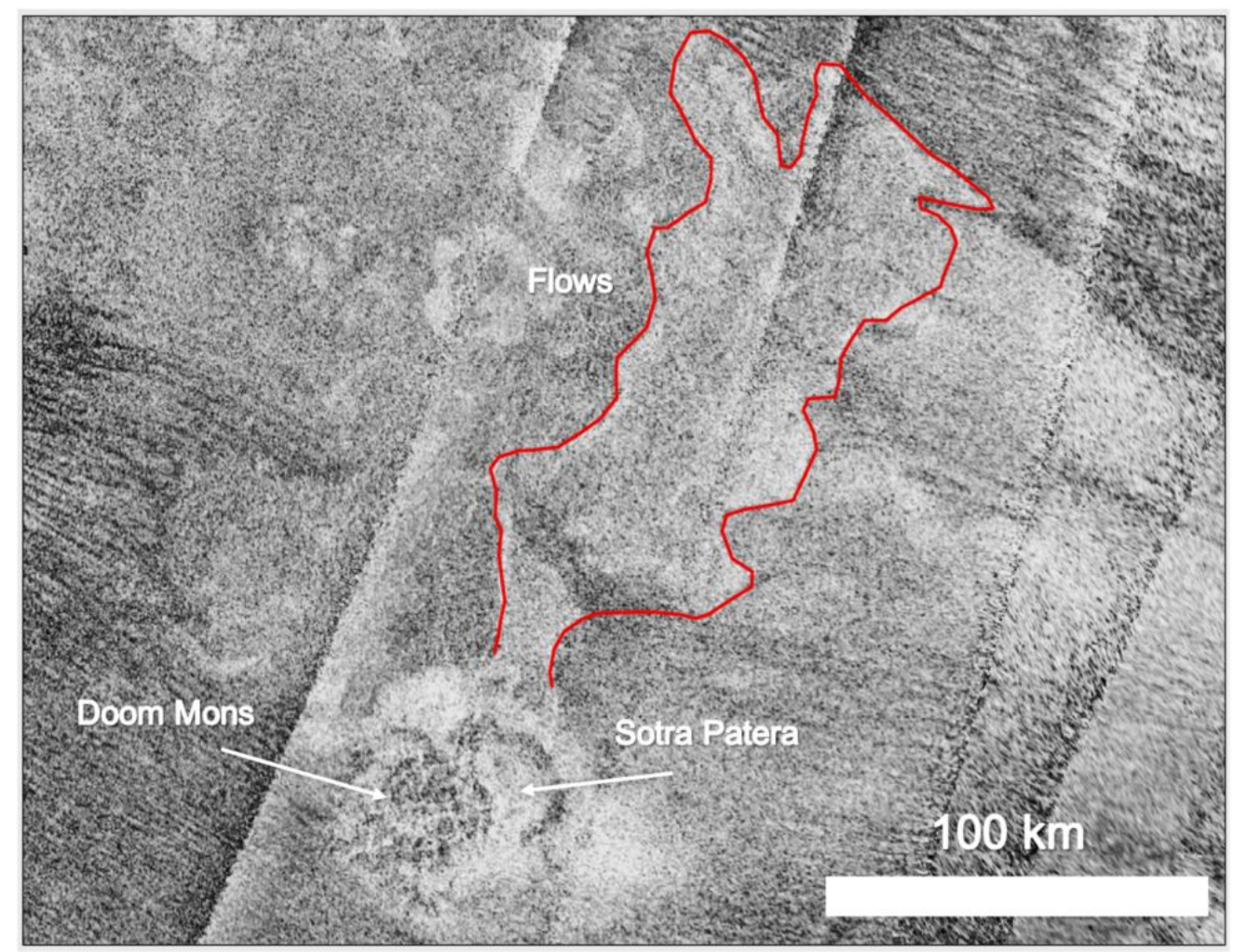

Figure 6: Radar image of potential cryovolcanic feature called Sotra Facula. Here, North is up. A $1450 \mathrm{~m}$ high mountain, Dooms Mons is to the west of Sotra Patera, a $1700 \mathrm{~m}$ deep pit. The associated lobate flows are outlined in red, flowing in a $\mathrm{NE}$ direction. 


\subsubsection{Aeolian features}

Sand dunes on Titan were discovered by the Cassini RADAR in 2005 during the T3 flyby (Elachi et al., 2006). The origin of these features was unknown at first, and they were initially dubbed 'cat scratches' (Radebaugh et al., 2008) (Figure 7). It has been discerned that there are thousands of longitudinal dunes found primarily between $30^{\circ} \mathrm{N}$ and $30^{\circ} \mathrm{S}$ of the equator (Radebaugh et al., 2008). They are organic rich (Barnes et al., 2007;

Soderblom et al., 2007), thought to be complex hydrocarbons with grain sizes of a few hundred microns (Radebaugh et al., 2013). They typically align with an E-W orientation (Radebaugh et al., 2008). Aeolian features appear to be among the youngest features on Titan, with little evidence of incision by streams (Jaumann et al., 2009).

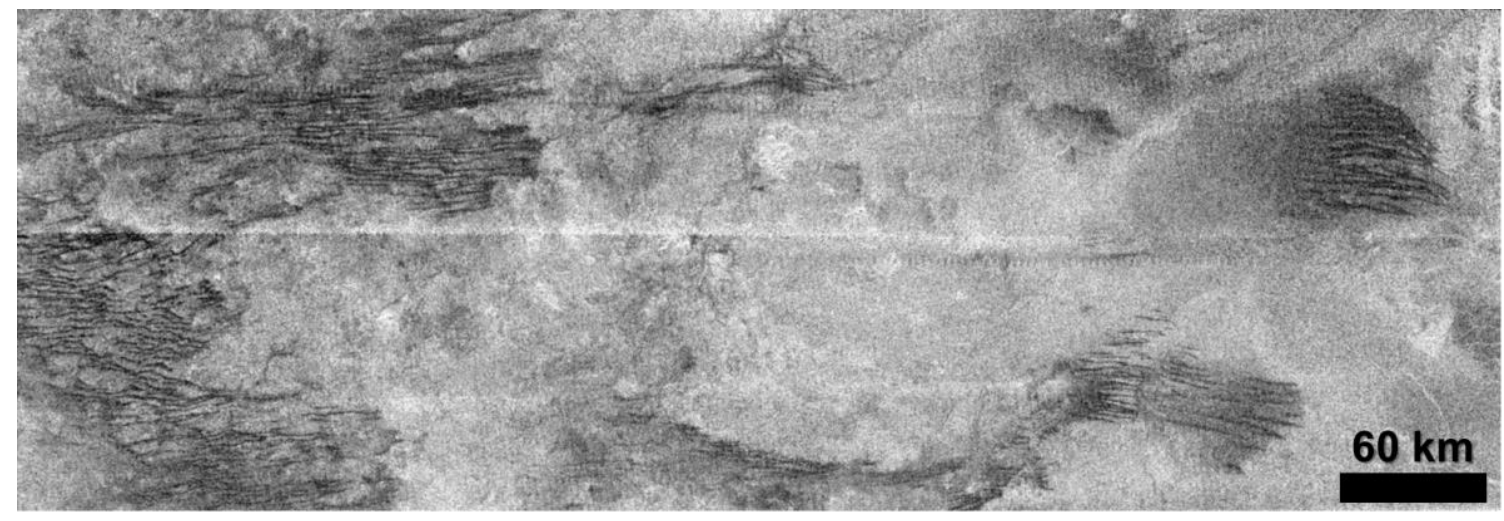

Figure 7: Cat scratch features $\left(\sim 16^{\circ} \mathrm{N}, 9^{\circ} \mathrm{W}\right)$ shown by the radar as dark streaks flanking the western and eastern sides of the image. These were later determined to be longitudinal dune features. Image from NASA's image archive.

\subsubsection{Fluvial features}

As mentioned in section 1.1, Titan has a hydrological cycle. This cycle creates fluvial channels and lakes, quite reminiscent of terrestrial features, with one obvious difference: these are created by flowing methane and (possibly) ethane. There were visual hints at features that could have been fluvial channels on Titan in the first radar images of the surface (Elachi et al., 2005), and were confirmed to be fluvial channels with images taken from the Huygens probe as it descended to the surface (Figure 8a) (Lunine and Lorenz, 2009). There seems to be no latitudinal trend with channels, they are widely dispersed, 
which is not the case for lakes (Lopes et al., 2010). Lakes are mostly found at high northern latitudes, with a few that exist at southern latitudes (Lopes et al., 2010). Aharonson et al. (2009), proposed this asymmetry to be a result of an unevenness in Titan's seasons due to the eccentricity of Saturn's orbit around the Sun. They believe this would result in hemispheric differences in evaporation and precipitation, which would lead to one hemisphere having larger amounts of lakes than the other (Aharonson et al., 2009). In this mechanism, it is likely that there would be reversals of the asymmetry on timescales on the order of tens of thousands of years (Aharonson et al., 2009).

Additionally, some of these lakes at high latitudes are considered seas due to their large size (Figure 8b) (Lopes et al., 2010). The shapes of these lakes vary and are classified into five categories: circular, irregular, nested, canyon-like, and diffuse (Jaumann et al., 2009).
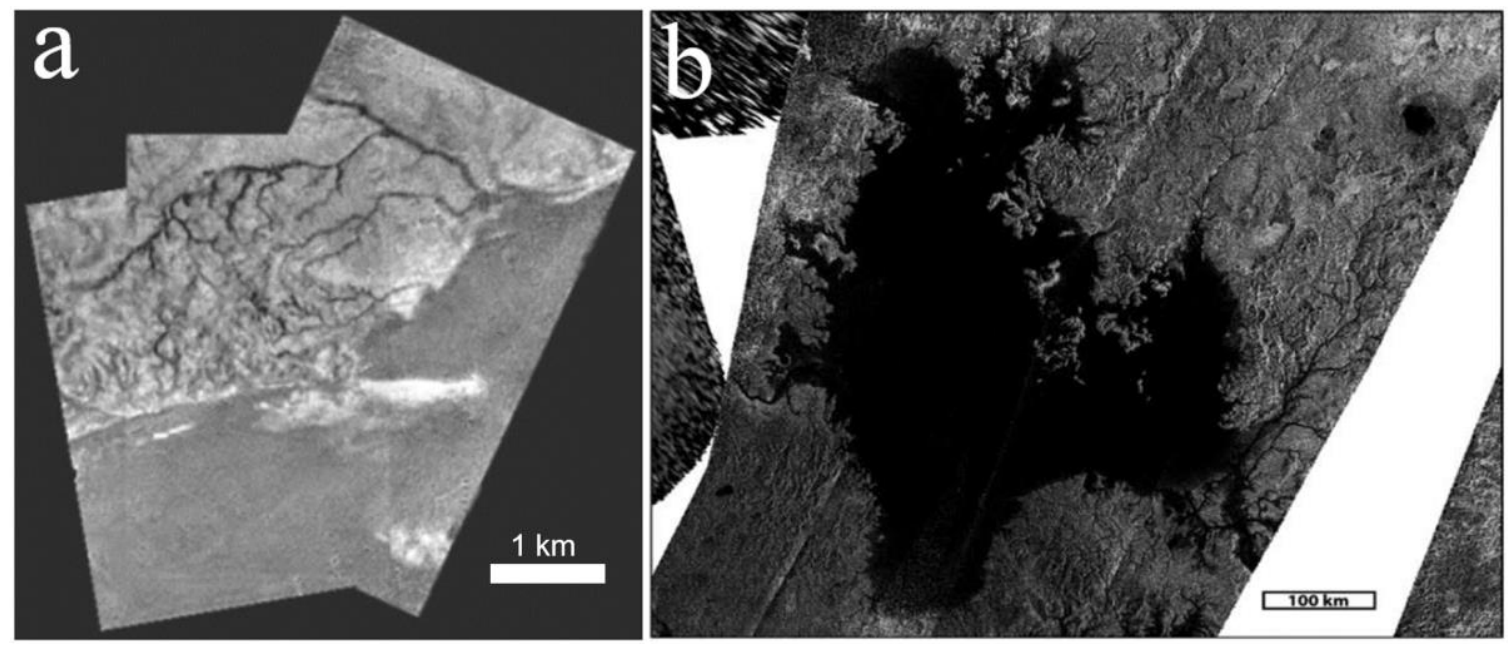

Figure 8: a) Visible images taken by the Huygens probe DISR showing dark, dendritic fluvial channels (modified from Lunine and Lorenz, 2009). b) Radar image of a lake, large enough to be classified as a sea, named Ligeia Mare. These images are in polar projection (modified from Lopes et al., 2010).

\subsubsection{Units of unknown origin}

In the mid-latitudes, approximately between $20-60^{\circ} \mathrm{N}$ and $\mathrm{S}$, there are relatively homogenous, radar dark, plains regions called undifferentiated plains (e.g. Lopes et al., 
2010). Undifferentiated plains are large scale, hundreds to thousands of $\mathrm{km}$, and are of low relief compared to the rest of the moon (Lopes et al., 2010; Lopes et al., 2016). A second plain type, mottled plains, exist primarily at high northern latitudes (Lopes et al., 2010). Mottled plains typically are found in patches, between 10s-100s of km across (Stofan et al., 2006). Some hypotheses for the origin of these two units include: cryovolcanic flood lavas, sedimentary/depositional, and aeolian deposition (for more detail, see Lopes et al., 2016). The preferred hypothesis for the undifferentiated plains is that they are sedimentary/depositional in origin (Lopes et al., 2016). These undifferentiated plains are highly organic (i.e. complex hydrocarbons), not water-ice rich, which supports the sedimentary hypothesis (Lopes et al., 2016). Additionally, there are some undifferentiated plains material inside craters, which is evidence for depositional origin (Lopes et al., 2016).

A feature type called labyrinth terrains are always associated with these undifferentiated plains (Malaska et al., 2014; Lopes et al., 2016). Labyrinth terrains cover a small amount of Titan's surface, less than 5\%, and are found mostly at high latitudes (Lopes et al., 2016). These terrains are locally elevated in relation to the nearby undifferentiated plains (Lopes et al., 2016). The elevation of this unit suggests two potential origins: these could be very ancient terrains that were resistant to erosion or deflation, or they were uplifted by an unknown mechanism (Lopes et al., 2016).

\subsection{Impact crater formation}

There are two main morphological categories of craters: simple and complex. Simple craters are basic bowl shaped impact features and are smaller in diameter than complex craters. The transition diameter between the two categories depends on the physical properties of the target body, primarily its mass and subsequent gravitational pull. On Titan, the transition diameter is thought to be similar to Ganymede, at about $3 \mathrm{~km}$ (Collins and Johnson, 2014). Complex craters are, as the name implies, more multifaceted than simple craters. They are much flatter than simple craters due to collapse, and have a central peak or uplift and a much more structurally complicated rim, 
often terraced. There are three general stages in the impact cratering process: contact and compression, excavation, and modification (Figure 9).
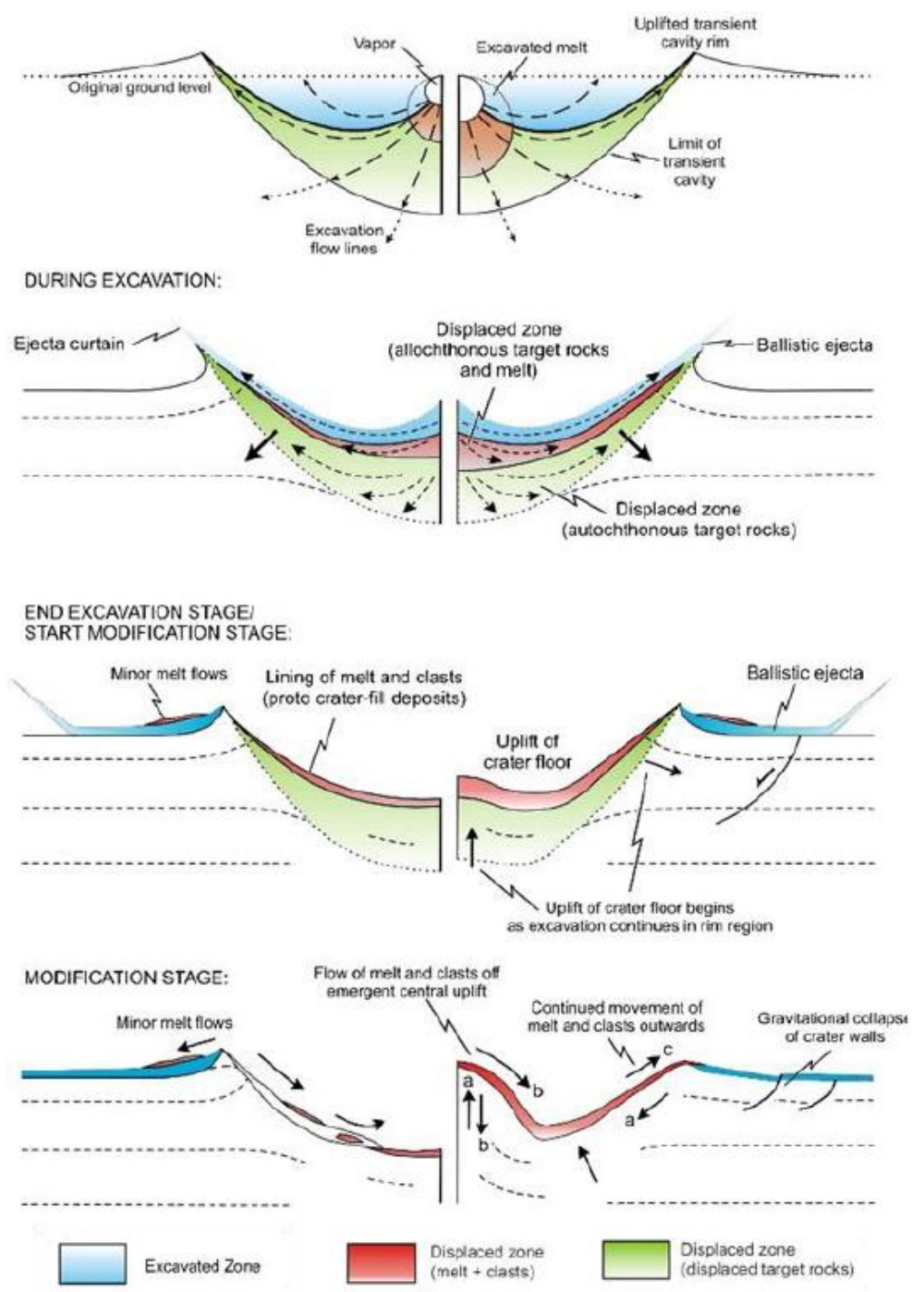

Figure 9: Series of schematic cross-sections depicting the three main stages in the formation of simple (left) and complex (right) craters. Modified from Osinski et al., 2011.

The first stage, contact and compression, is the fastest occurring of the three stages of impact crater formation (Figure 9). During this stage, the projectile or impactor (e.g., an asteroid or a comet) strikes the surface of a planetary body at high velocity (Melosh, 2013). Once this contact is made, the high kinetic energy enables shock waves to form at the projectile-target boundary and then propagate down and outward through both media, 
resulting in a compression and distortion of the target and projectile (Melosh, 2013). After the quick compression of the target and projectile, the rarefaction waves from the projectile propagate inward and rapidly decompress the shocked material, vaporizing the target, thus initializing an excavation flow (Melosh, 2013). The end of this stage is marked by the vaporization and complete passage of the rarefaction wave through the projectile (Melosh, 1989).

After the contact and compression stage, the crater formation transitions seamlessly into the excavation stage (Figure 9). The initial shock wave from the first stage expands hemispherically and deteriorates in strength into a plastic wave and then an elastic wave (Osinski et al., 2013). Portions of this shock wave interact with the upper ground surface and is then reflected back into the ground as rarefaction waves (Osinski et al., 2013). The combination of these complex shock and rarefaction waves moves target material into an 'excavation flow' (Osinski et al., 2013). This 'excavation flow' creates a bowl-shaped cavity and is opened up to create the 'transient cavity' or 'transient crater' (Melosh, 1989). The transient cavity is typically 10-20 times the diameter of the projectile (Kenkmann et al., 2013). The differing directions of materials in the excavation flow result in two separate zones: an upper excavated zone and a lower displaced zone (Osinski et al., 2013). The materials in the upper zone are ejected outward and away from the transient cavity, forming an ejecta blanket made of target material (Osinski et al., 2013). The materials in the lower zone, the displaced zone, have a downward and outward trajectory that forms the base of the expanding cavity (Stoffler et al., 1975; Grieve et al., 1977). There is some additional melt material generated, the majority of which remains in the transient cavity, but some deposits occur outside of the rim (Grieve et al., 1977; Melosh, 1989; Osinski et al., 2013).

The third and final stage is representative of the processes that alter the overall crater shape produced during the first two stages, resulting in the final crater form (Kenkmann et al., 2013). This stage is primarily driven by the gravitational forces on the planetary body, as well as the properties of the target rock, and typically initiates after the crater has been fully excavated (Melosh and Ivanov, 1999). The resulting product is either a simple or complex crater (Figure 9). There is no specific event which marks the end of this 
stage; this stage is considered a continuous geologic process, constantly being recharacterized by endogenic and exogenic processes.

\subsection{Titan's craters}

There is a paucity of craters on Titan's surface; in fact, the very first radar image taken by Cassini revealed no impact structures. As of present, there have only been 60 potential craters that have been published; however, current research by Hedgepeth et al., 2018, is updating this number to 90 . Each of these 90 potential impact features are ranked in different classes to represent the likelihood the feature is of impact origin (Wood et al., 2010). Craters given the 'certain' ranking have the clear morphology of an impact crater: a well-defined rim, interior, and possible ejecta blanket (Wood et al., 2010). 'Nearly certain' craters lack some of these diagnostic morphologies (Wood et al., 2010). The lowest ranked class, 'probable', is morphologically similar to those in the 'nearly certain' class, but are more degraded or are seen in much lower resolution (Wood et al., 2010). It is certainly possible that there are more craters than this on Titan since the entirety of the surface has not been mapped by radar and many craters are difficult to identify given the extensive erosion on the surface. Nonetheless, it is clear that there is a lack of these features, implying that Titan's surface is relatively young and quite active. The deficiency of smaller diameter craters $(<20 \mathrm{~km})$ is a direct result of Titan's dense atmosphere, which acts as a shield and destroys these smaller projectiles before they reach the surface (Lorenz et al., 2007). The low number of mid-sized craters is likely accounted for by erosional and burial processes, supporting the notion of an active world (Lorenz et al., 2007). Further evidence for Titan's high level of surface activity is shown by the relative depths of its known craters. Craters on Titan are consistently shallower than similar sized craters on Ganymede, suggestive of a modification process such as aeolian infilling (Neish et al., 2013). Section 1.2 noted the large regions of sand dunes on Titan, which would provide a modification process consistent with the locations of most craters. It also appears as though fluvial modification of craters is a factor (Neish et al., 2013). Demonstrated in radar images as well as VIMS images, fluvial channels and networks have been identified all over Titan, even in the equatorial regions dominated by sand dunes (Neish et al., 2016). Many of the craters on Titan do show some evidence of 
fluvial modification. For instance, there is evidence of channels cross-cutting ejecta blankets or dissecting crater rims (Wood et al., 2010; Neish et al., 2016). It is also worth noting the distribution of craters on the surface (Figure 10).

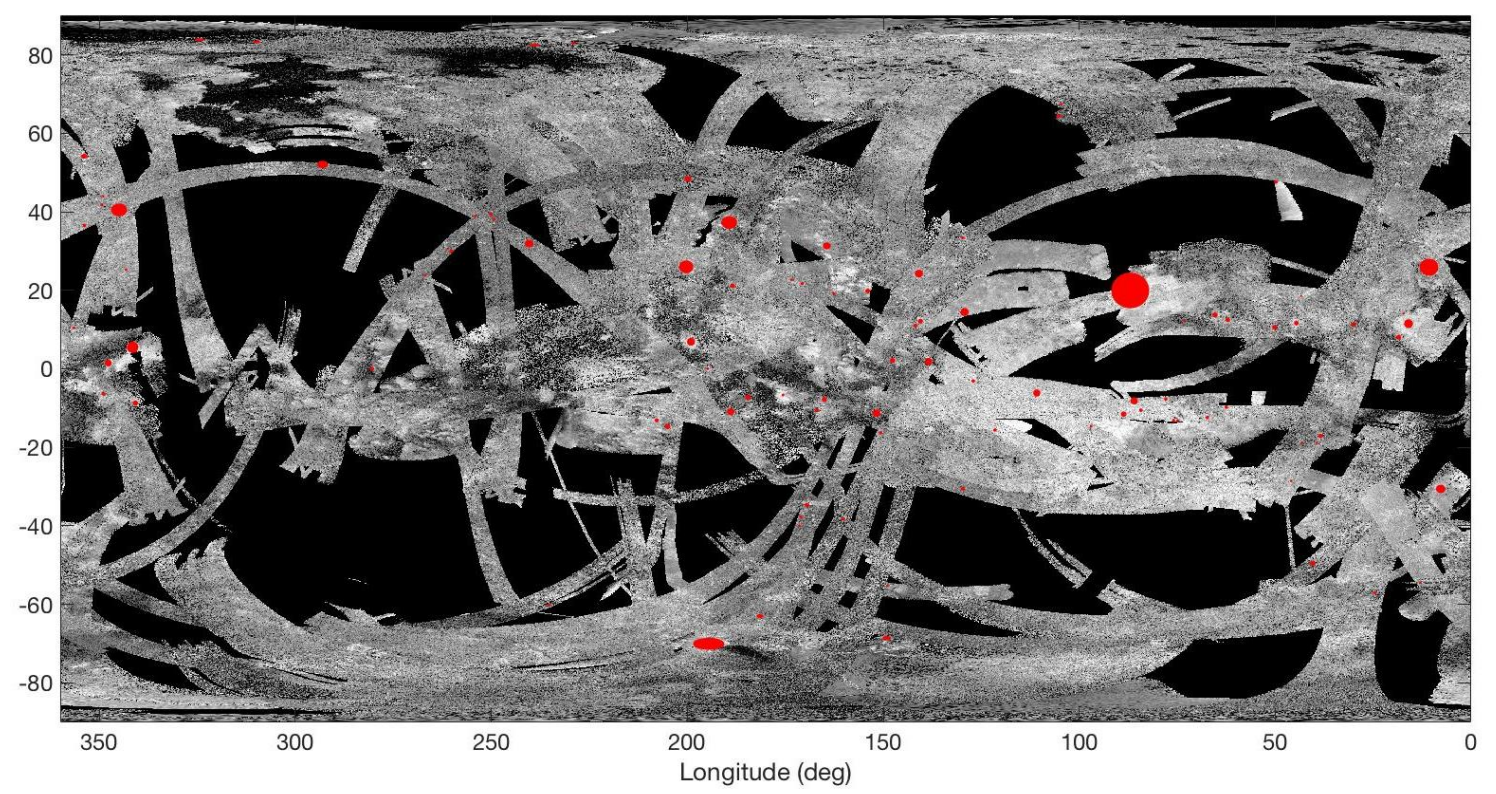

Figure 10: Radar map of Titan with the 90 craters circled in red. The size of the circle is proportional to the crater's diameter. Note the lack of craters near the poles. Image from Hedgepeth et al., 2018.

The majority of impact structures are found within 45 degrees of the equator, with only a few possible structures near the poles (Neish and Lorenz, 2014). One hypothesis for this asymmetrical crater distribution is extensive fluvial modification near the poles. This could occur given higher precipitation rates near the summer poles, which is consistent with predicted and observed weather patterns (Neish and Lorenz, 2014). There is also the possibility of an ocean existing in the past, at the poles or in lowland regions (Larsson and McKay, 2013; Neish and Lorenz, 2014). If this were the case, any impacts occurring in the ocean environments would lack any distinctive evidence or topography (Neish and Lorenz, 2014).

There is only one known large crater (diameter $>200 \mathrm{~km}$ ) on Titan and it was one of the first impact features discovered, since named Menrva (Lorenz et al., 2007). A crater the 
size of Menrva is only expected to occur on Titan once in 10 billion years, so it not surprising that only one such feature has been identified (Neish and Lorenz, 2012). However, in many ways, Menrva is an outlier among the potential craters that have been discovered. It is a two ring impact structure with diameter of $\sim 440 \mathrm{~km}$, located just north of the large, bright region called Xanadu (Wood et al., 2010). Westward of Menrva, there is evidence of fluvial features which terminate at the rim (Wood et al., 2010). On the eastern edge of the crater, bright fluvial features seem to begin at the rim low and then proceed to flow eastward (Wood et al., 2010). For comparison, the remaining impact features found on Titan are all less than $139 \mathrm{~km}$ in diameter (Hedgepeth et al., 2018).

\subsection{Summary and aim}

Titan has intrigued scientists for hundreds of years with its large size and substantial atmosphere. Since then, multiple missions as well as Earth-based telescopes have delved deeper into understanding this elusive moon. Cassini has uncovered a wide-range of geologic features with striking similarities to features observed on Earth. Though there is a relative scarcity of impact craters on Titan, by studying them, more can be learned about the subsurface as well as target environments. The aim of this research is to study the composition of multiple impact craters and their ejecta blankets, and learn how their compositions evolve over time, providing insight to the modification processes on Titan. This thesis is divided into four chapters, including this one. Chapter 2 provides a background on the remote sensing and data processing methods used in this research. Chapter 3 provides an in depth description of this research on understanding the compositional variations in Titan's craters and what the implications are for the moon and its processes. Chapter 4 provides interpretations, a conclusion, and future work for the thesis. 


\subsection{References}

Aharonson, O., Hayes, A. G., Lunine, J. I., Lorenz, R. D., Allison, M. D., and Elachi, C. 2009. An asymmetric distribution of lakes on Titan as a possible consequence of orbital forcing. Nature Geoscience 2, 851-854.

Barnes, J. W., Brown, R. H., Soderblom, L., Buratti, B. J., Sotin, C., Rodriguez, S., Le Mouelic, S., Baines, K. H., Clark, R., and Nicholson, P. 2007. Global-scale surface spectral variations on Titan seen from Cassini/VIMS. Icarus 180, 242258.

Collins, G., and Johnson, T. V. 2014. Ganymede and Callisto. In Spohn, T., Breuer, D., and Johnson, T. V. (Eds)., Encyclopedia of the Solar System, Amsterdam, Netherlands, Elsevier, 813-829.

Cottini, V., Nixon, C. A., Jennings, D. E., de Kok, R., Teanby, N. A., Irwin, P. G. J., and Flasar, F. M. 2012. Spatial and temporal variations in Titan's surface temperatures from Cassini CIRS observations. Planetary and Space Science 60, $62-71$.

Coustenis, A. 2014. Titan. In Spohn, T., Breuer, D., and Johnson, T. V. (Eds)., Encyclopedia of the Solar System, Amsterdam, Netherlands, Elsevier, 831-849.

Elachi, C., Wall, S., Allison, M., Anderson, Y., Boehmer, R., Callahan, P., Encrenaz, P., Flamini, E., Francescetti, G., Gim, Y., Hamilton, G., Hensley, S., Janssen, M. A., Johnson, W., Kelleher, K., Kirk, R. L., Lopes, R. M. C., Lunine, J. I., Muhleman, D., Ostro, S., Paganelli, F., Picardi, G., Posa, F., Roth, L., Seu, R., Shaffer, S., Soderblom, L., Stiles, B., Stofan, E., Vetrella, S., West, R., Wood, C., Wye, L., and Zebker, H. 2005. Cassini radar views the surface of Titan. Science 308, 970-974.

Elachi, C., Wall, S., Janssen, M. A., Stofan, E., Lopes, R. M. C., Kirk, R. L., Lorenz, R. D., Lunine, J. I., Paganelli, F., Soderblom, L., Wood, C., Wye, L., Zebker, H., Anderson, Y., Ostro, S., Allison, M., Boehmer, R., Callahan, P., Encrenaz, P., 
Flamini, E., Francescetti, G., Gim, Y., Hamilton, G., Hensley, S., Johnson, W., Kelleher, K., Muhleman, D., Picardi, G., Posa, F., Roth, L., Seu, R., Shaffer, S., Stiles, B., Vetrella, S., and West, R. 2006. Titan Radar Mapper observations from Cassini's T3 fly-by. Nature 441, 709-716.

Fulchignoni, M., Ferri, F., Angrilli, F., Ball, A. J., Bar-Nun, A., Barucci, M. A., Bettanini, C., Bianchini, G., Borucki, W., Colombatti, G., Coradini, M., Coustenis, A., Debei, S., Falkner, P., Fanti, G., Flamini, E., Gaborit, V., Grard, R., Hamelin, M., Harri, A. M., Hathi, B., Jernej, I., Leese, M. R., Lehto, A., Lion Stoppato, P. F., Lopez-Moreno, J. J., Makinen, T., McDonnell, J. A. M., McKay, C. P., Molina-Cuberos, G., Neubauer, F. M., Pirronello, V., Rodrigo, R., Saggin, B., Schwingenschuh, K., Seiff, A., Simoes, F., Svedhem, H., Tokano, T., Towner, M. C., Trautner, R., Withers, P., and Zarnecki, J. C. 2005. In situ measurements of the physical characteristics of Titan's environment. Nature 438, 785-791.

Grieve, R. A. F., Dence, M. R., and Robertson, P. B. 1977. Cratering processes: as interpreted from the occurrences of impact melts. In Roddy, D. J., Pepin, R. O., and Merrill, R. B. (Eds.), Impact Explosion Cratering, New York, NY, Pergaman Press, 791-814.

Hanel, R., Conrath, B., Flasar, F. M., Kunde, V., Maguire, W., Pearl, J., Pirraglia, J., Samuelson, R., Herath, L., Allison, M., Cruikshank, D., Gautier, D., Gierasch, P., Horn, L., Koppany, R., and Ponnamperuma, C. 1981. Infrared observations of the Saturnian system from Voyager 1. Science 212, 192-200.

Hedgepeth, J. E., Neish, C. D., Turtle, E. P., and Stiles, B. W. 2018. Impact craters on Titan: Finalizing Titan's crater population. 49th Lunar and Planetary Science Conference, Houston. Abstract \#2105.

Horst, S. M., 2017. Titan's atmosphere and climate. Journal of Geophysical Research: Planets 122, 432-482. 
Iess, L., Jacobson, R. A., Ducci, M., Stevenson, D. J., Lunine, J. I., Armstrong, J. W., Asmar, S. W., Racioppa, P., Rappaport, N. J., and Tortora, P. 2012. The tides of Titan. Science 337, 457-459.

Jaumann, R., Brown, R. H., Stephan, K., Barnes, J. W., Soderblom, L. A., Sotin, C., Le Mouelic, S., Clark, R. N., Soderblom, J., Buratti, B. J., Wagner, R., McCord, T. B., Rodriguez, S., Baines, K. H., Cruikshank, D. P., Nicholson, P. D., Griffith, C. A., Langhans, M., and Lorenz, R. D. 2008. Fluvial erosion and post-erosional processes on Titan. Icarus 197, 526-538.

Jaumann, R., Kirk, R. L., Lorenz, R. D., Lopes, R. M. C., Stofan, E., Turtle, E. P., Keller, H. U., Wood, C. A., Sotin, C., Soderblom, L. A., and Tomasko, M. 2009. Geology and surface processes on Titan. In Brown, R. H., Lebreton, J., and Waite, J. H (Eds)., Titan from Cassini-Huygens, New York, NY, Springer, 75140.

Jennings, D. E., Flasar, F. M., Kunde, V. G., Samuelson, R. E., Pearl, J. C., Nixon, C. A., Carlson, R. C., Mamoutkine, A. A., Brasunas, J. C., and Gaundique, E. 2009. Titan's surface brightness temperatures. The Astrophysical Journal Letters 691, L103-L105.

Jennings, D. E., Cottini, V., Nixon, C. A., Flasar, F. M., Kude, V. G., Samuelson, R. E., Romani, P. N., Hesman, B. E., Carlson, R. C., and Gorius, N. J. P. 2011. Seasonal changes in Titan's surface temperatures. The Astrophysical Journal Letters 737, L15.

Kenkmann, T., Collins, G. S., and Wunnemann, K. 2013. The modification stage of crater formation. In Osinski, G. R., and Pierazzo, E (Eds.), Impact Cratering: Processes and Products, Oxford, UK, Blackwell Publishing, 60-75.

Kunde, V. G., Aikin, A. C., Hanel, R. A., Jennings, D. E., Maguire, W. C., and Samuelson, R. E. 1981. $\mathrm{C}_{4} \mathrm{H}_{2}, \mathrm{HC}_{3} \mathrm{~N}$ and $\mathrm{C}_{2} \mathrm{~N}_{2}$ in Titan's atmosphere. Nature 292, 686-688. 
Larsson, R. and McKay, C. P. 2013. Timescale for oceans in the past on Titan. Planetary and Space Science 78, 22-24.

Lebreton, J., Witasse, O., Sollazzo, C., Blancquaert, T., Couzin, P., Schipper, A., Jones, J. B., Matson, D. L., Gurvits, L. I., Atkinson, D. H., Kazeminejad, B., and PerezAyucar, M. 2005. An overview of the descent and landing of the Huygens probe on Titan. Nature 438, 758-764.

Lopes, R. M. C., Stofan, E. R., Peckyno, R., Radebaugh, J., Mitchell, K. L., Mitri, G., Wood, C. A., Kirk, R. L., Wall, S. D., Lunine, J. I., Hayes, A., Lorenz, R. D., Farr, T., Wye, L., Craig, J., Ollerenshaw, R. J., Janssen, M. A., Le Gall, A., Paganelli, F., West, R., Stiles, B. W., Callahan, P., Anderson, Y., Valora, P., Soderblom, L., and the Cassini RADAR team. 2010. Distribution and interplay of geologic processes on Titan from Cassini radar data. Icarus 205, 540-558.

Lopes, R. M. C., Kirk, R. L., Mitchell, K. L., Le Gall, A., Barnes, J. W., Hayes, A., Kargel, J., Wye, L., Radebaugh, J., Stofan, E. R., Janssen, M. A., Neish, C. D., Wall, S. D., Wood, C. A., Lunine, J. I., and Malaska, M. J. 2013. Cryovolcanism on Titan: New results from Cassini RADAR and VIMS. Journal of Geophysical Research: Planets 118, 416-435.

Lopes, R. M. C., Malaska, M. J., Solomonidou, A., Le Gall, A., Janssen, M. A., Neish, C. D., Turtle, E. P., Birch, S. P. D., Hayes, A. G., Radebaugh, J., Coustenis, A., Schoenfeld, A., Stiles, B. W., Kirk, R. L., Mitchell, K. L., Stofan, E. R., Lawrence, K. J., and the Cassini RADAR team. 2016. Nature, distribution, and origin of Titan's undifferentiated plains. Icarus 270, 162-182.

Lorenz, R. D., Wood, C. A., Lunine, J. I., Wall, S. D., Lopes, R. M. C., Mitchell, K. L., Paganelli, F., Anderson, Y. Z., Wye, L., Tsai, C., Zebker, H., and Stofan, E. R. 2007. Titan's young surface: Initial impact crater survey by Cassini RADAR and model comparison. Geophysical Research Letters 34, L07204.

Lorenz, R. D., and Mitton, J. 2008. Titan unveiled. Princeton, NJ: Princeton University Press. 
Lunine, J. I. and Lorenz, R. D. 2009. Rivers, lakes, dunes, and rain: Crustal processes in Titan's methane cycle. Annual Review of Earth and Planetary Sciences 37, 299320.

MacKenzie, S. M., Barnes, J. W., Sotin, C., Soderblom, J. M., Le Mouelic, S., Rodriguez, S., Baines, K. H., Buratti, B. J., Clark, R. N., Nicholson, P. D., and McCord, T. B. 2014. Evidence of Titan's climate history from evaporite distribution. Icarus 243, 191-207.

Malaska, M. J., Radebaugh, J., Lopes, R. M. C., Mitchell, K. L., Hayes, A. G., Le Gall, A., Turtle, E., Solomonidou, A., and Lorenz, R. 2014. Labyrinth terrain on Titan. 2014 Annual Meeting of the Geological Society of America, Vancouver. Abstract \#T227.

Melosh, H. J. 1989. Impact cratering: A geologic process. Oxford University Press, New York, NY.

Melosh, H. J., and Ivanov, B. A., 1999. Impact crater collapse. Annual Review of Earth and Planetary Science 27, 385-415.

Melosh, H. J. 2013. The contact and compression stage of impact cratering. In Osinski, G. R., and Pierazzo, E (Eds.), Impact Cratering: Processes and Products, Oxford, UK, Blackwell Publishing, 32-42.

Mitri, G., Showman, A. P., Lunine, J. I., and Lopes, R. M. C. 2008. Resurfacing of Titan by ammonia-water cryomagma. Icarus 196, 216-224.

Mitri, G., Meriggiola, R., Hayes, A., Lefevre, A., Tobie, G., Genova, A., Lunine, J. I., and Zebker, H. 2014. Shape, topography, gravity anomalies and tidal deformation of Titan. Icarus 236, 169-177.

Moore, J. M. and Pappalardo, R. T. 2011. Titan: An exogenic world? Icarus 212, 790806. 
Neish, C. D., and Lorenz, R. D. 2012. Titan's global crater population: A new assessment. Planetary and Space Sciences 60, 26-33.

Neish, C. D., Kirk, R. L., Lorenz, R. D., Bray, V. J., Schenk, P., Stiles, B. W., Turtle, E, Mitchell, K., Hayes, A., and the Cassini RADAR team. 2013. Crater topography on Titan: Implications for landscape evolution. Icarus 223, 82-90.

Neish, C. D. and Lorenz, R. D. 2014. Elevation distribution of Titan's craters suggests extensive wetlands. Icarus 228, 27-34.

Neish, C. D., Molaro, J. L., Lora, J. M., Howard, A. D., Kirk, R. L., Schenk, P., Bray, V. J., and Lorenz, R. D. 2016. Fluvial erosion as a mechanism for crater modification on Titan. Icarus 270, 114-129.

Nimmo, F., and Bills, B. G. 2010. Shell thickness variations and the long-wavelength topography of Titan. Icarus 208, 896-904.

Osinski, G. R., Tornabene, L. L., and Grieve, R. A. F. 2011. Impact ejecta emplacement on the terrestrial planets. Earth and Planetary Science Letters 310, 167-181.

Osinski, G. R., Grieve, R. A. F., and Tornabene, L. L. 2013. Excavations and impact ejecta implacement. In Osinski, G. R., and Pierazzo, E (Eds.), Impact Cratering: Processes and Products, Oxford, UK, Blackwell Publishing, 43-59.

Radebaugh, J., Lorenz, R. D., Kirk, R. L., Lunine, J. O., Stofan, E. R., Lopes, R. M. C., Wall, S. D., and the Cassini RADAR team. 2007. Mountains on Titan observed by Cassini Radar. Icarus 192, 77-91.

Radebaugh, J., Lorenz, R. D., Lunine, J. I., Wall, S. D., Boubin, G., Reffet, E., Kirk, R. L., Lopes, R. M. C., Stofan, E. R., Soderblom, L., Allison, M., Janssen, M. A., Paillou, P., Callahan, P., Spencer, C., and the Cassini RADAR team. 2008. Dunes on Titan observed by Cassini Radar. Icarus 194, 690-703.

Radebaugh, J. 2013. Dunes on Saturn's moon Titan as revealed by the Cassini mission. Aeolian Research 11, 23-41. 
Rannou, P., Montmessin, F., Hourdin, F., and Lebonnois, S. 2006. The latitudinal distribution of clouds on Titan. Science 311, 201-205.

Richardson, J., Lorenz, R. D., and McEwen, A. 2004. Titan's surface and rotation: new results from Voyager 1 images. Icarus 170, 113-124.

Schinder, P. J., Flasar, F. M., Marouf, E. A., French, R. G., McGhee, C. A., Kliore, A. J., Rappaport, N. J., Barbinis, E., Fleischman, D., and Anabtawi, A. 2011. The structure of Titan's atmosphere from Cassini radio occultations. Icarus 215, 460474.

Schinder, P. J., Flasar, F. M., Marouf, E. A., French, R. G., McGhee, C. A., Kliore, A. J., Rappaport, N. J., Barbinis, E., Fleischman, D., and Anabtawi, A. 2012. The structure of Titan's atmosphere from Cassini radio occultations: Occultations form the Prime and Equinox missions. Icarus 221, 1020-1031.

Schneider, T., Graves, S. D. B., Schaller, E. L., and Brown, M. E. 2012. Polar methane accumulation and rainstorms on Titan from simulations of the methane cycle. Nature 481, 58-61.

Soderblom, L. A., Kirk, R. L., Lunine, J. I., Anderson, J. A., Baines, K. H., Barnes, J. W., Barrett, J. M., Brown, R. H., Buratti, B. J., Clark, R. N., Cruikshank, D. P., Elachi, C., Janssen, M. A., Jaumann, R., Karkoschka, E., Le Mouelic, S., Lopes, R. M. C., Lorenz, R. D., McCord, T. B., Nicholson, P. D., Radebaugh, J., Rizk, B., Sotin, C., Stofan, E. R., Sucharski, T. L., Tomasko, M. G., and Wall, S. D. 2007. Correlations between Cassini VIMS spectra and RADAR SAR images: Implications for Titan's surface composition and the character of the Huygens Probe Landing Site. Planetary and Space Science 55, 2025-2036.

Sotin, C., and Tobie, G. 2004. Internal structure and dynamics of the large icy satellites. Comptes Rendes Physique 5, 769-780. 
Sotin, C., Mitri, G., Rappaport, N., Schubert, G., and Stevenson, D. 2009. Titan's interior structure. In Brown, R. H., Lebreton, J., and Waite, J. H (Eds)., Titan from Cassini-Huygens, New York, NY, Springer, 61-74.

Stofan, E. R., Lunine, J. I., Lopes, R. M. C., Paganelli, F., Lorenz, R. D., Wood, C. A., Kirk, R. L., Wall, S. D., Elachi, C., Soderblom, L. A., Ostro, S., Janssen, M. A., Radebaugh, J. Wye, L., Zebker H., Anderson, Y., Allison, M., Boehmer, R., Callahan, P., Encrenaz, P., Flamini, E., Francescetti, G., Gim, Y., Hamilton, G., Hensley, S., Johnson, W. T. K., Kelleher, K., Muhleman, D., Picardi, G., Posa, F., Roth, L., Seu, R., Shaffer, S., Stiles, B. W., Vetrella, S., and West, R. 2006. Mapping of Titan: Results from the first Titan radar passes. Icarus 185, 443-456.

Stoffler. D., Gault, D. E., Wedekind, J., and Polkowski, G. 1975. Experimental hypervelocity impact into quartz sand: distribution and shock metamorphism of ejecta. Journal of Geophysical Research 80, 4062-4077.

Tobie, G., Grasset, O., Lunine, J. I., Mocquet, A., and Sotin, C., 2005. Titan's internal structure inferred from a coupled thermal-orbital model. Icarus 175, 496-502.

Tomasko, M. G., Archinal, B., Becker, T., Bezard, B., Bushroe, M., Combes, M., Cook, D., Coustenis, A., de Bergh, C., Dafoe, L. E., Doose, L., Doute, S., Eibl, A., Engel, S., Gliem, F., Grieger, B., Holso, K., Howington-Kraus, E., Karkoschka, E., Keller, H. U., Kirk, R., Kramm, R., Kuppers, M., Lanagan, P., Lellouch, E., Lemmon, M., Lunine, J., McFarlane, E., Moores, J., Prout, G. M., Rizk, B., Rosiek, M., Rueffer, P., Schroder, S. E., Schmitt, B., See, C., Smith, P., Soderblom, L., Thomas, N., and West, R. 2005. Rain, winds and haze during the Huygens probe's descent to Titan's surface. Nature 438, 765-778.

Wood, C. A., Lorenz, R., Kirk, R., Lopes, R., Mitchel, K., Stofan, E., and the Cassini RADAR Team, 2010. Impact craters on Titan. Icarus 206, 334-344. 


\section{Chapter 2}

\section{Remote Sensing Datasets and Methodology}

\subsection{Remote sensing datasets}

In order to study craters on different planetary surfaces, remote sensing techniques are often used. There are two main types of remote sensing: passive and active. Passive instruments utilize an external energy source (such as the Sun) and detect radiation emitted or reflected from the surface of the object being viewed. Active instruments utilize their own energy source and send a pulse of energy from the sensor to the object being viewed. This energy is then reflected or backscattered from the object. On Titan, the wavelengths that can view the surface are very limited due to its dense atmosphere (see section 1.2). The Cassini spacecraft was equipped with a RADAR instrument capable of observing the surface through its atmosphere at $2.18-\mathrm{cm}$ wavelength, and providing insights into its surface roughness properties, elevation, and composition. Cassini was also equipped with the Visible and Infrared Mapping Spectrometer (VIMS), which measures both visible and infrared light to learn more about the composition of objects. Remote sensing data from the RADAR instrument and VIMS are used in this study.

\subsubsection{Radar}

Radar is an active remote sensing technique and therefore does not rely on an external energy source to operate. It involves transmitting a radio signal towards a target and receiving the associated echo. Radar images are sensitive to electrical and physical properties such as surface roughness, dielectric constants of the target surface and subsurface, as well as topography (Neish and Carter, 2014). One advantage of using radar to study distant planetary bodies such as Titan is its ability to penetrate Titan's thick atmosphere at 2.18-cm wavelength and thus 'see' the surface. Synthetic aperture radar (SAR) is useful for the geologic mapping of Titan's surface because it is sensitive to surface roughness (Figure 11). Smooth surfaces, with roughness features smaller than the centimeter scale, appear dark in radar because they reflect the signal away from the 
receiver which produces weaker responses. However, a smooth surface can produce a strong signal depending on the incidence angle of the active beam. The incidence angle is the angle between the source beam to the surface normal. If the difference between the incidence angle of the active beam and the surface slope angle is minimal, a strong signal can be produced (Neish and Carter, 2014). On the contrary, rough surfaces will scatter the beam in multiple directions and therefore more of the beam will be scattered back towards the receiver and will create a stronger response (Neish and Carter, 2014).

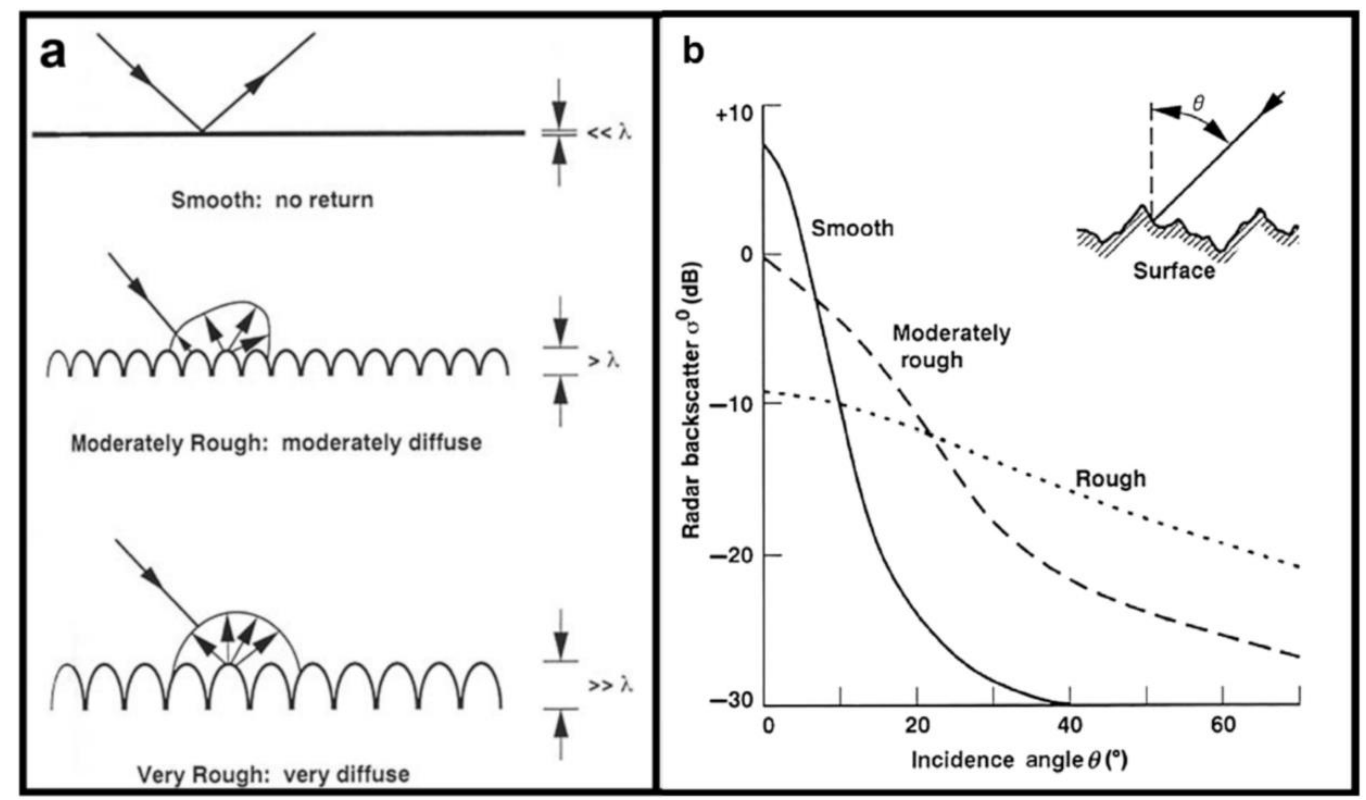

Figure 11: a) Schematic showing how a surface will scatter the radar energy in certain directions based on the wavelength-scale roughness of its surface. b) Radar backscatter also depends on the incidence angle of the beam. Smoother surfaces can have strong returns when the incidence angle is close to the surface slope angle, but have very weak returns at incidence angles greater than $30^{\circ}$. Image from Neish and Carter, 2014, adapted from Farr, 1993.

Radar's sensitivity to surface roughness is especially useful to distinguish crater features on planetary surfaces. For instance, crater rims and ejecta appear brighter in radar. This is due to the impact crater formation processes: the resulting crater could have a structurally complex rim or a terraced rim, in addition to rocky rims and ejecta blankets. Moreover, the crater floor appears radar dark because in a geologic context, these floors 
are typically smoother as a result of erosional deposition of sediments or aeolian infill by sand (Figure 12).

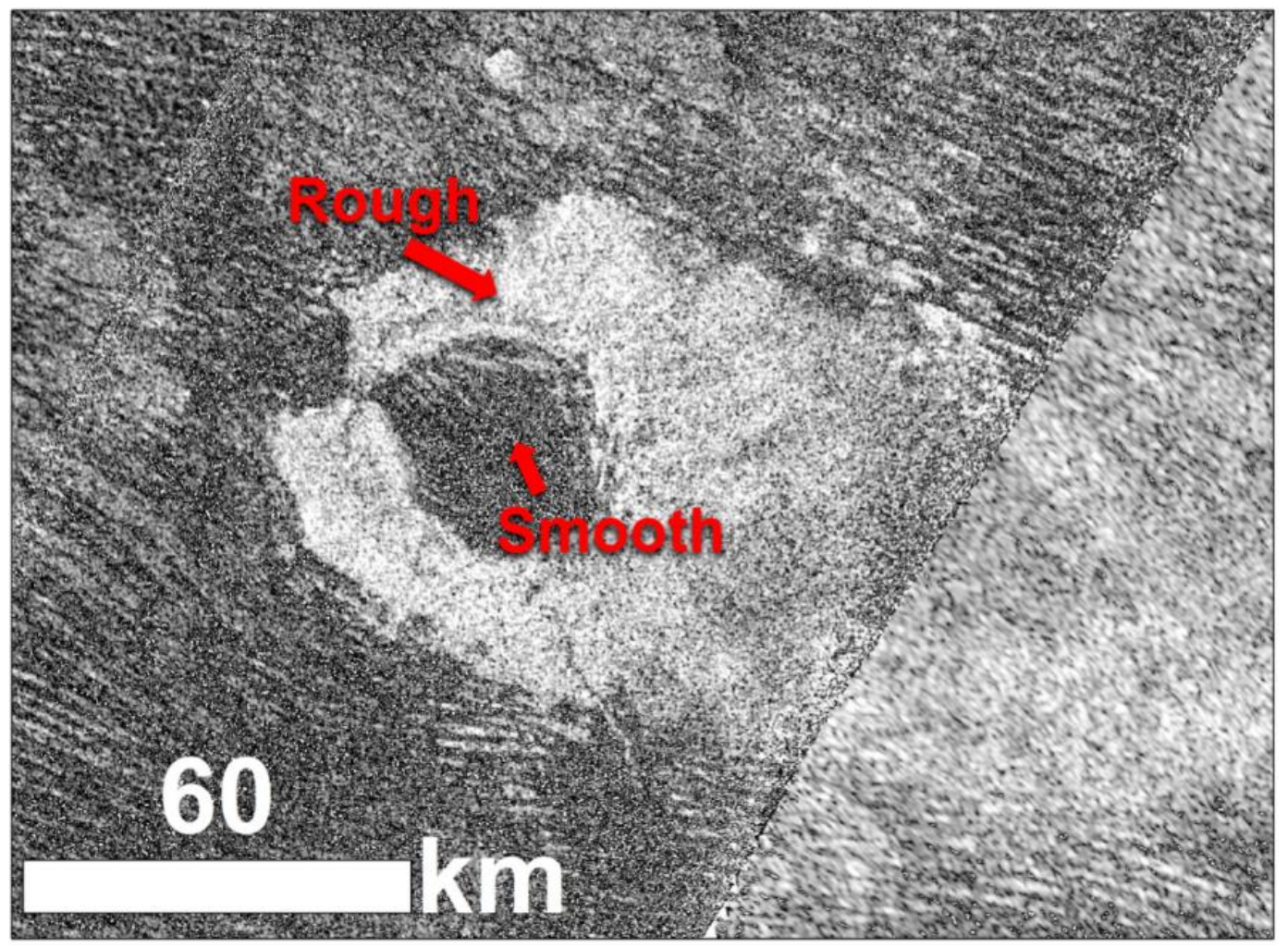

Figure 12: Cassini RADAR image of Santorini crater located at $2.2^{\circ} \mathrm{N}, 147.7^{\circ} \mathrm{W}$. Radar bright regions correspond with the rough crater rim and ejecta blanket. Radar dark regions correspond with the smooth surrounding sand dunes and sediment infill in the crater interior. Sand dunes appear smooth in radar because grain size is only a few hundred microns and the radar senses surface roughness at centimeter scales.

Another surface property radar is sensitive to is topography. For Titan, there are multiple ways radar was used to determine topography with Cassini: radar altimetry, stereophotogrammetry, and a method called SARTopo. Radar altimetry utilizes only the central, narrow antenna beam at nadir to make surface elevation measurements by considering the distance and travel time the echo takes to reach the elevated surface and return to the receiver (Elachi et al., 1999). Unfortunately, altimetry measurements cannot take place while SAR imaging is occurring (Elachi et al., 1999), resulting in altimetry 
covering only approximately $1.6 \%$ of the entire surface in regions rarely covered by SAR imagery (Corlies et al., 2017). Therefore, other techniques were implemented and derived to determine topography. One technique is stereophotogrammetry. This technique uses two overlapping radar images taken from different positions with favorable geometries, combined to provide a 3-dimensional representation of the surface (Elachi et al., 1999). This technique has provided topography data for $\sim 2.1 \%$ of the surface of Titan (Kirk et al., 2012). Another topographic method for Titan that is derived from radar is called SARTopo. Cassini RADAR has five beams that collect the resulting radar imagery (Stiles et al., 2009). These beams have zones which overlap and heights can be calculated in these zones in the course of image calibration (Stiles et al., 2009). SARTopo data covers approximately 5.2\% of Titan's surface (Corlies et al., 2017), compared to the coverage of all radar images of Titan, which amounts to approximately $75 \%$ of the surface (Lopes et al., 2018).

\subsubsection{Thermal microwave emission}

Emissivity of a surface is a dimensionless number between 0 and 1 which represents its effectiveness in emitting energy as thermal radiation. In broad terms, it is the ratio of the thermal radiation from the surface to the radiation emitted from an ideal blackbody, or perfect emitter, at the same temperature. An emissivity value of 1 corresponds with a blackbody or perfect emitter, therefore objects in nature have values less than 1 (Figure 13). Information about an object's emissivity helps determine the physical and chemical properties of the target, such as deriving composition from measured dielectric constants. 


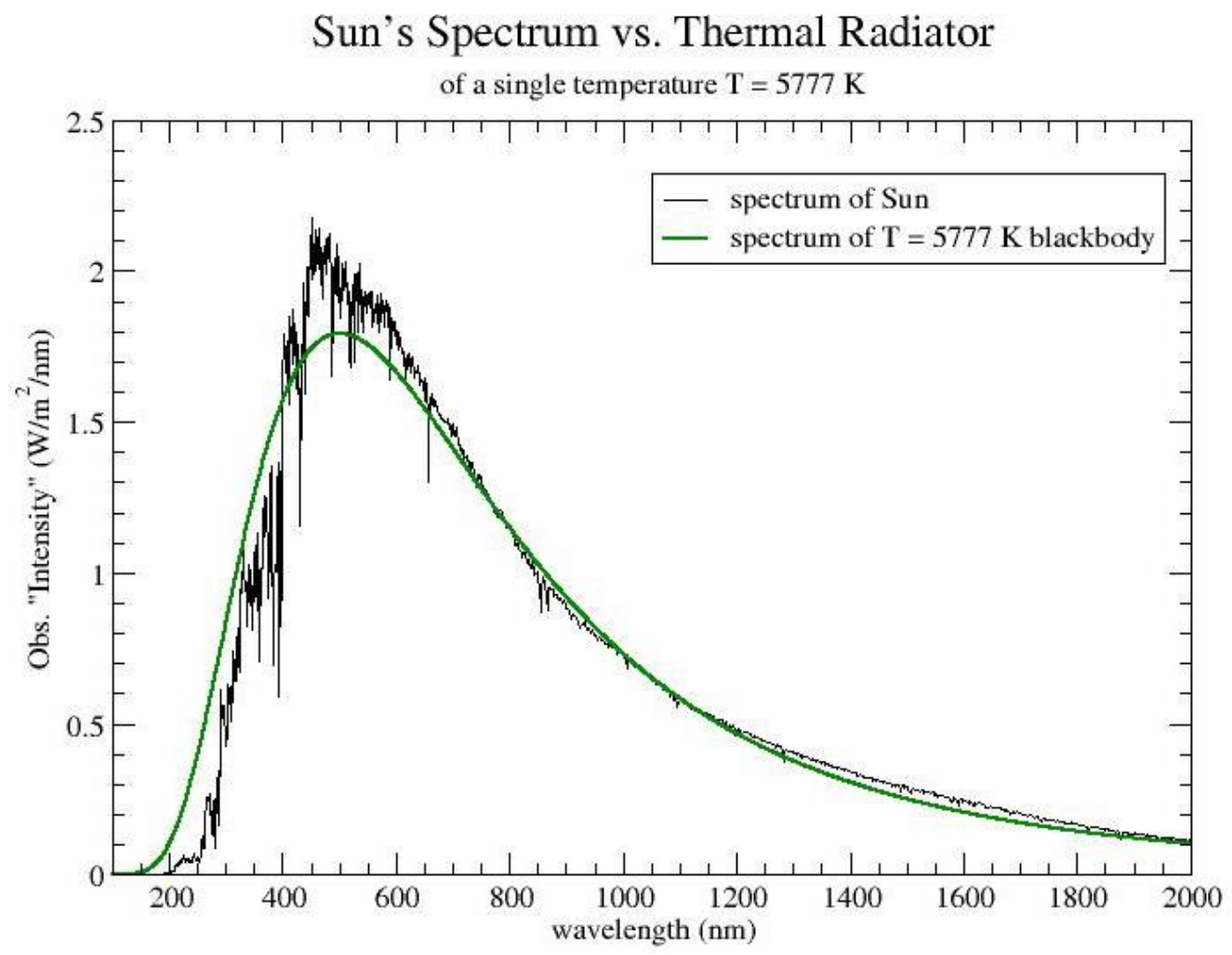

Figure 13: The Sun's spectrum (black) in relation to a perfect emitter, or blackbody (green), at the same temperature. The Sun is considered a blackbody but note how the Sun's spectrum does not match up evenly with a laboratory spectrum of a similar temperature blackbody. In nature, nothing is 'perfect', therefore objects in nature will have emissivity values less than 1. Image from Physics Stack Exchange.

Emissivity measurements for Titan were gathered using radiometry data via the Cassini RADAR instrument. Radiometers are a passive remote sensing technique and are used to measure the amount of electromagnetic energy that is present at a specific wavelength range. An advantage of using passive Cassini radiometry is that this mode can be operated either alone or in conjunction with other radar modes such as SAR imaging (Elachi et al., 1999). Additionally, because the Cassini radiometer samples the thermal microwave emission of Titan at $2.18-\mathrm{cm}$, it is able to probe the surface and subsurface at centimeter to meter depths (Figure 14) (Janssen et al., 2016). 


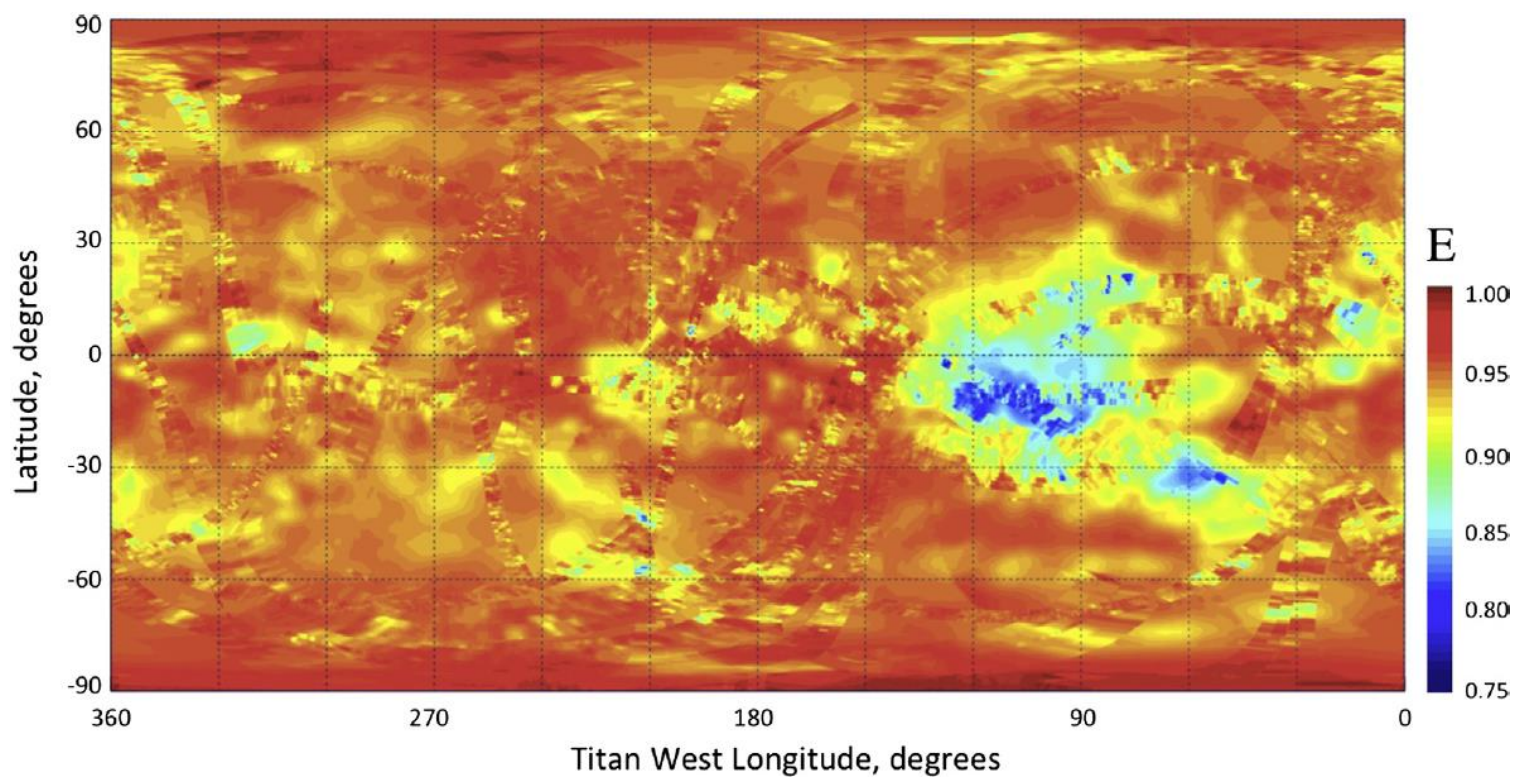

Figure 14: Global emissivity map of Titan from Janssen et al., 2016. Higher emissivities are represented by warmer colors and indicate organic enrichment. Lower emissivity values are represented by cooler colors and are interpreted as water-ice enrichment.

Radiometry provides the volume scattering and dielectric constants of the sampled media which allows composition to be inferred. For instance, on Titan, those regions with lower emissivity values are likely dominated by strong volume scattering (Janssen et al., 2016). Volume scattering occurs if a medium has voids, fractures, or other impurities. When electromagnetic radiation transmits through the medium-medium boundary and comes in contact with these voids, the radiation is scattered. An example which illustrates volume scattering is when sunlight passes through a cover of trees and is scattered by the leaves and branches (Figure 15). Water-ice under Titan conditions is known to be a strong volume scatterer from previous radar observations of the icy satellites of Jupiter and Saturn (Ostro et al., 2006). Conversely, the regions with higher emissivity values are likely organic enriched (Janssen et al., 2016). This is considered a strong candidate for high emissivity regions because of the complex organic compounds produced by photochemistry in Titan's atmosphere (Janssen et al., 2016). These photochemical products are likely widely distributed across Titan's surface, consistent with the wide distribution of low dielectric constants and high emissivities (Yung et al., 1984; Janssen 
et al., 2016). The surface composition of Titan is not well-constrained, so we focus on two broad compositional candidates: (1) water-ice or (2) organic enriched material. The exact composition of this organic material is not known, but it is likely a collection of large organic molecules, which themselves are combinations of carbon, nitrogen, and hydrogen.

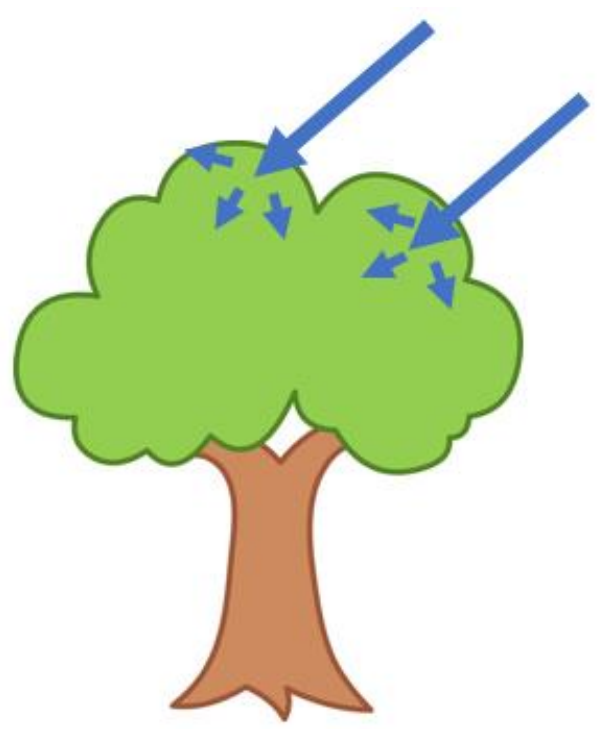

Figure 15: An example of volume scattering of sunlight on a tree top. Leaves, as well as branches, can scatter the incoming light in different directions.

The measured emissivity of Titan is primarily due to the absorbed heat from the Sun; there is little internal energy contributing in comparison. However, this absorbed heat is quite limited. Only $1 \%$ of the solar energy that reaches Earth reaches Titan, and of this, only $10 \%$ of that energy is able to pass through Titan's thick atmosphere and reach the surface (Lorenz and Mitton, 2008). There is not only limited energy being absorbed by Titan's surface, but there are other restrictions regarding the interpretations of the compositions seen with emissivity data. For instance, this data does not provide direct evidence for composition, it must be interpreted from the inferred volume scattering and dielectric constant derived from the emissivity data. However, these values can be interpreted a number of different ways. Janssen et al. (2009; 2016) and Ostro et al. (2006) have shown that water-ice is a strong volume scatterer given the conditions on Titan even though the mechanism for such is not well understood (Black et al., 2001; 
Janssen et al., 2011). It is possible that there are other low-loss organic mediums which scatter light in a similar way, but the best candidate remains water-ice. This is the best candidate because there should be some manifestation of the water-ice rich crust onto the surface, presumably associated with impact features or hummocky/mountainous terrains. The majority of these low emissivity, proposed water-ice regions do correlate with impact craters or hummocky/mountainous terrains (Janssen et al., 2016). Interpretations of organic-rich material on Titan are also somewhat ambiguous. The dune field regions have an average dielectric constant of 1.55 (Le Gall et al., 2011; Janssen et al., 2016). This low dielectric constant requires a low dielectric material $(\varepsilon \sim 2)$ and significant porosity (Janssen et al., 2016). These characteristics are consistent with a layer of organic grains with porosities ranging from 30-50\%, similar to Earth sand dunes (Pye and Tsoar, 1990). It is extremely unlikely that the dunes are composed primarily of water-ice because water-ice has a higher dielectric constant $(\varepsilon \sim 3.1)$. In order for water-ice to be the dominant composition, its porosity would have to be much greater than $60 \%$, which is unlikely (Janssen et al., 2016). In this scenario, organics are the most plausible composition.

\subsubsection{Visible and Infrared Mapping Spectrometer (VIMS)}

In section 1.2, atmospheric windows of Titan were briefly discussed. As a reminder, the 7 main windows for Titan in the visible and infrared are 0.94, 1.08, 1.28, 1.6, 2.0, 2.7-2.8, and 5.0 microns (Barnes et al., 2007). The Visible and Infrared Mapping Spectrometer (VIMS) utilizes these windows to provide compositional information gathered from 64 different wavelengths which complements that of the emissivity data (Barnes et al., 2007). The VIMS instrument operates under two detectors: VIMS-visible and VIMSinfrared. VIMS-VIS uses a two-dimensional array detector and a slit-scanning spectrometer operating at 0.30-1.05 microns (Capaccioni et al., 1998) and VIMS-IR is a linear array detector that acts as a single spot-scanning near-infrared spectrometer operating at 0.88-5.1 microns (Brown et al., 2004). The VIMS-IR channel is hyperspectral and the wavelength range covers a total of 256 spectral bands (Brown et al., 2004). The majority of Titan's atmospheric windows fall within the range of the VIMSIR channel, therefore, VIMS-IR data is used exclusively in this work. 
To maximize the information displayed, and to make the data more manageable, the 64 VIMS channels which show Titan's surface are categorized into 3 peak wavelength ranges represented by the colors red, green, and blue (Figure 16) (Barnes et al., 2007). As one example, red coloring is averaged from the window of 4.8-5.0 microns and shows the most variation relative to the other windows (Barnes et al., 2007). Greens span the 2.0 micron window, whereas blues account for the 1.3 micron window (Barnes et al., 2007). This is a common way to represent the data and has been utilized in many peerreviewed publications using VIMS data (e.g. MacKenzie et al., 2014; Neish et al., 2015). Resulting VIMS spectral images range in resolution from > $50 \mathrm{~km} /$ pixel up to 250 m/pixel (Barnes et al., 2007).

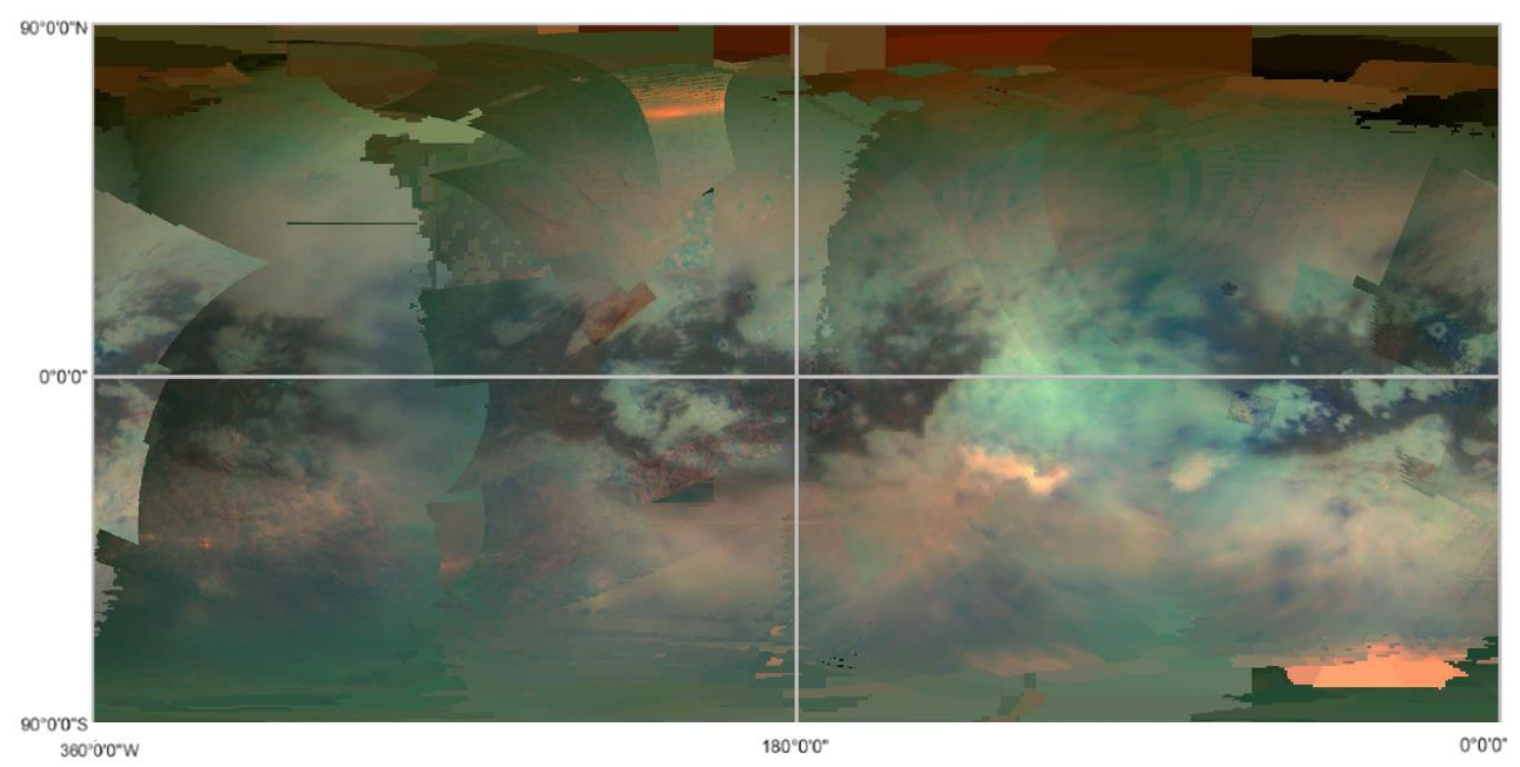

Figure 16: Global VIMS mosaic of Titan from Cassini observations by Barnes et al., 2007. Colors are mapped with red as 4.8-5.2 $\mu \mathrm{m}$, green as $2.0 \mu \mathrm{m}$, and blue as 1.28 $\mu \mathrm{m}$. Reds are either clouds or evaporites, blue represents water-ice, browns are sand dunes, and green is an unknown unit, likely a mix of organics and water-ice. Figure modified from Neish et al., 2015.

Composition can be inferred from spectra due to absorption or reflection features specific to each molecule. Each material has its own unique atomic makeup and when electromagnetic radiation interacts with the material, electrons can transition to and from different atomic energy levels. For instance, on Titan, the VIMS dark blue unit is 
interpreted to be water-ice. Water-ice strongly absorbs at about 1.5 and 2.0 microns and reflects strongly at $\sim 0.9,1.2$, and 1.4 microns (Figure 17) (Kokaly et al., 2017). Spectrally, on Titan, this unit has a strong absorption feature at 2.0 and also absorbs at 1.6 and 5.0 microns (Barnes et al., 2007). The dark blue unit is moderately reflective at 1.3, 1.08, and 0.94 microns (Barnes et al., 2007). These specific absorption and reflection features indicate that this material is likely a dirty water-ice (i.e. not pure water-ice). This 'dirtiness' could be some slight organic enrichment.

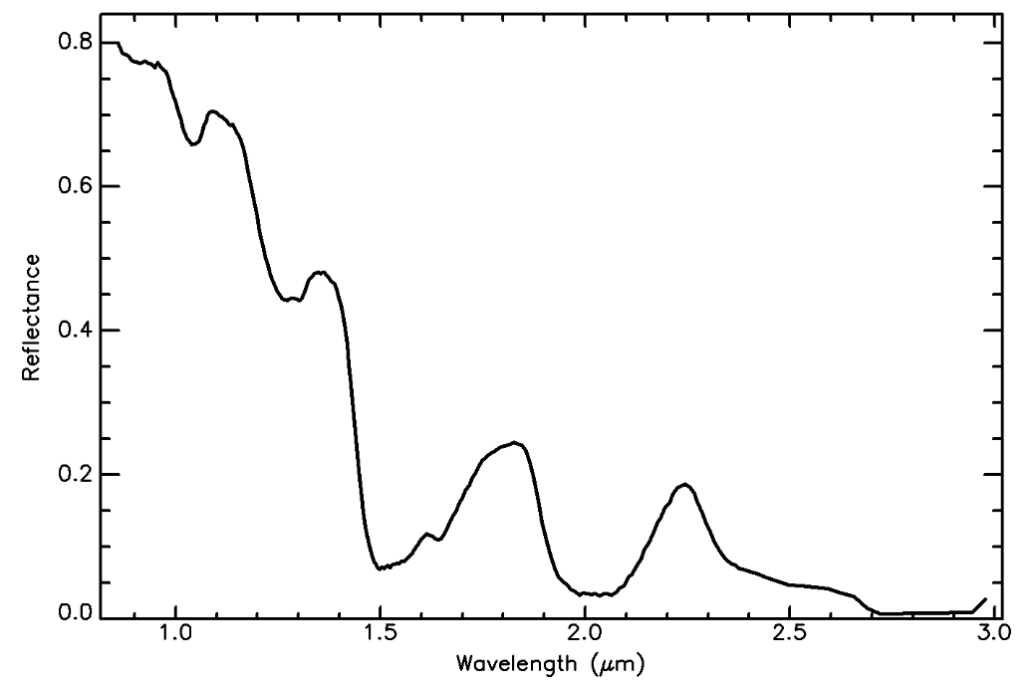

Figure 17: Spectra of pure water-ice shown from a wavelength range of 0.8-3.0 microns. Note the large absorption bands at $\sim 1.5$ and 2.0 microns (Kokaly et al., 2017).

The dark brown unit is more spectrally neutral than the blue unit, implying it is not waterice enriched and likely organic (Soderblom et al., 2007). Additionally, the dark brown units have a strong correlation with sand dunes as seen in Cassini RADAR images, providing further evidence for an organic composition (Soderblom et al., 2007). Red units are 5-micron bright regions, usually associated with dry lake features (Barnes et al., 2011; MacKenzie et al., 2014). Barnes et al. (2011) demonstrated that the 5-micron bright, water-ice poor spectra could be consistent with an evaporitic formation. Barnes et al. (2011) proposed that the deposits would re-crystallize when the solute evaporated and this would only take place in the saturated solutions, explaining the spectra and geographic link to the lake features. The bright green unit is perhaps the most ambiguous 
- it is currently dubbed the 'unknown' unit but is proposed to be a mix of water-ice and organics (Neish et al., 2015). Neish et al. (2015) found that some craters have an ejecta blanket with a green spectral signature. They proposed that this green unit is fractured excavated water-ice, with cracks filled with a soluble organic material (Neish et al., 2015). Figure 18 shows spectral plots from these units.

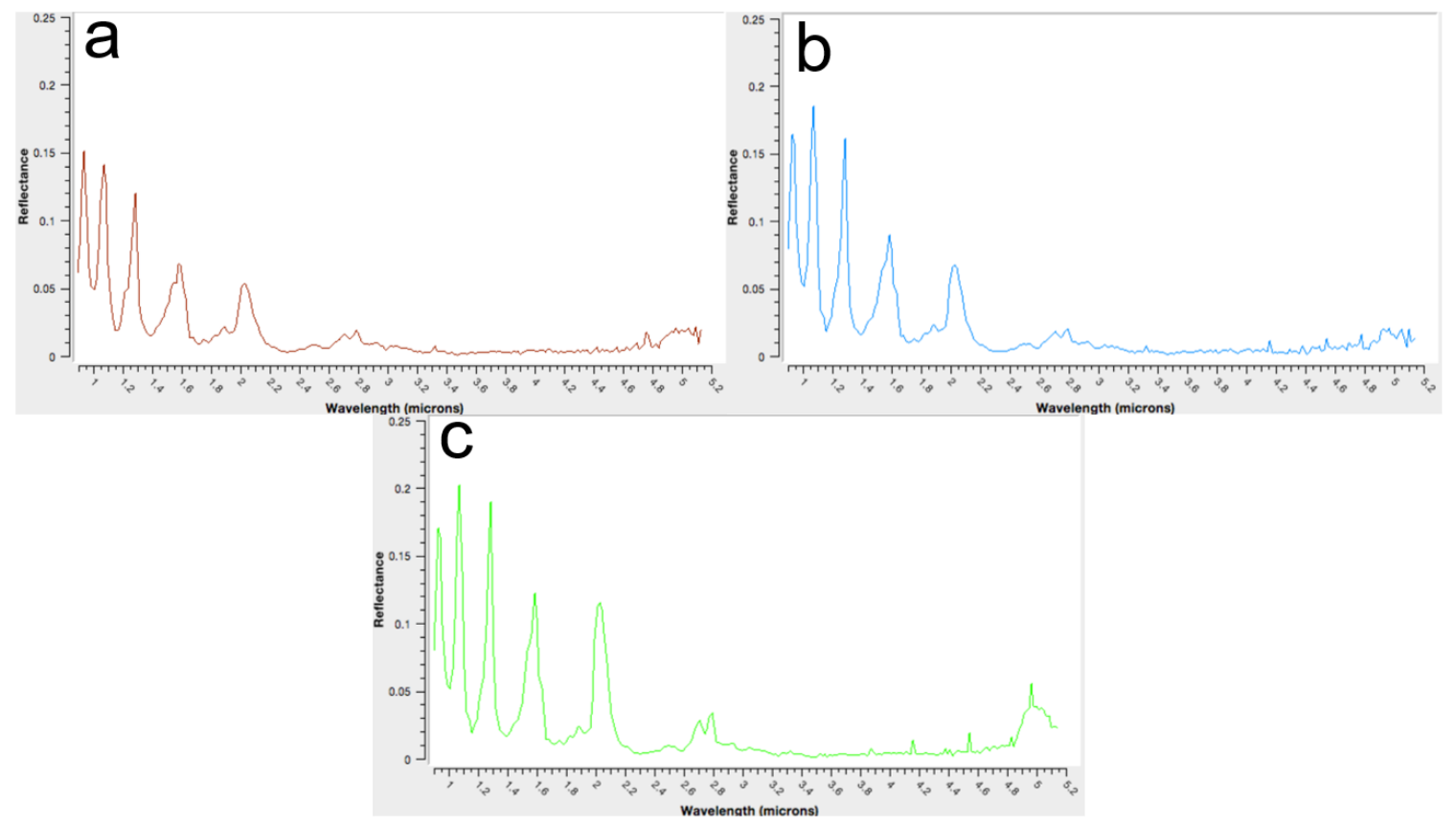

Figure 18: VIMS spectra from 3 distinct units on Titan. a) VIMS brown spectra, indicative of organics. b) VIMS blue spectra, indicative of a water-ice enrichment. c) VIMS green spectra, an unknown unit, potentially a mix of water-ice and organics.

Though the most common color scheme for VIMS images is represented by the color scheme illustrated in Barnes et al., 2007, some studies utilizing band ratio images have been conducted (e.g. Le Mouelic, et al, 2007; Buratti et al., 2012). One such instance, conducted by Le Mouelic et al., 2007, created a band ratio image over the crater Sinlap (Figure 19). Le Mouelic et al. (2007) utilize the scheme (in microns) $\mathrm{R}=1.59 / 1.27$, $\mathrm{G}=2.03 / 1.27$, and $\mathrm{B}=1.27 / 1.08$ because previous studies conducted by VIMS team members have found that these are the most sensitive for displaying the relative abundance of water-ice versus organics on the surface. 


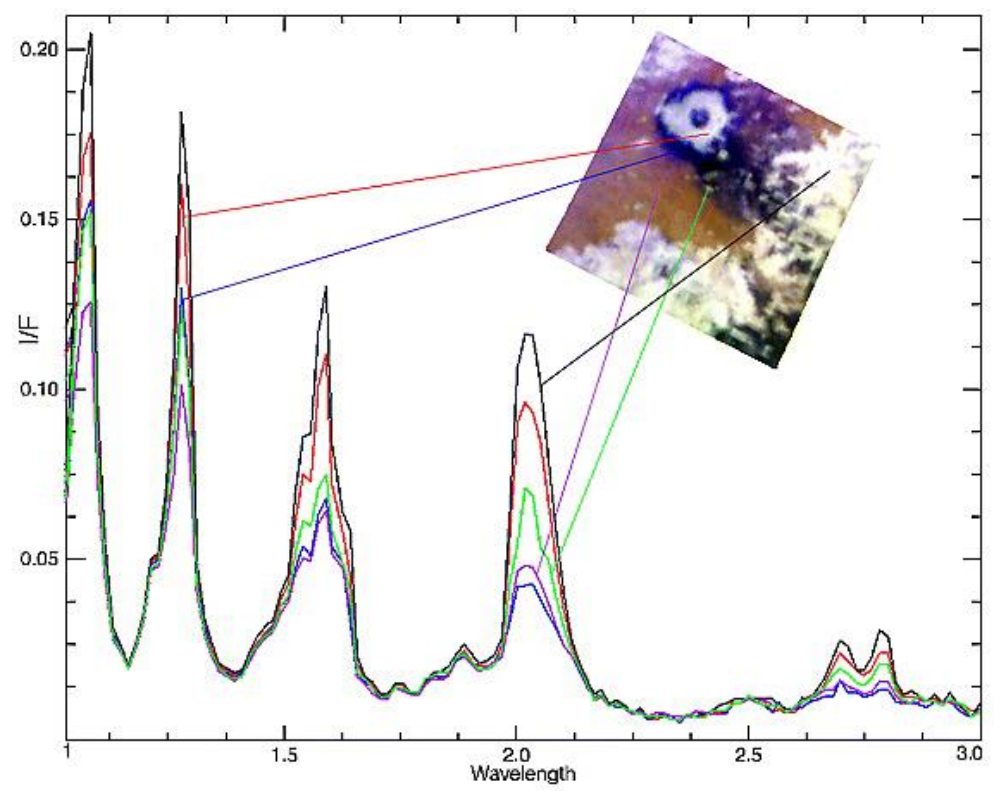

Figure 19: VIMS spectra for Sinlap crater and the surrounding region on Titan. The RGB image shown is a band ratio image (R: $1.59 / 1.27, \mathrm{G}: \mathbf{2 . 0 3 / 1 . 2 7}$, and $\mathrm{B}$ : 1.27/1.08). Blue regions and spectra correspond with a proposed water-ice unit, brown regions and purple spectra are likely organic, white regions and red and black spectra represent an unknown unit. The green spectra is derived from a single pixel and could be affected by a cosmic ray, however, this pixel has been captured in previous images and likely represents a surface heterogeneity. I/F is the observed spectral radiance divided by the solar irradiance (Le Mouelic et al., 2007).

However, as with the emissivity compositions outlined in the previous section, there are some assumptions inherent to the VIMS compositional data. Titan's atmosphere makes it more difficult to identify the absorption and reflectance bands at the surface and atmospheric haze needs to be removed from the resulting spectra (McCord et al., 2006; Barnes et al., 2007; Vixie et al., 2012). Haze is thought to be created by solar ultraviolet photolysis of methane in the atmosphere (Flasar, 1983; Lunine et al., 1983; Yung et al., 1984). This haze efficiently scatters and absorbs both incoming and outgoing electromagnetic radiation (McCord et al., 2006). There is less scattering occurring in the windows between the strong methane absorption bands, and these are the windows used 
for imaging (McCord et al., 2006; Barnes et al., 2007); however, the haze has a more obvious, stronger scattering effect at shorter wavelengths (Figure 20). Workers have attempted to remove scattering and absorption from images by using radiative transfer equations (Griffith et al., 1991; Coustenis et al., 1995). Once the radiative transfer equations are derived, they are applied to the images and the haze is removed as best as possible. However, this process is not perfect, and workers are still trying to develop more sophisticated models for haze removal (Barnes et al., 2018). It is due to these atmospheric restrictions that make VIMS data much more qualitative in comparison to data from other bodies in the solar system. However, in this case qualitative analysis is sufficient to understand the main compositional constituents of the surface.

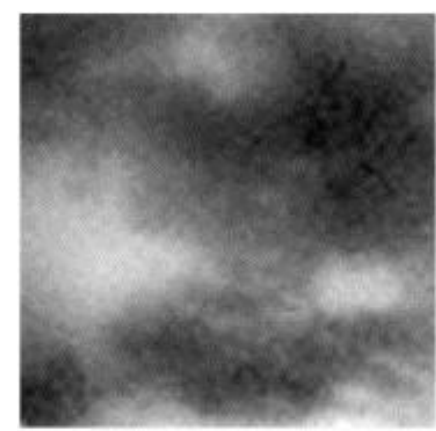

$0.93 \mu \mathrm{m}$

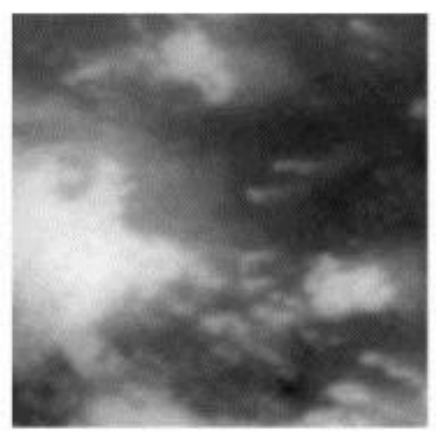

$1.28 \mu \mathrm{m}$

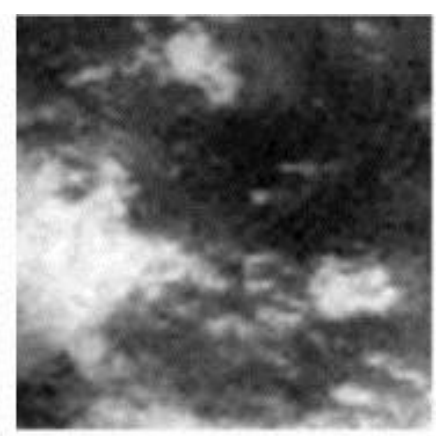

$2.02 \mu \mathrm{m}$

Figure 20: VIMS-IR images of the same area of Titan at 3 different wavelengths. As the wavelength gets shorter, there are more scattering effects caused by the haze in the atmosphere (McCord et al., 2006).

The Huygens probe attempted to infer the composition of the landing site using VNIR data, but it was limited by the light it received at the surface. As mentioned, only $10 \%$ of the sunlight that reaches Titan gets filtered through the atmosphere and onto the surface (Lorenz and Mitton, 2008). However, the composition of this landing site has been inferred using data from the Huygens probe, such as DISR images and GCMS data, in conjunction with VIMS data. GCMS data has shown the landing site is host to a high abundance of $\mathrm{N}_{2}, \mathrm{CH}_{4}, \mathrm{AND} \mathrm{H}_{2}$ (Figure 21) (Niemann et al., 2005). The DISR images revealed rounded cobbles, dry riverbeds, dark streaks, and bright terrains. VIMS data, acquired both before and after landing, show bright and dark blue spectra in the region (Rodriguez et al., 2006). Using the color scheme outlined in Rodriguez et al. (2006), 
brighter regions indicate a depletion in water-ice. The probe itself landed on a VIMS dark blue unit, suggestive of water-ice enrichment (Rodriguez et al., 2006), which is not directly representative of the entirety of Titan's surface; this dark blue terrain comprises less than $10 \%$ of the equatorial dark regions (Barnes et al., 2007).

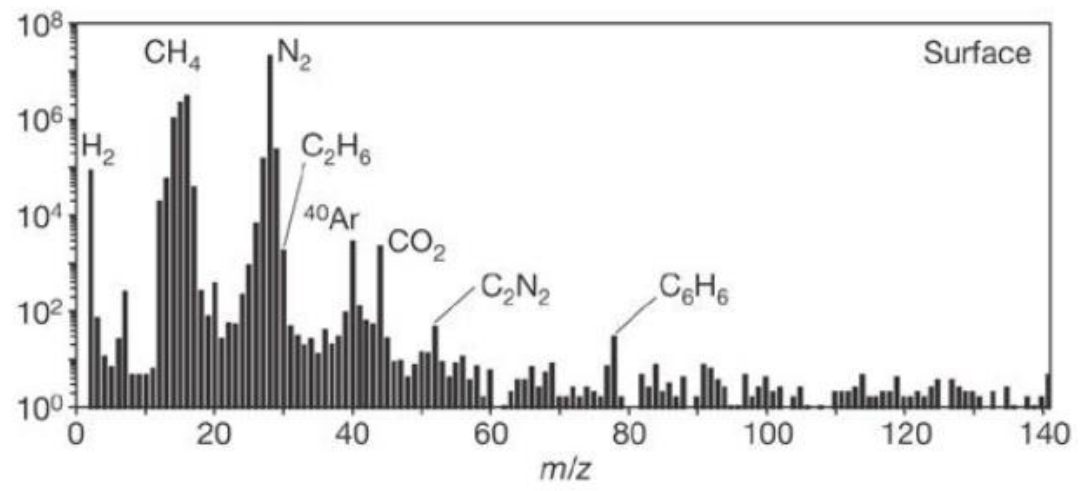

Figure 21: Surface mass to charge ratios acquired from the GCMS on board the Huygens probe. Data was taken starting upon impact until signal was lost (Niemann et al., 2005).

\subsection{Methodology}

Remote sensing data of Titan is available through a multitude of publicly available outlets. Websites such as the Planetary Data System (PDS) were used to download the data used in this research. Data used that was not made publicly available or was manipulated by other researchers was obtained through these researchers or collaborators. Once all the data was acquired, a variety of software was employed to process, project, manipulate and analyze the data.

\subsubsection{Radar}

The Cassini RADAR images are a product of NASA, a publicly funded government institution, and are therefore publicly available. The RADAR images are located on a website called the Planetary Data System, henceforth referred to as the PDS. The PDS is a continually updated archive used to hold data collected by all NASA Solar System missions. Cassini RADAR Basic Image Data Records (BIDR) files are all stored on the PDS Imaging Node portion of the website. There are multiple resolution levels to these 
BIDR files, each with different file name prefixes. The file name prefixes from highest to lowest resolution are: BIBQI- at $256 \mathrm{ppd}$ (175 m/pixel), BIBQH- at $128 \mathrm{ppd}$ (351 m/pixel), BIBQG- at 64 ppd (702 m/pixel), and BIBQF- at 32 ppd (1404 m/pixel). We downloaded all available BIDR files at every resolution tier from the PDS to construct a radar basemap used in this research.

The BIDR files have a .IMG file extension, a file type easily processed in a publicly available software package developed by the United States Geological Survey (USGS) This program is called the Integrated Software for Imagers and Spectrometers or ISIS. The USGS has a well-documented website regarding all ISIS commands. We used this website to understand how to process and project all BIDR files used in this project. We gave all radar images a simple cylindrical projection centered at $180^{\circ} \mathrm{W}$. Once these files were processed and projected, they were converted into .cub file types. A .cub file type is a collection of structured data exported from a data source. We then uploaded these files into ESRI's ArcGIS, specifically ArcMap. As mentioned, there are various resolutions to the images, so precedence was given to images with higher resolution. BIBQI- images were placed on top of the basemap, followed underneath by BIBQH-, BIBQG-, and finally, BIBQF- images, allowing the highest available resolution to be visible on the basemap (Figure 22).

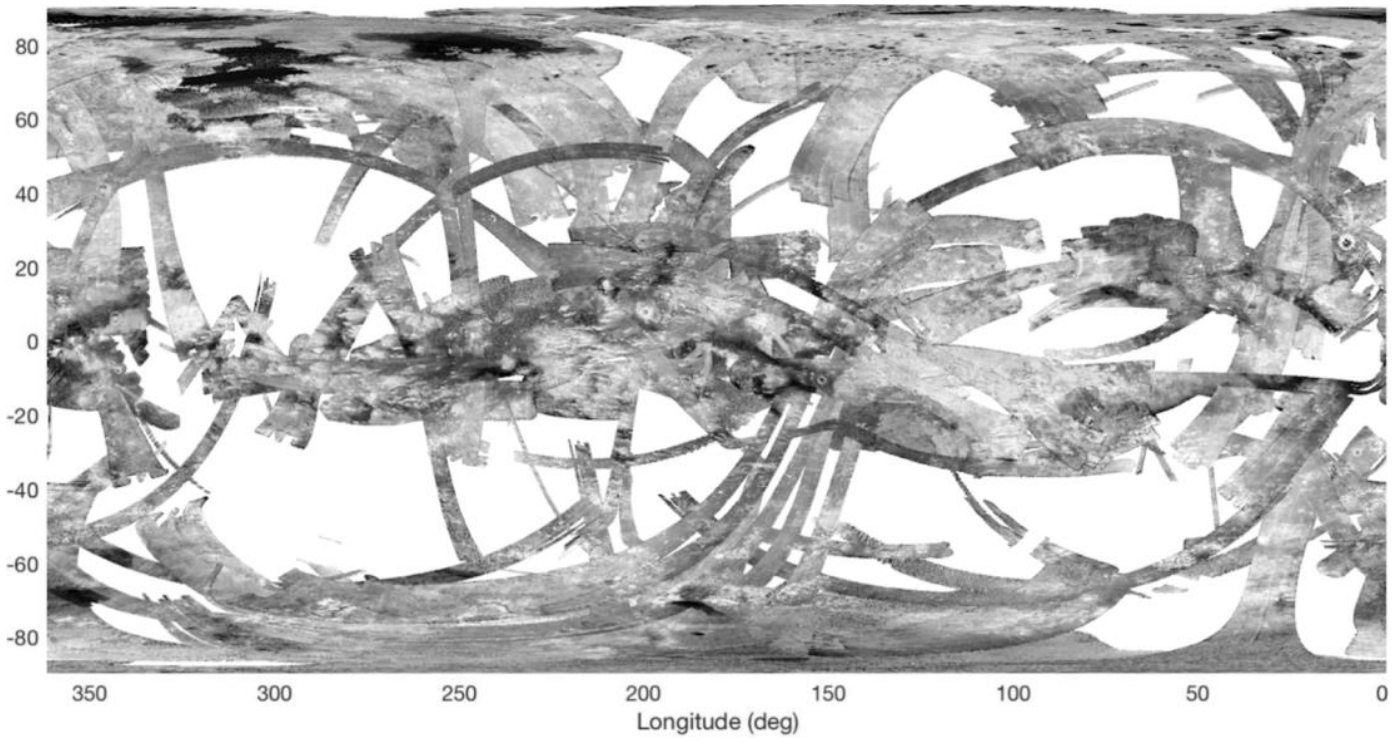

Figure 22: Cassini RADAR basemap comprised of all available radar images. 
Radar remote sensing data is also sensitive to topography. Less than $10 \%$ of the surface of Titan is covered by topography data, so a global interpolated elevation map constructed by Corlies et al. (2017) was used in this research. This data product was obtained directly from the researchers and had a longitude range of $180^{\circ} \mathrm{E}-180^{\circ} \mathrm{W}$. For this research, it was necessary to manipulate the provided data file to display in the longitude range of $0-360^{\circ} \mathrm{W}$. We accomplished this through ISIS. Next, we projected the resulting file in ISIS to the same simple cylindrical projection given to the previously created radar basemap and then uploaded this to ArcMap (Figure 23).

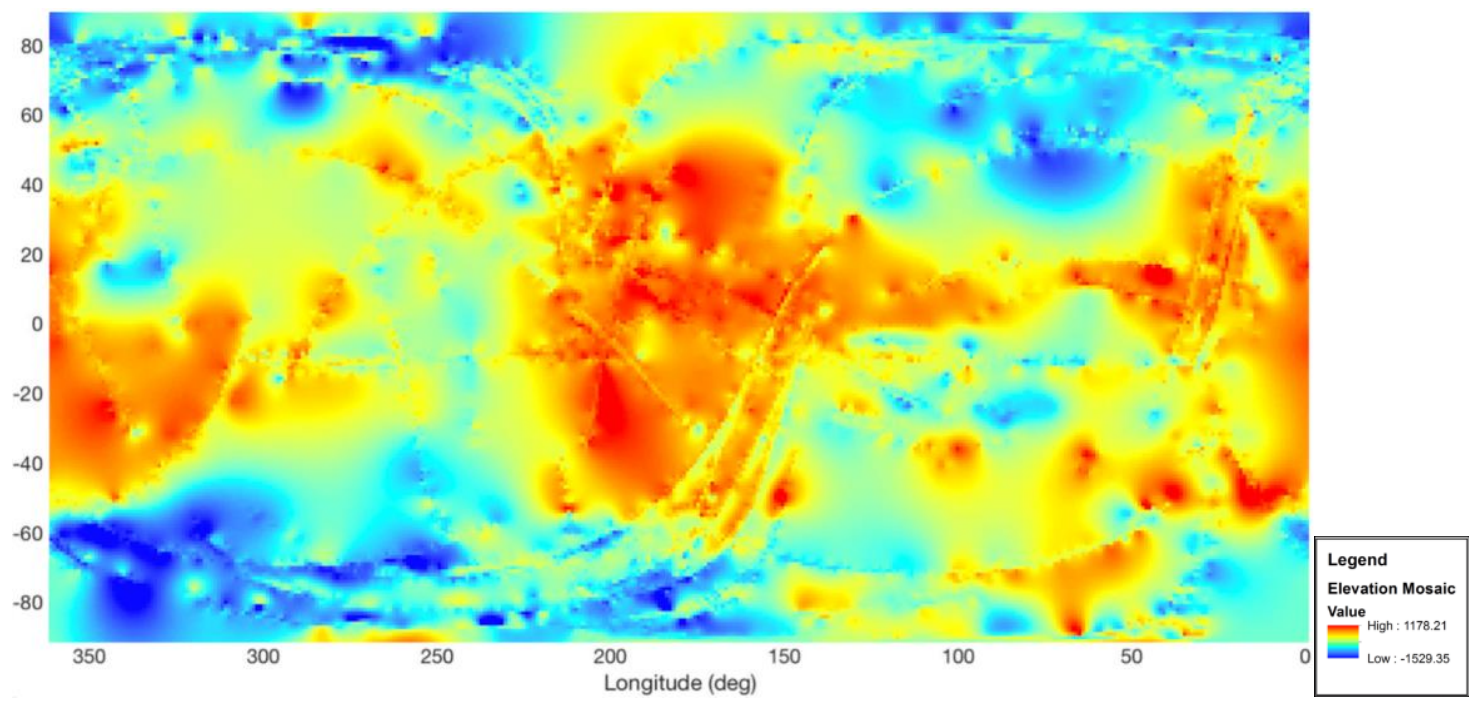

Figure 23: Interpolated global elevation map of Titan obtained from Corlies et al., 2017. High elevation areas are shown in red, low elevation in blue.

\subsubsection{Thermal microwave emission}

The global thermal microwave emission data, also referred to as the global emissivity data, was provided by a collaborator, Dr. Mike Janssen. We needed to give this file the same projection as the rest of the project data and we accomplished this through ISIS.

As with the radar image swatches, there are different resolutions to the emissivity dataset. The global emissivity file encompasses a wide range of spatial resolutions, the highest of which range from 5 km-50 km (Janssen et al., 2016; Le Gall et al., 2016) (Figure 24a). Higher resolutions are preferable to get a more accurate representation of the emissivity; lower resolutions $(\sim 500 \mathrm{~km})$ average the emissivity values over a larger area, thus 
encompass a variety of geologic units, skewing the resulting value. For this research, we wanted to look at the emissivity of craters using the global, or low resolution dataset, as well as the high resolution dataset. All high resolution emissivity swatches were acquired with the highest resolution radar image files, the BIBQI- prefix, and therefore match up well with the radar images (Figure 24b). The first step we took in creating this high resolution emissivity file was to mosaic all BIBQI- .cub files together in ISIS. Alternatively, these .cub files were converted to .tif files in ArcMap using the Export raster data tool. These tif files were then mosaicked in another program called Geospatial Data Abstraction Library (GDAL). Both mosaic methods achieved the same result.

Then, the mosaicked BIBQI- .cub (or alternatively, .tif) file was added to ArcMap. In ArcMap, we used the Extract by mask tool to extract all emissivity data within the high resolution BIBQI- boundary or footprint regions. The resulting product from this tool is shown in Figure 24c. 


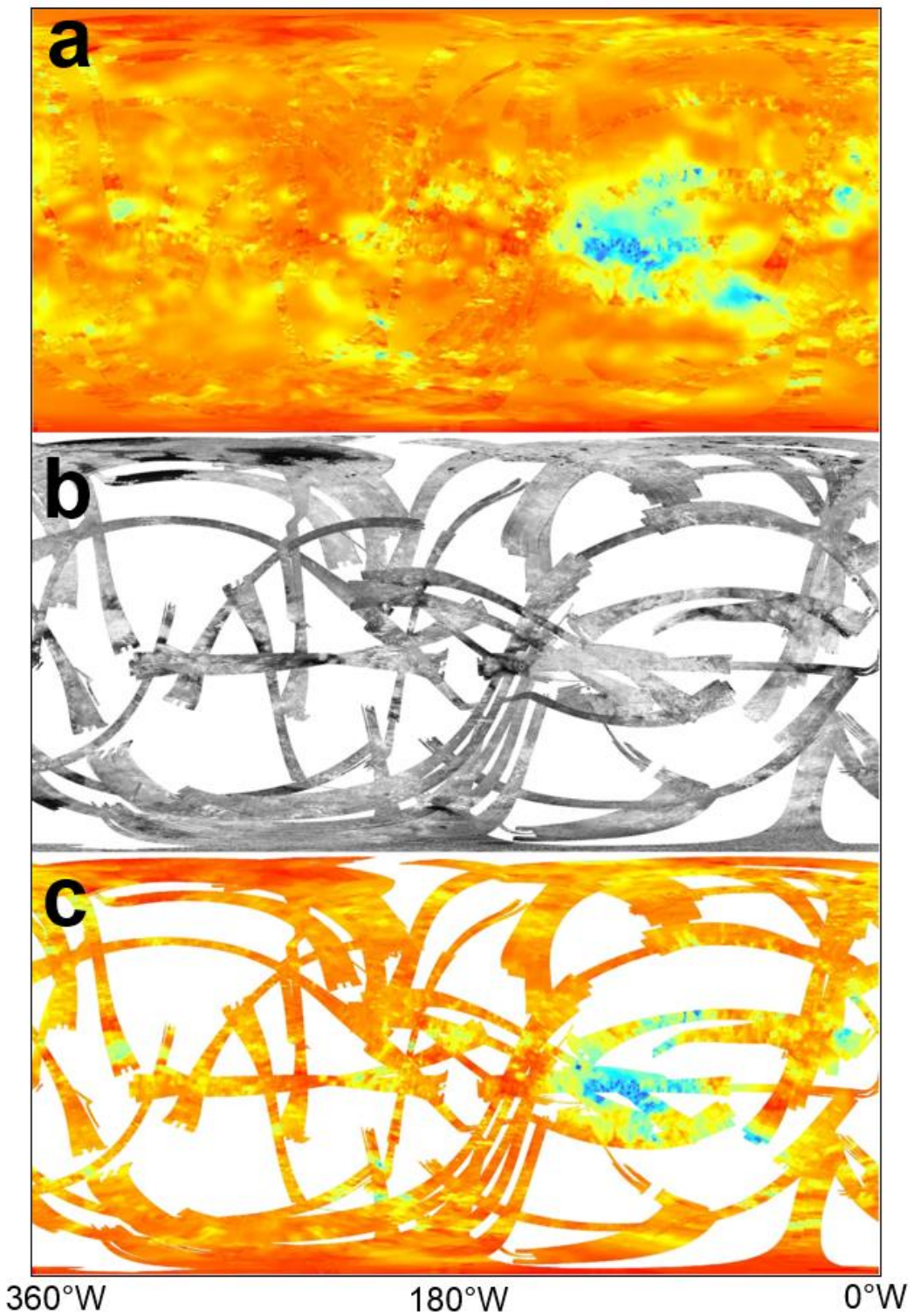

Figure 24: Image showing process of creating the high resolution emissivity mosaic. a) The global, low resolution, emissivity dataset for Titan. b) All high resolution, BIBQI-, radar images of Titan. These images were acquired at the same time as the highest resolution emissivity swatches and therefore match up with each other. c) The radar swatches shown in b) were used to extract the emissivity data from a) to create the high resolution data product shown here. 


\subsubsection{Visible and Infrared Mapping Spectrometer (VIMS)}

All VIMS images are publicly available on the PDS. We accessed these images using two different websites. The first is a joint USGS and NASA website. This website is a faction of the PDS Cartography and Imaging Science Node website, called Planetary Image Locator Tool, or PILOT. PILOT organizes raw spacecraft images by planetary body and allows the user to search for specific images (in this instance, VIMS-IR) by selecting multiple options such as latitude and longitude or geologic feature. This website is only updated through 2011, so we utilized a second website managed by the Jet Propulsion Laboratory for images obtained after 2011. This website is called the PDS image atlas and we were able to search by mission (Cassini), location, and resolution. The highest resolution VIMS data in the archive was downloaded for all craters in the study. Once all the available VIMS images were downloaded, they were processed through ISIS. We used a script, modified from Dr. Catherine Neish, to mass process all downloaded VIMS images to create RGB images. This script pulled out the designated red, green, and blue bands established in section 2.1.3. Once the separate R, G, and B image files were created, they were then merged into one calibrated RGB .cub file that was then given the same simple cylindrical projection as previous datasets.

Once all downloaded VIMS images were processed into RGB images and projected, we uploaded them into ArcMap (Figure 25). Once they were in ArcMap, we quality inspected all VIMS images. Some downloaded VIMS images did not correspond with the crater features in the study and were discarded. Other images were discarded for poor resolution or quality. 


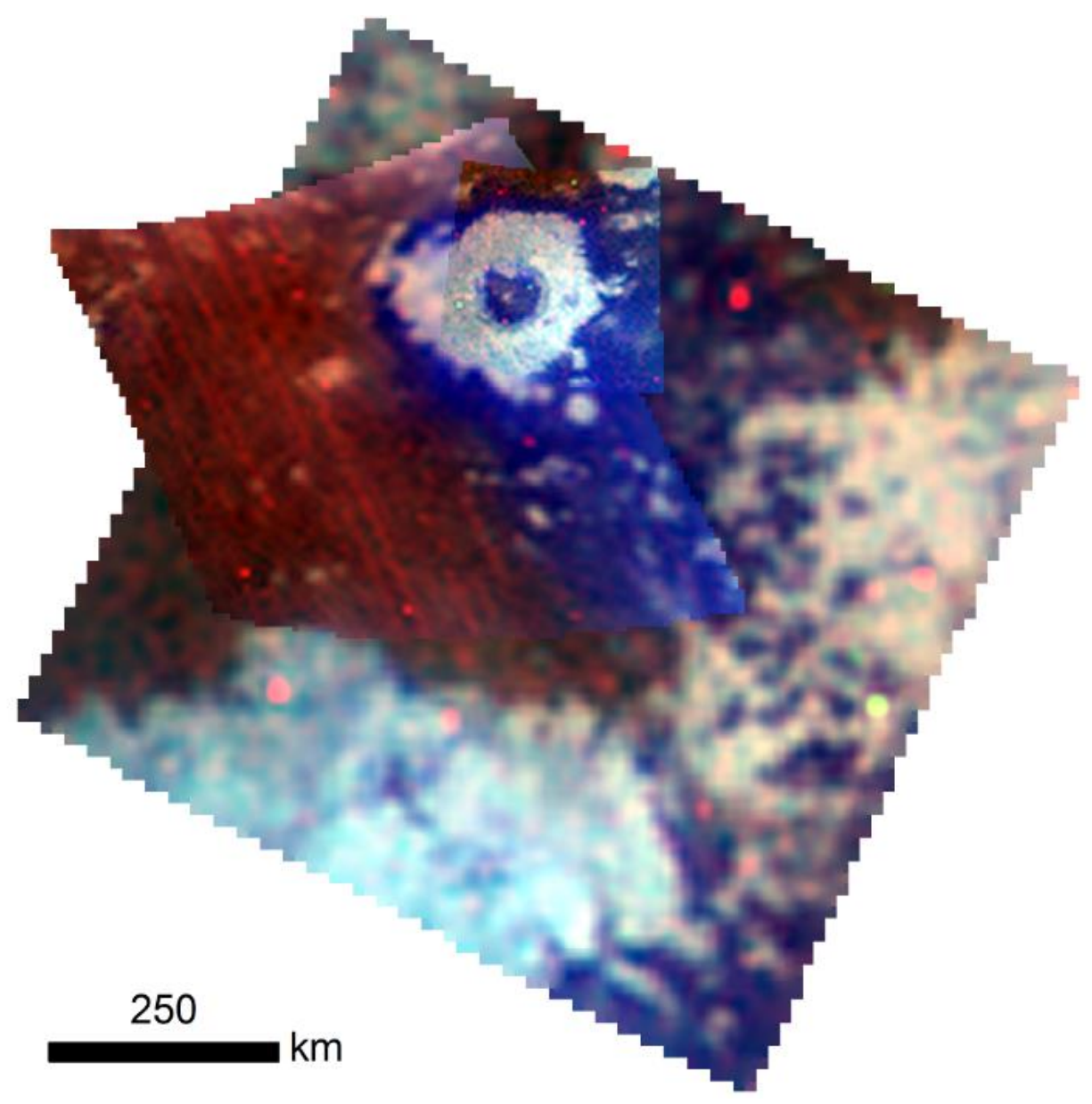

Figure 25: Three VIMS images with the color scheme outlined in Barnes et al., 2007 showing Sinlap crater. The highest resolution image is placed on top. The lowest resolution is placed on the bottom, providing more context to the region. 


\subsection{References}

Barnes, J. W., Brown, R. H., Soderblom, L., Buratti, B. J., Sotin, C., Rodriguez, S., Le Mouelic, S., Baines, K. H., Clark, R., and Nicholson, P. 2007. Global-scale surface spectral variations on Titan seen from Cassini/VIMS. Icarus 180, 242258.

Barnes, J. W., Bow, J., Schwartz, J., Brown, R. H., Soderblom, J. M., Hayes, A. G., Vixie, S., Le Mouelic, S., Rodriguez, S., Sotin, C., Jaumann, R., Stephan, K., Soderblom, L. A., Clark, R. N., Buratti, B. J., Baines, K. H., and Nicholson, P. D. 2011. Organic sedimentary deposits in Titan's dry lakebeds: Probable evaporite. Icarus 216, 136-140.Black, G. J., Campbell, D. B., and Nicholson, P. D. 2001. Icy Galilean satellites: Modeling radar reflectivities as a coherent backscattering effect. Icarus 151, 167-180.

Barnes, J. W., MacKenzie, S., Young, E. F., Trouille, L. E., Rodriguez, S., Cornet, T., Jackson, B. K., Adamkovics, M., Sotin, C., and Soderblom, J. M. 2018. Spherical Radiative Transfer in C++ (SRTC++): A Parallel Monte-Carlo Radiative Transfer Model for Titan. The Astronomical Journal 155, 264.

Black, G. J., Campbell, D. B., and Nicholson, P. D. 2001. Icy Galilean satellites: Modeling radar reflectivities as a coherent backscattering effect. Icarus 151, 167180.

Brown, R. H., Baines, K. H., Bellucci, G., Bibring, J. P., Buratti, B. J., Capaccioni, F., Cerroni, P., Clark, R. N., Coradini, A., Cruikshank, D. P., Drossart, P., Formisano, V., Jaumann, R., Langevin, Y., Matson, D. L., McCord, T. B., Mennella, V., Miller, E., Nelson, R. M., Nicholson, P. D., Sicardy, B., and Sotin, C. 2004. The Cassini Visual and Infrared Mapping Spectrometer (VIMS) investigation. Space Science Review 115, 111-168.

Buratti, B. J., Sotin, C., Lawrence, K., Brown, R. H., Le Mouelic, S., Soderblom, J. M., Barnes, J., Clark, R. N., Baines, K. H., and Nicholson, P. D. 2012. A newly 
discovered crater in Titan's Senkyo: Cassini VIMS observations and comparison with other impact features. Planetary and Space Science 60, 18-25.

Capaccioni, F., Coradini, A., Cerroni, P., and Amici, S. 1998. Imaging spectroscopy of Saturn and its satellites: VIMS-V onboard Cassini. Planetary and Space Science 46, 1263-1276.

Corlies, P., Hayes, A. G., Birch, S. P. D., Lorenz, R. D., Stiles, B. W., Kirk, R. L., Poggiali, V., Zebker, H., and Iess, L. 2017. Titan's topography and shape at the end of the Cassini mission. Geophysical Research Letters 44, 11754-11761.

Coustenis, A., Lellouch, E., Maillard, J. P., and McKay, C. P. 1995. Titan surface: Composition and variability from its near-infrared albedo. Icarus 118, 87-104.

Elachi, C., Allison, M. D., Borgarelli, L., Encrenaz, P., Im, E., Janssen, M. A., Johnson, W. T. K., Kirk, R. L., Lorenz, R. D., Lunine, J. I., Muhleman, D. O., Ostro, S. J., Picardo, G., Posa, F., Rapley, C. G., Roth, L. E., Seu, R., Soderblom, L. A., Vetrella, S., Wall, S. D., Wood, C. A., and Zebker, H. A. 1999. Radar: The Cassini Titan radar mapper. Space Science Reviews 115, 71-110.

Farr, T. G. 1993. Guide to Magellan image interpretation. Jet Propulsion Laboratory, Cap. Radar Interactions with Geologic Surfaces, 45-56.

Flasar, F. M. 1983. Oceans on Titan? Science 221, 55-57.

Griffith, C. A., Owen, T., and Wagener, R. 1991. Titan's surface and troposphere, investigated with ground-based, near-infrared observations. Icarus 93, 362-378.

Janssen, M. A., Lorenz, R. D., West, R., Paganelli, F., Lopes, R. M. C., Kirk, R. L., Elachi, C., Wall, S. D., Johnson, W. T. K., Anderson, Y., Boehmer, R. A., Callahan, P., Gim, Y., Hamilton, G. A., Kelleher, K. D., Roth, L., Stiles, B., Le Gall, A., and the Cassini RADAR team. 2009. Titan's surface at 2.2-cm wavelength imaged by the Cassini RADAR radiometer: Calibration and first results. Icarus 200, 222-239. 
Janssen, M. A., Le Gall, A., and Wye, L. C. 2011. Anomalous radar backscatter from Titan's surface? Icarus 212, 321-328.

Janssen, M. A., Le Gall, A., Lopes, R. M. C., Lorenz, R. D., Malaska, M. J., Hayes, A. G., Neish, C. D., Solomonidou, A., Mitchell, K. L., Radebaugh, J., Keihm, S. J., Choukroun, M., Leyrat, C., Encrenaz, P. J., and Mastrogiuseppe, M. 2016. Titan's surface at $2.18-\mathrm{cm}$ wavelength imaged by the Cassini RADAR radiometer: Results and interpretations through the first ten years of observation. Icarus 270, 443-459.

Kirk, R. L., Howington-Kraus, E., Redding, B., Callahan, P., Hayes, A. G., Le Gall, A., Lopes, R. M. C., Lorenz, R. D., Lucas, A., Mitchell, K. L., Neish, C. D., Aharonson, O., Radebaugh, J., Stiles, B. W., Stofan, E. R., Wall, S. D., and Wood, C. A. 2012. Topographic mapping of Titan: Latest results. 43rd Lunar and Planetary Science Conference, Houston. Abstract \#2759.

Kokaly, R. F., Clark, R. N., Swayze, G. A., Livio, K. E., Hoefen, T. M., Pearson, N. C., Wise, R. C., Benzel, W. M., Lowers, H. A., Driscoll, R. L., and Klein, A. J. 2017. Spectra for H2O-Ice. USGS Spectral Library Version 7: U.S. Geological Survey Data Series 1035, 51.

Le Gall, A., Janssen, M. A., Wye, J. C., Hayes, A. G., Radebaugh, J., Savage, C., Zebker, H., Lorenz, R. D., Lunine, J. I., Kirk, R. L., Lopes, R. M. C., Wall, S., Callahan, P., Stofan, E. R., Farr, T., and the Cassini RADAR team. 2011. Cassini SAR, radiometry, scatterometry and altimetry observations of Titan's dune fields. Icarus 213, 608-624.

Le Gall, A., Malaska, M. J., Lorenz, R. D., Janssen, M. A., Tokano, T., Hayes, A. G., Mastrogiuseppe, M., Lunine, J. I., Veyssiere, G., Encrenaz, P., and Karatekin, O. 2016. Composition, seasonal change, and bathymetry of Ligeia Mare, Titan, derived from its microwave thermal emission. Journal of Geophysical Research: Planets 121, 233-251. 
Le Mouelic, S., Paillou, P., Janssen, M. A., Barnes, J. W., Rodriguez, S., Sotin, C., Brown, R. H., Baines, K. H., Buratti, B. J., Clark, R. N., Crapeau, M., Encrenaz, P. J., Jaumann, R., Geudtner, D., Paganelli, F., Soderblom, L., Tobie, G., and Wall, S. 2007. Mapping and interpretation of Sinlap crater on Titan using Cassini VIMS and RADAR data. Journal of Geophysical Research 113, E04003.

Lopes, R.M.C et al. 2018. Titan as revealed by the Cassini RADAR. Space Science Reviews, submitted.

Lorenz, R. D., and Mitton, J. 2008. Titan unveiled. Princeton, NJ: Princeton University Press.

Lunine, J. I., Stevenson, D. J., and Yung, Y. L. 1983. Ethane ocean on Titan. Science $222,1229$.

MacKenzie, S. M., Barnes, J. W., Sotin, C., Soderblom, J. M., Le Mouelic, S., Rodriguez, S., Baines, K. H., Buratti, B. J., Clark, R. N., Nicholson, P. D., and McCord, T. B. 2014. Evidence of Titan's climate history from evaporite distribution. Icarus 243, 191-207.

McCord, T. B., Hansen, G. B., Buratti, B. J., Clark, R. N., Cruikshank, D. P., D’Aversa, E., Griffith, C. A., Baines, E. K. H., Brown, R. H., Dalle Ore, C. M., Filacchione, G., Formisano, V., Hibbitts, C. A., Jaumann, R., Lunine, J. I., Nelson, R. M., Sotin, C., and the Cassini VIMS Team. 2006. Composition of Titan's surface from Cassini VIMS. Planetary and Space Science 54, 1524-1539.

Neish, C. D. and Carter, L. M. 2014. Planetary Radar. In Encyclopedia of the Solar System, 1133-1159.

Neish, C. D., Barnes, J. W., Sotin, C., MacKenzie, S., Soderblom, J. M., Le Mouelic, S., Kirk, R. L., Stiles, B. W., Malaska, M. J., Le Gall, A., Brown, R. H., Baines, K. H., Buratti, B., Clark, R. N., and Nicholson, P. D. 2015. Spectral properties of Titan's impact craters imply chemical weathering of its surface. Geophysical Research Letters 42, 3746-3754. 
Niemann, H. B., Atreya, S. K., Bauer, S. J., Carignan, G. R., Demick, J. E., Frost, R. L., Gautier, D., Haberman, J. A., Harpold, D. N., Hunten, D. M., Israel, G., Lunine, J. I., Kasprzak, W. T., Owen, T. C., Paulkovich, M., Raulin, F., Raaen, E., and Way, S. H. 2005. The abundances of constituents of Titan's atmosphere from the GCMS instrument on the Huygens probe. Nature 438, 779-784.

Ostro. S. J., West, R. D., Janssen, M. A., Lorenz, R. D., Zebker, H. A., Black, G. J., Lunine, J. I., Wye, L. C., Lopes, R. M. C., Wall, S. D., Elachi, C., Roth, L., Hensley, S., Kelleher, K., Hamilton, G. A., Gim, Y., Anderson, Y. Z., Boehmer, R. A., Johnson, W. T. K., and the Cassini RADAR team. 2006. Cassini RADAR observations of Enceladus, Tethys, Dione, Rhea, Iapetus, Hyperion, and Phoebe. Icarus $183,479-490$.

Pye, K., and Tsoar, H. 1990. Aeolian sand and sand dunes. London, UK: Unwin Hyman.

Rodriguez, S., Le Mouelic, S., Sotin, C., Clenet, H., Clark, R. N., Buratti, B. J., Brown, R. H., McCord, T. B., and the VIMS Science Team. 2006. Cassini/VIMS hyperspectral observations of the Huygens landing site on Titan. Planetary and Space Science 54, 1510-1523.

Soderblom, L. A., Kirk, R. L., Lunine, J. I., Anderson, J. A., Baines, K. H., Barnes, J. W., Barrett, J. M., Brown, R. H., Buratti, B. J., Clark, R. N., Cruikshank, D. P., Elachi, C., Janssen, M. A., Jaumann, R., Karkoschka, E., Le Mouelic, S., Lopes, R. M. C., Lorenz, R. D., McCord, T. B., Nicholson, P. D., Radebaugh, J., Rizk, B., Sotin, C., Stofan, E. R., Sucharski, T. L., Tomasko, M. G., and Wall, S. D. 2007st. Correlations between Cassini VIMS spectra and RADAR SAR images: Implications for Titan's surface composition and the character of the Huygens Probe Landing Site. Planetary and Space Science 55, 2025-2036.

Stiles, B. W., Hensley, S., Gim, Y., Bates, D. M., Kirk, R. L., Hayes, A., Radebaugh, J., Lorenz, R. D., Mitchell. K. L., Callahan, P. S., Zebker, H., Johnson, W. T. K., Wall, S. D., Lunine, J. I., Wood, C. A., Janssen, M. A., Pelletier, F., West, R. D., 
Veeramacheneni, C., and the Cassini RADAR team. 2009. Determining Titan surface topography from Cassini SAR data. Icarus 202, 584-598.

Vixie, G., Barnes, J. W., Bow, J., Le Mouelic, S., Rodriguez, S., Brown, R. H., Cerroni, P., Tosi, F., Burratti, B., Sotin, C., Filacchione, G.,Capaccioni, F., and Coradini, A. 2012. Mapping Titan's surface features within the visible spectrum via Cassini VIMS. Planetary and Space Science 60, 52-61.

Yung, Y. L., Allen, M., and Pinto, J. P. 1984. Photochemistry of the atmosphere of Titan: comparison between model and observations. The Astrophysical Journal 55, 465506. 


\section{Chapter 3}

\section{Compositional Variations of Titan's Impact Craters Indicates Active Surface Erosion}

Titan, the only moon in the solar system with a considerable atmosphere, is host to a variety of exogenic processes that shape its surface. These processes form features that are quite similar to features on Earth, including sand dunes, rivers, and lakes. The combination of Titan's thick atmosphere and its active surface processes also leads to a scarcity of impact craters on its surface. The compositions of these craters vary and may relate to the type and extent of erosion occurring on its surface. In this work, we examined the composition of 15 impact features on Titan using Cassini's Visible and Infrared Mapping Spectrometer (VIMS) and 2.18-cm emissivity data from its radiometer. Comparisons were made between crater composition as inferred from the VIMS and emissivity data with corresponding crater characteristics such as latitude, longitude, elevation and erosional state. We see a correlation between a crater's subsurface composition as inferred from the emissivity data and its erosional state and location. Well-preserved craters typically have more water-ice enrichment than degraded, organicrich craters, suggesting variations in composition are partially controlled by erosion and infilling. Moreover, dunes craters show more subsurface organic enrichment than plains craters, suggesting the efficiency of erosion and infilling varies with location and geologic context. VIMS data provides complementary information about a crater's surficial composition. We see that a crater's VIMS spectra does not change with erosional state, but rather appears to tie most closely to the crater's location on the moon. We suggest that there are active surface processes occurring on Titan, such as wind or rain, which are actively clearing off its surface and filling in subsurface fractures with organic materials. These processes would act to change the emissivity of the craters over time but leave the surface sensed by VIMS unchanged.

\subsection{Introduction}

Exclusive among solar system satellites, Titan has a substantial atmosphere. This restricts knowledge of its surface composition due to the limited number of atmospheric 
windows in the visible and near-infrared, from which compositional inferences are typically made. Three Cassini instruments - The Imaging Science Subsystem (ISS), the Visual and Infrared Mapping Spectrometer (VIMS), and the RADAR instrument - have the ability to observe the surface at a few specific wavelengths. There are 7 main windows for Titan which span the visible and near infrared - 0.94, 1.08, 1.28, 1.6, 2.0, 2.7-2.8, and 5.0 microns (Barnes et al., 2007) - and the radar receiver is sensitive to 2.18$\mathrm{cm}$.

Despite the limited number of wavelengths available for analysis, the Cassini VIMS and radiometry data have revealed a number of spectrally diverse and geologically distinct regions. For example, when VIMS images are viewed with a color scheme consisting of 4.8-5.2 $\mu \mathrm{m}(\mathrm{R}), 2 \mu \mathrm{m}(\mathrm{G})$, and $1.28 \mu \mathrm{m}(\mathrm{B})$, large regions of the surface appear dark blue, bright green, bright red, and dark brown. There are two interpretations for the dark blue VIMS spectra: either dirty water-ice (Rodriguez et al., 2006; Barnes et al., 2007; Soderblom et al., 2007; Le Mouélic et al., 2008) or possibly an organic-rich material (Clark et al., 2010). The bright green unit has an unknown composition, potentially a mix of organics and water-ice (Neish et al., 2015), the red units are associated with evaporites (MacKenzie et al., 2014), and the brown units correspond to organic-rich sand dunes (Barnes et al., 2007). In the radiometry data, low emissivity values, around 0.75 , are interpreted to be indicative of an enrichment in water-ice. Crater features, but also the entire mountainous region of Xanadu and hummocky regions, display emissivities lower than their surroundings (Janssen et al., 2016; Lopes et al., 2016). Elsewhere on Titan is representative of higher emissivity values, perhaps because the surface is covered by a sedimentary layer of organics (Janssen et al., 2016).

The composition of one geologic unit on Titan has not yet been studied in any detail: impact craters. Intriguingly, we observe a paucity of craters across Titan's surface (Lorenz et al., 2007; Wood et al., 2010; Neish and Lorenz, 2012). The absence of craters is most noticeable in the polar regions, which could be the result of saturated lowland terrains present in these regions or a former polar ocean (Neish and Lorenz, 2014) and/or increased weathering rates near the poles (Neish et al., 2016). Titan's crust is thought to be composed primarily of water-ice (e.g. Tobie et al., 2005; Dunaeva et al., 2014), and 
since impact craters expose subsurface material, one would expect impact craters to be more enriched in water-ice than other geologic units. However, an initial survey of impact craters by Neish et al. (2015) found a wide range of compositions in the VIMS data set. They suggested weathering played a role in altering the appearance of impact craters in the near-infrared. Conversely, in 2.18-cm emissivity data which probe larger depths than VIMS, many of the areas that show evidence of near-surface water-ice correlate with crater features (Janssen et al., 2016). It is not known how these crater compositions evolve over time or how the changes relate to the exogenic processes that modify Titan's surface.

Titan has an active hydrological cycle with a multitude of processes that can alter the appearance of its impact craters, such as hydrocarbon rain, aeolian infill, and sedimentary infill (e.g. Radebaugh et al., 2008; Lunine and Lorenz, 2009). For instance, aeolian or sedimentary infill can fill in the crater bottom and fractures with organic material. On the other hand, hydrocarbon rain or wind activity can lead to a continual clearing of the upper surface of the crater, and in the case of rain, possibly cause chemical weathering of organic materials in the subsurface (Neish et al., 2015). In this work, we seek to understand the relationship between crater characteristics (age/erosional state, location, elevation) and their composition. For example, differences in crater composition could be related to regional variations in substrate composition and/or active erosional processes that alter the crater over time. Here we use radiometry data, in conjunction with VIMS data, to provide insight into the processes that shape Titan's surface. Using both radiometry and VIMS data is a beneficial approach because of their differing wavelengths and therefore differing probing depths. Radiometry data is capable of probing a few tens of centimeters deep into the subsurface whereas VIMS only samples the top few microns, providing complimentary information. Thus, we are able to build upon initial findings of Neish et al. (2015), by sampling a broader region of the surface and subsurface, and use this information to constrain the processes that shape Titan's surface. 


\subsection{Methods}

There are approximately 60 potential craters on Titan that have been revealed by Cassini RADAR and VIMS images (Wood et al., 2010; Buratti et al., 2012; Neish and Lorenz, 2012). These 60 features are ranked by how likely they are to be of impact origin. The ranking system ranges from 'certain' $(\sim 12)$ to 'nearly certain' $(\sim 25)$ to 'probable' $(\sim 25)$. For this study, 15 total craters were selected out of the potential 60 (Figure 26). These 15 are classified as either 'certain' or 'nearly certain' to be of impact origin (Figure 27). Diameter was also a factor in selecting craters. Larger diameters were preferable because of the limited resolution of the data sets used in this work; all craters chosen had a diameter greater than $30 \mathrm{~km}$, with the majority well above a diameter of $60 \mathrm{~km}$.

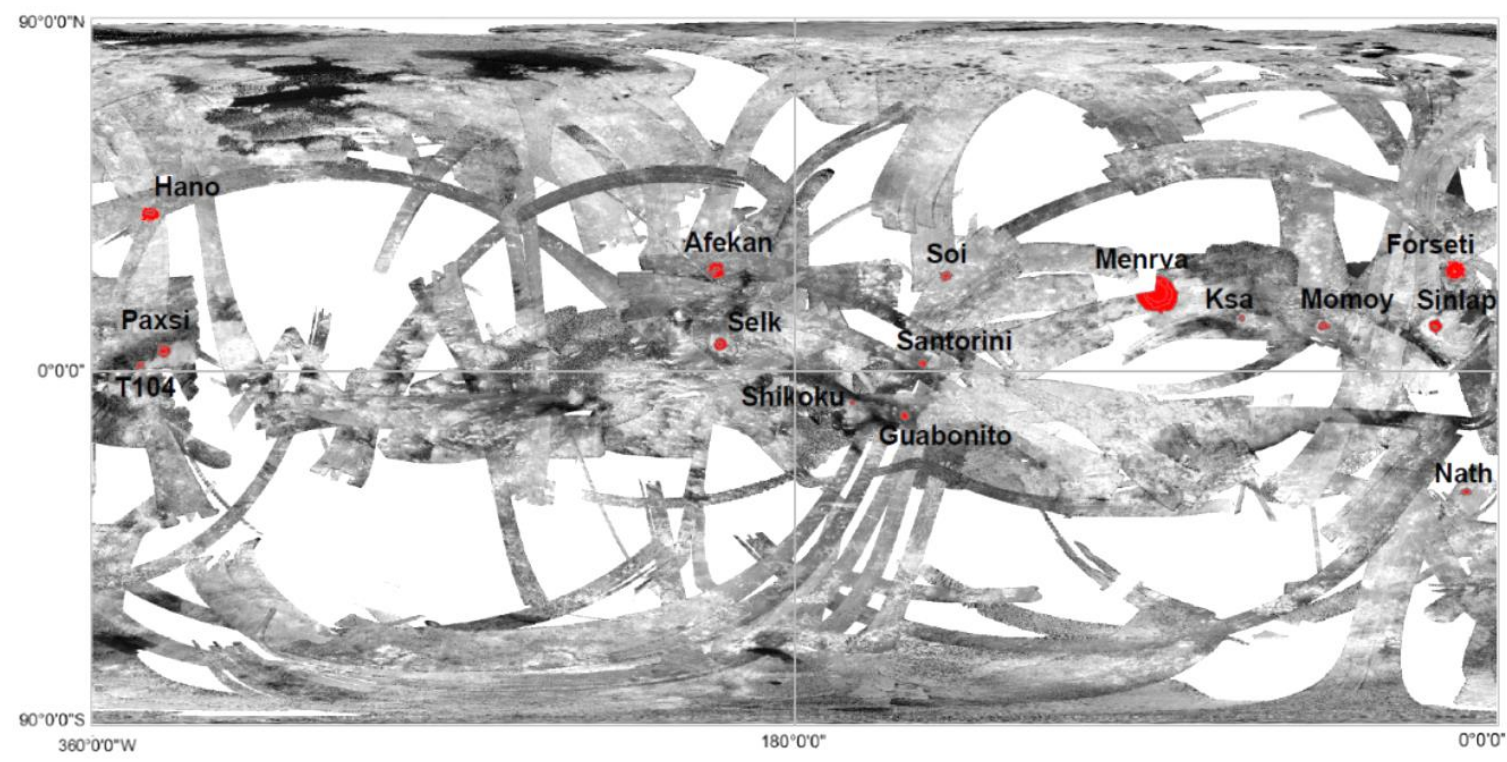

Figure 26: Cassini RADAR map of Titan. All 15 craters in this study are shown in red and labeled.

Compositional information was gathered from two different data sets: VIMS hyperspectral data and 2.18-cm thermal microwave emission data from the Cassini radiometer. The Cassini radiometer measurements give access to the $2.18-\mathrm{cm}$ emissivity of Titan's near surface which is a measure of the effectiveness of the surface in emitting the energy it has received (e.g. from the Sun) as thermal radiation (Le Gall et al., 2016; Janssen et al., 2016). The microwave emissivity from a near-surface depends on its 


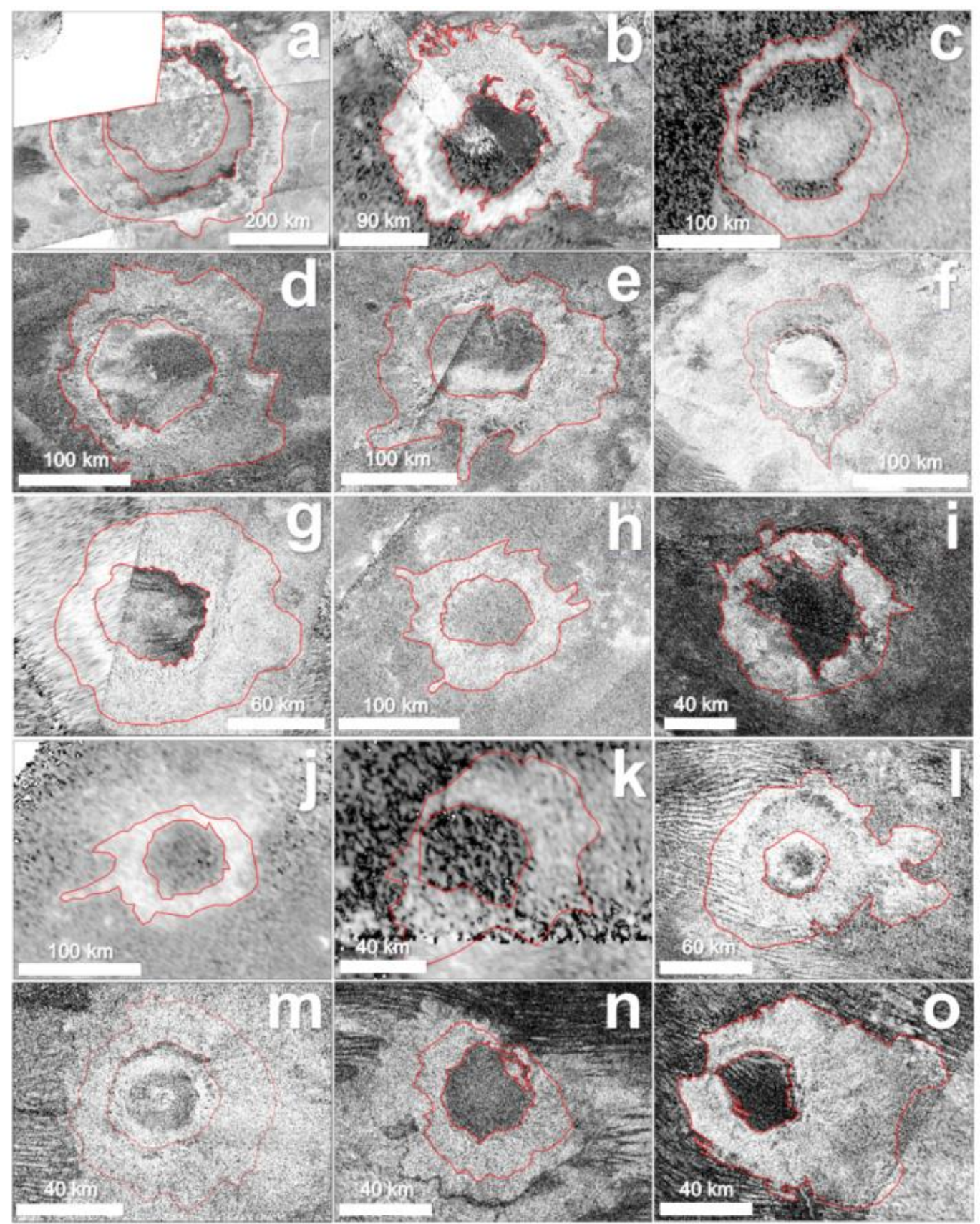

Figure 27: Cassini RADAR images of the 15 craters (outlined in red) studied in this work, in order of size. North points up in all images. a) Menrva, D $\sim 425 \mathrm{~km}$. b) Forseti, D 139 km. c) Paxsi, D 120 km. d) Afekan, D 115 km. e) Hano, D 100 km. f) Sinlap, D 82 km. g) Selk, D 80 km. h) Soi, D 78 km. i) Guabonito, D $68 \mathrm{~km}$. j) Nath, D $58 \mathrm{~km}$. k) Unnamed crater discovered in flyby T104, D 57 km. I) Momoy, D $\sim 40$ km. m) Ksa, D $\sim 39$ km. n) Shikoku, D $\sim 35$ km. o) Santorini, D $\sim 33 \mathrm{~km}$. 
composition and structure. In the case of icy objects, it tends to decrease with an increase of volume scattering in the subsurface which is, in turn, related to purity and complexity of the water-ice regolith. Figure 28 shows the craters analyzed in this study with their corresponding emissivity data, and Figure 29 shows the available VIMS data for the craters used in this study. Here, the colors correspond with specific wavelengths in three atmospheric windows: blue is $1.28 \mu \mathrm{m}$, green is $2 \mu \mathrm{m}$, and red is $4.8-5.2 \mu \mathrm{m}$. However, there are some restrictions with using these data sets to determine composition. In addition to the limited number of atmospheric windows, which impacts our ability to identify specific absorption bands at the surface, atmospheric haze must be removed in the sampling windows at visible and near-infrared wavelengths (McCord et al., 2006; Vixie et al., 2012). Furthermore, there are some restrictions with using radiometry data to infer composition as well. Radiometry data does not provide direct evidence for any single composition, but rather provides information about the dielectric constant, the degree of volume scattering in the subsurface and its emissivity. These values can be interpreted in a number of different ways. For example, Janssen et al. (2009; 2016) have shown that lower emissivity values are caused by strong volume scattering in the subsurface, which is suggestive of an enrichment in water-ice because water-ice, due to its high transparency at microwaves, is a medium very favorable to wave scattering. However, other organic substances may also act as equally efficient volume scatterers. 


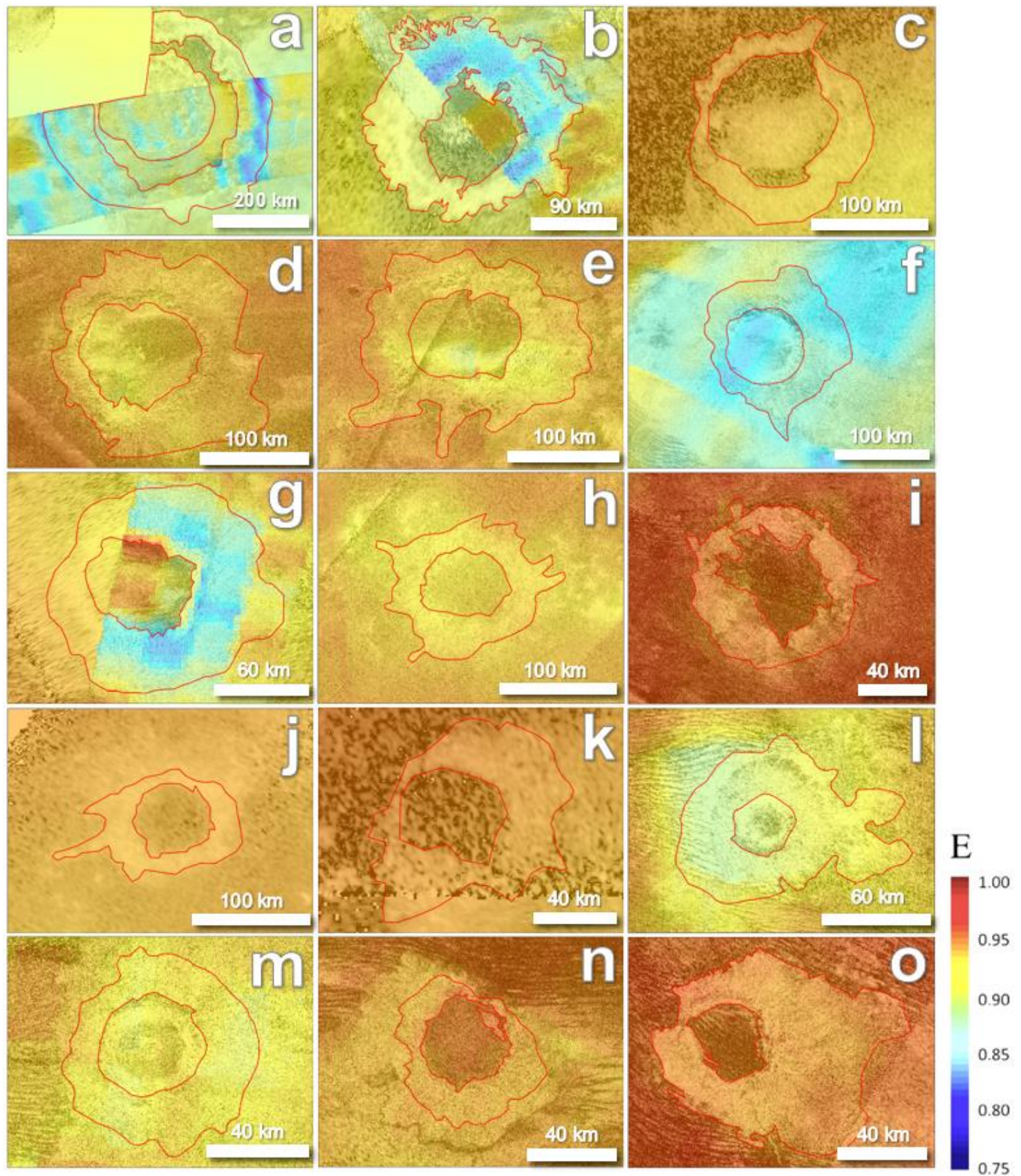

Figure 28: $2.18 \mathrm{~cm}$ emissivity data overlain on Cassini RADAR images of the 15 craters of interest on Titan (outlined in red), in order of size. North points up in all images. a) Menrva, D 425 km. b) Forseti, D 139 km. c) Paxsi, D 120 km. d) Afekan, D 115 km. e) Hano, D 100 km. f) Sinlap, D 82 km. g) Selk, D 80 km. h) Soi, D 78 km. i) Guabonito, D 68 km. j) Nath, D 58 km. k) Unnamed crater discovered with flyby T104, D 57 km. I) Momoy, D 40 km. m) Ksa, D 39 km. n) Shikoku, D $~ 35$ km. o) Santorini, D $\sim 33$ km. 

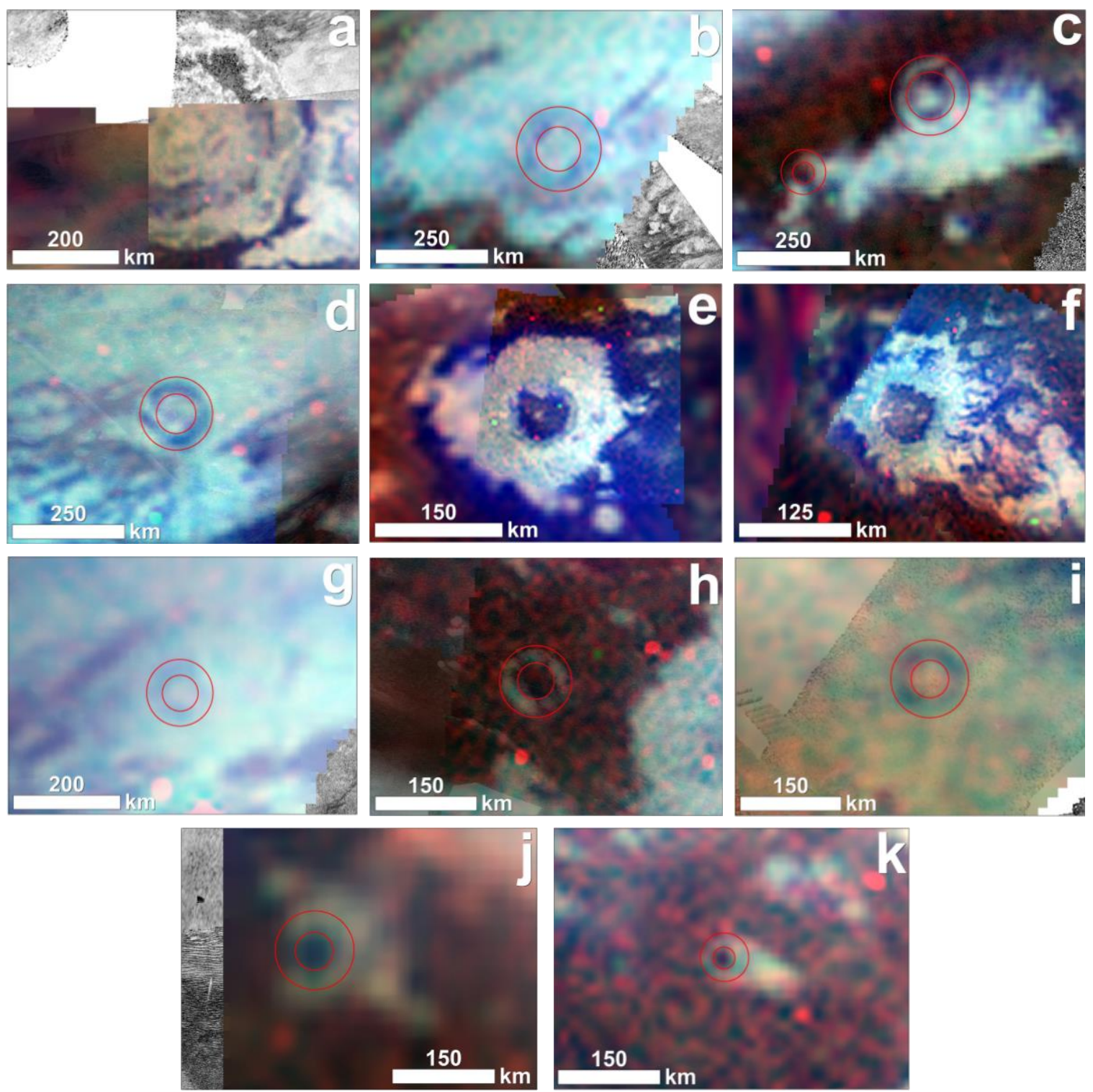

Figure 29: Available VIMS data overlain on Cassini RADAR images for 12 of the 15 craters, outlined in red. VIMS spectra colors: blue is $1.28 \mu \mathrm{m}$, green is $2 \mu \mathrm{m}$, and red is 4.8-5.2 $\mu \mathrm{m}$. Blue units are water-ice, green units are an unknown unit potentially organics and water-ice, and brown units are sand dunes. a) Menrva crater, b) Forseti, c) Paxsi (larger) and unnamed crater discovered with flyby T104 (smaller), d) Afekan, e) Sinlap, f) Selk, g) Soi, h) Guabonito, i) Nath, j) Ksa, and k) Santorini. 


\subsubsection{Average emissivity of Titan's impact craters}

First, each of the 15 crater features were mapped using the highest resolution Cassini RADAR data available. For this study, we were primarily interested in the crater rim and ejecta blanket because that is where the excavated subsurface material resides after impact formation, but we also mapped the crater floor. The ejecta blanket + rim typically corresponds with radar bright regions, indicating a rough surface, while the floor is often radar dark, consistent with infilling by smooth and/or absorbing sediments (Figure 30).

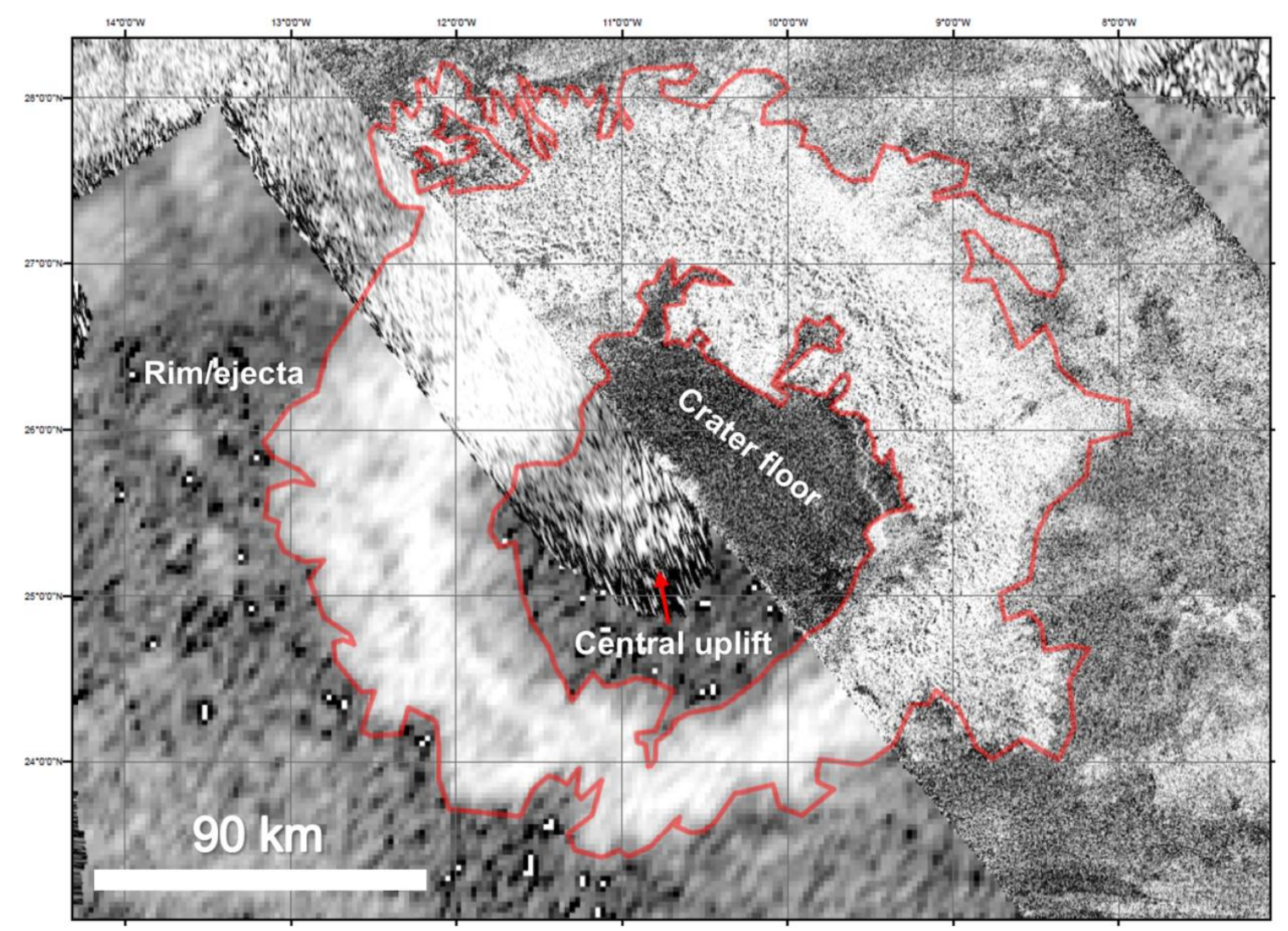

Figure 30: Cassini RADAR image of Forseti crater. Radar bright regions here correlate with the crater's rough rim and ejecta blanket, outlined in red. The radar dark material in the crater floor may be smooth sediments deposited there by aeolian or/and fluvial activity. A possible central uplift as inferred from crater diameter and radar imagery is observed on the floor as well.

The emissivity of each mapped feature was determined from a global mosaic constructed by Janssen et al. (2016). This data was collected using passive radiometry data from the 
Cassini RADAR instrument, acquired from the first Titan flyby (Ta), in October 2004, up until T126 marking the end of the Cassini mission. This map was constructed from a number of different data sets with varying resolutions (for details, see Janssen et al., 2016). These resolutions were taken into consideration for the compositional analysis.

First, the average composition was calculated for each crater's ejecta blanket + rim using the entire emissivity mosaic, henceforth dubbed the low resolution data set. Then, the process was repeated using only the high resolution data set (Figure 31). This high resolution data was acquired in SAR or altimetry mode with resolutions ranging between 5 and $50 \mathrm{~km}$ (Le Gall et al., 2016).

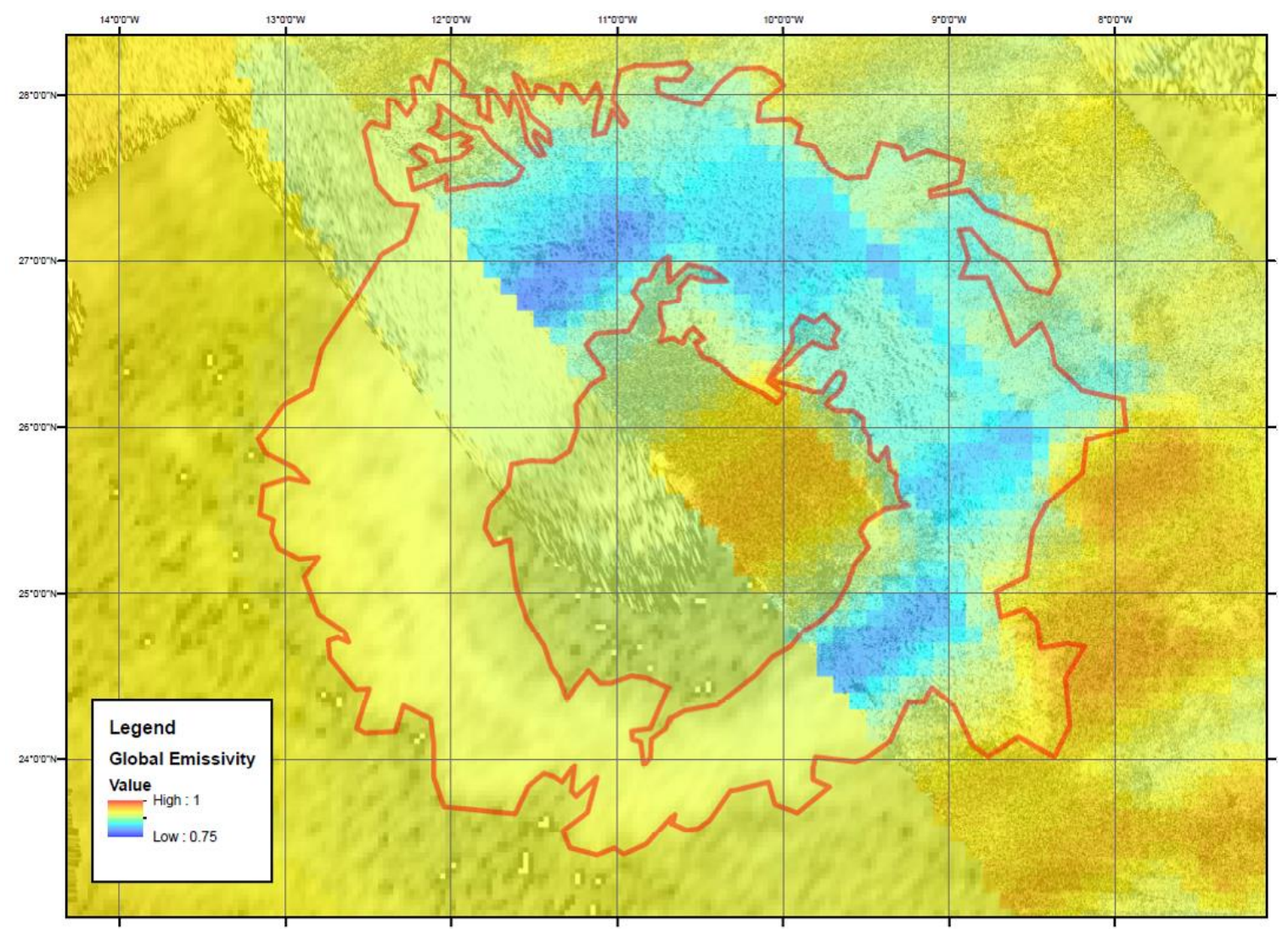

Figure 31: Cassini RADAR image of Forseti crater with global emissivity data overlain. The NE segment of the crater shows the higher resolution emissivity data available whereas the SW segment of the crater is covered by the lower resolution data set.

The average emissivity value was then compared with crater characteristics such as location, elevation, and relative depth. Location information was used to determine if the 
crater compositions show regional trends associated with the global geologic features observed on Titan, i.e., sand dunes near the equator, plains in the mid-latitudes, and lakes and seas near the poles. Location was further broken into latitude and longitude. The latitude and longitude was determined by measuring the center of the craters in the Cassini RADAR data set.

Elevation was calculated for each feature using an interpolated global elevation map of Titan (Lorenz et al., 2013; Corlies et al., 2017). This was used to provide information about the overall topographic trends on Titan. Generally, there are highland regions surrounding the equator, and lowland regions closer to the poles (Lorenz et al., 2013; Corlies et al., 2017). The majority of craters in this study are in elevated regions, with a few in low lying areas, consistent with the results of Neish and Lorenz (2014). If there is a correlation between crater composition and elevation, it could be related to mass wasting events or weathering such as rainfall or runoff.

The erosional state of the craters was quantified by a relative depth measurement. Relative depth is a depth (d) comparison between craters of diameter D on both Ganymede and Titan, calculated using the relationship $R(D)=1-\operatorname{dt}(D) / \operatorname{dg}(D)$, where $\operatorname{dt}(\mathrm{D})$ is the depth of a crater with diameter $\mathrm{D}$ on Titan and $\operatorname{dg}(\mathrm{D})$ is depth of a fresh (unrelaxed) crater with diameter D on Ganymede (Schenk et al., 2002; Bray et al., 2012; Neish et al., 2013). Ganymede was chosen for comparison because it is of similar size, composition, and interior structure to Titan, and thus represents the best airless analogue (Neish et al., 2013). Table 4 shows the calculated relative depth measurements for craters with available topographic profiles. Five craters do not have topographic profiles due to the limited data coverage of Titan. These values were determined using SARTopo and stereophotogrammetry data for craters on Titan (Neish et al., 2013; Neish et al., 2015; Neish et al., 2016; Neish et al., 2018) as well as stereophotogrammetry and topography measurements from shadow lengths on Ganymede (Schenk et al., 2002; Bray et al., 2012). Relative depths closer to 0 indicate fresher craters, while values closer to 1 indicate more degraded craters (Neish et al., 2013). 
Table 4: Relative depths for 10 craters on Titan.

\begin{tabular}{|c|c|c|c|c|c|}
\hline Crater & Diameter, D (km) & Depth, d (km) & Technique & Relative depth ${ }^{a}$ & $\begin{array}{c}\text { Depth } \\
\text { measurement } \\
\text { source }\end{array}$ \\
\hline Shikoku & $35 \pm 1$ & $0.34 \pm 0.05$ & Stereo & $0.71 \pm 0.043$ & $\begin{array}{c}\text { Neish et al. } \\
2016\end{array}$ \\
\hline \multirow[t]{2}{*}{ Ksa } & $39 \pm 2$ & $0.75 \pm 0.18$ & Stereo & $0.34 \pm 0.15$ & $\begin{array}{c}\text { Neish et al. } \\
2013\end{array}$ \\
\hline & & $0.66 \pm 0.17$ & SARTopo & $0.42 \pm 0.15$ & $\begin{array}{c}\text { Neish et al. } \\
2013\end{array}$ \\
\hline Momoy & $40 \pm 1$ & $0.68 \pm 0.10$ & Autostereo & $0.40 \pm 0.088$ & $\begin{array}{c}\text { Neish et al. } \\
2013\end{array}$ \\
\hline Santorini & $40 \pm 5$ & $0.34 \pm 0.07$ & Stereo & $0.70 \pm 0.06$ & $\begin{array}{c}\text { Neish et al. } \\
2015\end{array}$ \\
\hline Soi & $78 \pm 2$ & $0.24 \pm 0.12$ & Stereo & $0.76 \pm 0.12$ & $\begin{array}{c}\text { Neish et al. } \\
2015\end{array}$ \\
\hline Selk & $79 \pm 7$ & $0.47 \pm 0.09$ & SARTopo & $0.53 \pm 0.09$ & $\begin{array}{c}\text { Neish et al. } \\
2018\end{array}$ \\
\hline Sinlap & $82 \pm 2$ & $0.64 \pm 0.15$ & SARTopo & $0.36 \pm 0.15$ & $\begin{array}{c}\text { Neish et al. } \\
2013\end{array}$ \\
\hline \multirow[t]{2}{*}{ Hano } & $100 \pm 5$ & $0.42 \pm 0.04$ & SARTopo & $0.56 \pm 0.04$ & $\begin{array}{c}\text { Neish et al. } \\
2018\end{array}$ \\
\hline & & $\sim 0$ & Stereo & $\sim 1$ & $\begin{array}{c}\text { Neish et al. } \\
2018\end{array}$ \\
\hline Afekan & $115 \pm 5$ & $0.455 \pm 0.18$ & SARTopo & $0.52 \pm 0.19$ & $\begin{array}{c}\text { Neish et al. } \\
2013\end{array}$ \\
\hline \multirow[t]{2}{*}{ Forseti } & $140 \pm 10$ & $>0.41 \pm 0.05$ & SARTopo & $<0.55 \pm 0.055$ & $\begin{array}{c}\text { Neish et al. } \\
2018\end{array}$ \\
\hline & & $0.18 \pm 0.06$ & Stereo & $0.80 \pm 0.07$ & $\begin{array}{c}\text { Neish et al. } \\
2018\end{array}$ \\
\hline
\end{tabular}

${ }^{a}$ Calculated using Ganymede crater depths from Figure $2 b$ in Schenk et al 2002.

\subsubsection{Filling factor emissivity of Titan's impact craters}

The emissivity of the selected craters was also estimated using a technique first described in Bonnefoy et al. (2016), that takes into account the areal fraction of the radiometry footprint covered by the mapped crater rim and ejecta blanket. The radiometry footprints have, at best, a resolution of $5 \mathrm{~km}$ and therefore often include a mixture of different terrains. In order to obtain the most accurate estimate of the emissivity of each crater, we compared the emissivity value for each radiometry footprint to the fraction of the rim and ejecta blanket covered by that footprint, what we term its "filling factor". The emissivity was derived by extrapolating this value to $100 \%$ filling factor assuming a linear mixture. 
An example of this technique for Forseti crater is illustrated in Figure 32. The same approach was used to estimate the emissivity of the crater floor when possible (i.e. where they are large enough).
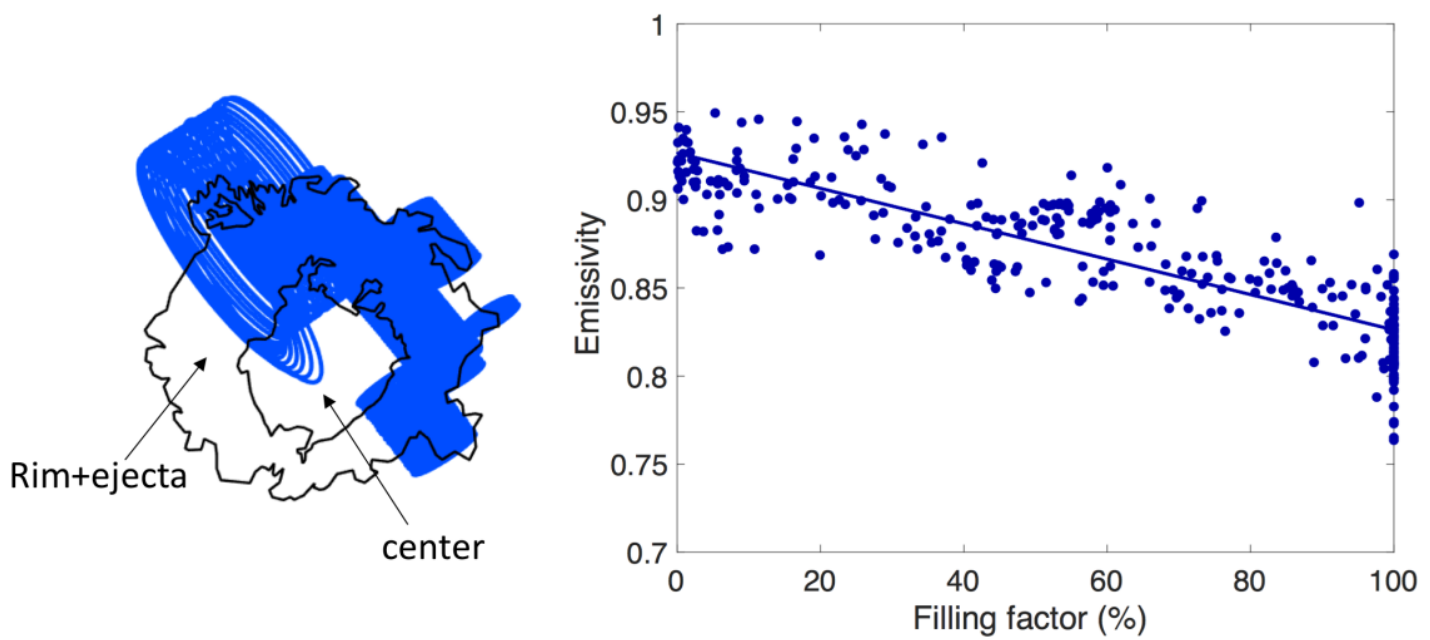

Figure 32: Left: Outlines of the Forseti crater (black) and radiometry footprints (blue) over the crater region. Right: Emissivity of the crater area as a function of the areal filling factor by the crater rim and ejecta of each radiometry footprint and associated linear fit (solid line).

\subsubsection{VIMS signatures of Titan's impact craters}

A previous study conducted by Neish et al. (2015) found Titan's craters have a range of spectral signatures and inferred compositions in VIMS. They suggested that chemical weathering was altering the appearance of the craters, as methane rain dissolved organics in the ejecta to produce a water-ice enhancement in more degraded craters. For this study, a larger sample size is used to analyze the VIMS data to see if chemical weathering is still a likely candidate for the variations in the spectra, or if there is another possible cause. This work was completed by qualitatively determining the available VIMS signatures for each of the 15 craters in this study and comparing them with crater location and relative depth. We produced an RGB composite for each VIMS image, where $\mathrm{R}=$ 4.8-5.2 $\mu \mathrm{m}, \mathrm{G}=2 \mu \mathrm{m}$, and $\mathrm{B}=1.28 \mu \mathrm{m}$. Dark blue regions were inferred to be enriched 
in water-ice, dark brown regions were inferred to be enriched in sand, and bright green regions remain an unknown unit, thought to be a mixture of water-ice and organics.

\subsection{Results}

\subsubsection{Average emissivity of Titan's impact craters}

The calculated average emissivity values for each of the 15 crater features are shown below (Table 5).

Table 5: Calculated high and low resolution mean emissivity for 15 craters on Titan

\begin{tabular}{|r|c|c|c|c|}
\hline & \multicolumn{2}{|c|}{ High Resolution Emissivity } & \multicolumn{2}{c|}{ Low Resolution Emissivity } \\
\hline $\begin{array}{c}\text { Crater } \\
\text { Name }\end{array}$ & Ejecta + rim & Interior & Ejecta + rim & Interior \\
\hline Sinlap & $0.85 \pm 0.02$ & $0.84 \pm 0.01$ & $0.85 \pm 0.02$ & $0.84 \pm 0.1$ \\
\hline Forseti & $0.86 \pm 0.03$ & $0.90 \pm 0.02$ & $0.87 \pm 0.03$ & $0.90 \pm 0.02$ \\
\hline Menrva & $0.87 \pm 0.03$ & $0.89 \pm 0.01$ & $0.88 \pm 0.03$ & $0.89 \pm 0.01$ \\
\hline Selk & $0.87 \pm 0.03$ & $0.92 \pm 0.03$ & $0.88 \pm 0.04$ & $0.93 \pm 0.03$ \\
\hline Momoy & $0.90 \pm 0.01$ & $0.896 \pm 0.006$ & $0.90 \pm 0.01$ & $0.898 \pm 0.006$ \\
\hline Ksa & $0.919 \pm 0.007$ & $0.919 \pm 0.007$ & $0.919 \pm 0.007$ & $0.919 \pm 0.006$ \\
\hline Soi & $0.928 \pm 0.006$ & $0.926 \pm 0.003$ & $0.929 \pm 0.006$ & $0.927 \pm 0.003$ \\
\hline Hano & $0.94 \pm 0.01$ & $0.93 \pm 0.01$ & $0.936 \pm 0.01$ & $0.93 \pm 0.01$ \\
\hline Paxsi & -- & -- & $0.939 \pm 0.008$ & $0.942 \pm 0.005$ \\
\hline Afekan & $0.940 \pm 0.006$ & $0.930 \pm 0.007$ & $0.940 \pm 0.006$ & $0.930 \pm 0.007$ \\
\hline Nath & -- & -- & $0.9478 \pm 0.0008$ & $0.9480 \pm 0.0004$ \\
\hline Shikoku & $0.950 \pm 0.007$ & $0.962 \pm 0.006$ & $0.952 \pm 0.008$ & $0.954 \pm 0.009$ \\
\hline T104 & -- & -- & $0.956 \pm 0.003$ & $0.958 \pm 0.002$ \\
\hline Santorini & $0.961 \pm 0.006$ & $0.965 \pm 0.002$ & $0.962 \pm 0.007$ & $0.960 \pm 0.004$ \\
\hline Guabonito & $0.967 \pm 0.004$ & $0.967 \pm 0.004$ & $0.970 \pm 0.006$ & $0.967 \pm 0.004$ \\
\hline & & & & \\
\hline
\end{tabular}

We compared the average emissivity values for each mapped ejecta blanket + rim to the crater characteristics. We observe that craters near Xanadu $\left(\sim 0-100^{\circ} \mathrm{W}\right)$ tend to have lower emissivity values, indicative of water-ice (Figure 33a). A study conducted by Griffith et al. (2016) found large scale water-ice spectral features between $0-120^{\circ} \mathrm{W}$ in VIMS data, consistent with what is observed in Figure 33a. Another correlation we noted 
was with crater latitude and emissivity. South of the equator, crater ejecta tend to have higher emissivity values, indicative of organics, but there is a noticeable drop off in emissivity values north of the equator, suggestive of water-ice enrichment (Figure 33b). These groupings appear to correspond with feature type, such as the organic dunes. For instance, Guabonito, Santorini, and Shikoku have emissivities higher than the average background emissivity and are all located in the organic dunes. Afekan, Hano, and Soi are located in the plains regions. The remaining craters between $\sim 6-26^{\circ} \mathrm{N}$, are a mixture of dunes and plains region craters, and are therefore classified as a transitional zone. As a result, the emissivity values are likely somewhat dependent on the geologic context in which the crater is found. We did not see a trend between emissivity and elevation (Figure 33c).

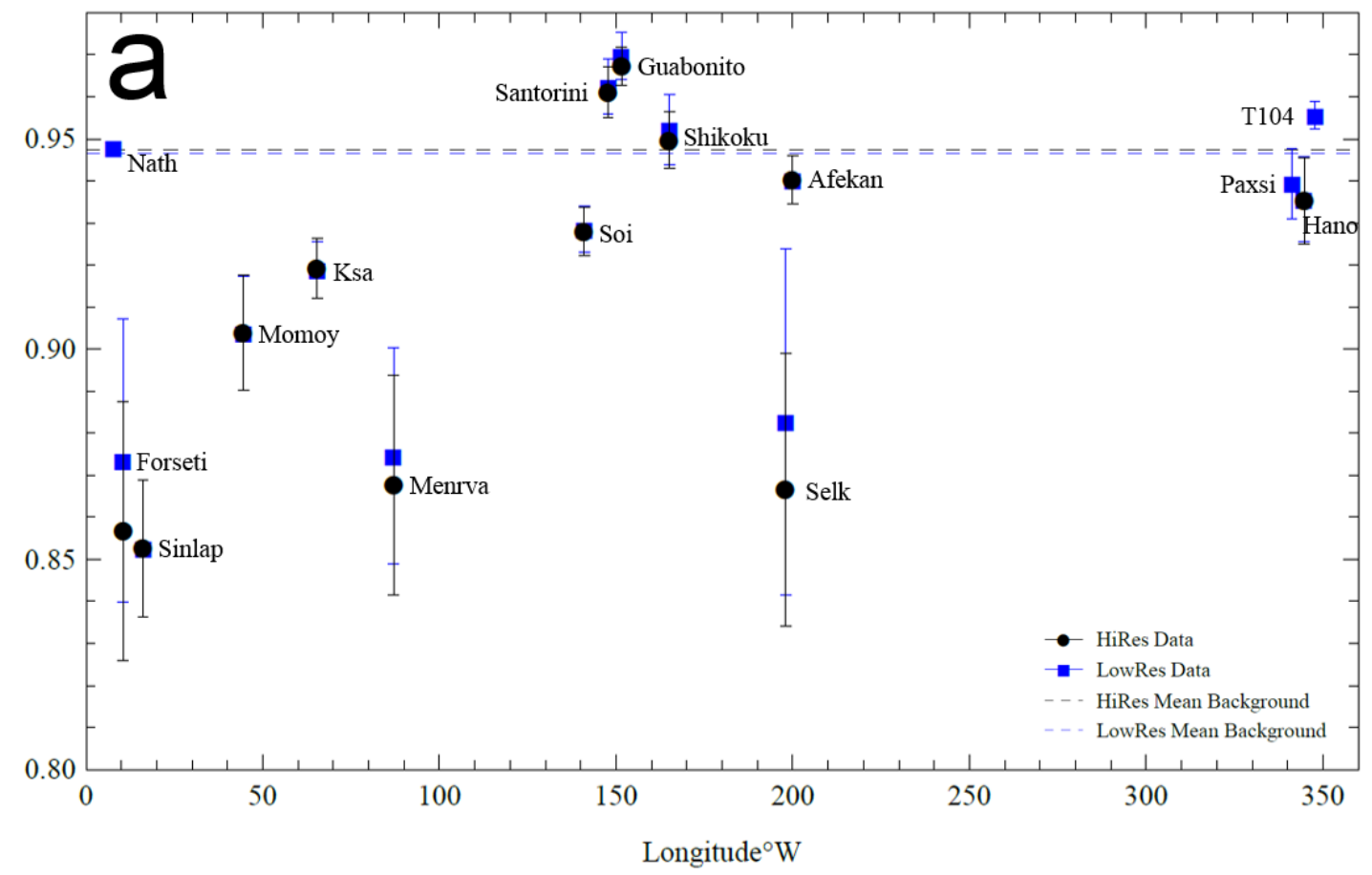



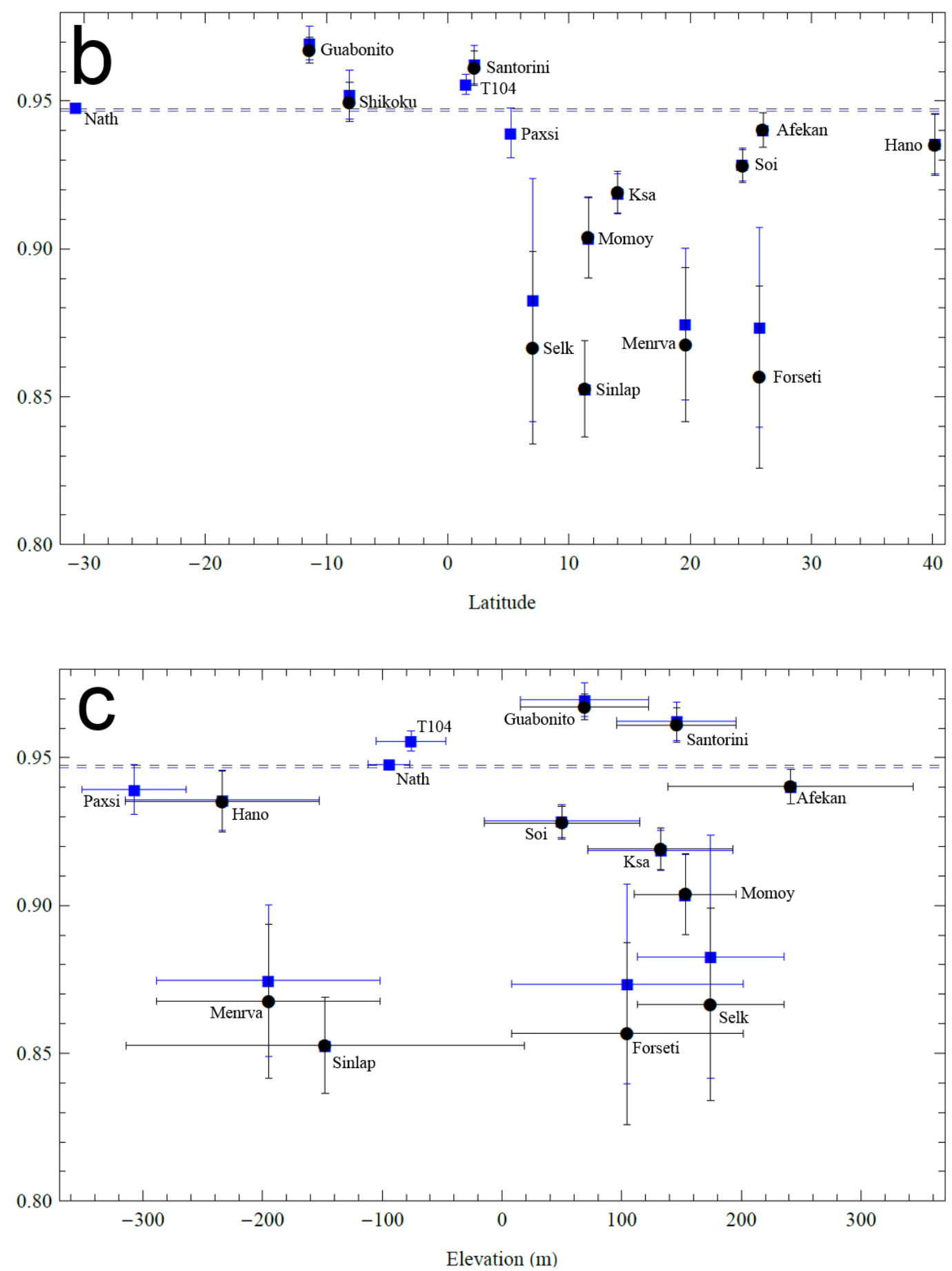

Figure 33: Mean emissivity versus (a) crater longitude $\left({ }^{\circ} \mathrm{W}\right)$, (b) crater latitude and (c) crater elevation. The dashed lines represent average global background values for the high resolution data set in addition to the low resolution data set. Blue boxes correspond to the low resolution data set, black circles represent the high resolution data set. 
There is also a trend with relative depth and emissivity (Figure 34). For this data set, we used the upper limit on relative depth derived from a partial SARTopo profile through Forseti crater (Neish et al., 2018). An earlier digital terrain model created from the overlapping of flyby T23 and T84 of the same crater suggested it was much shallower (Neish et al., 2018), but this is inconsistent with its observed morphology. Forseti has a well-defined rim and central peak, characteristic of fresher craters with minimal infilling. The discrepancy in the two depth calculations for Forseti may be the result of interpolation in the stereo data generation, variations in rim crest topography, or a combination of the two.

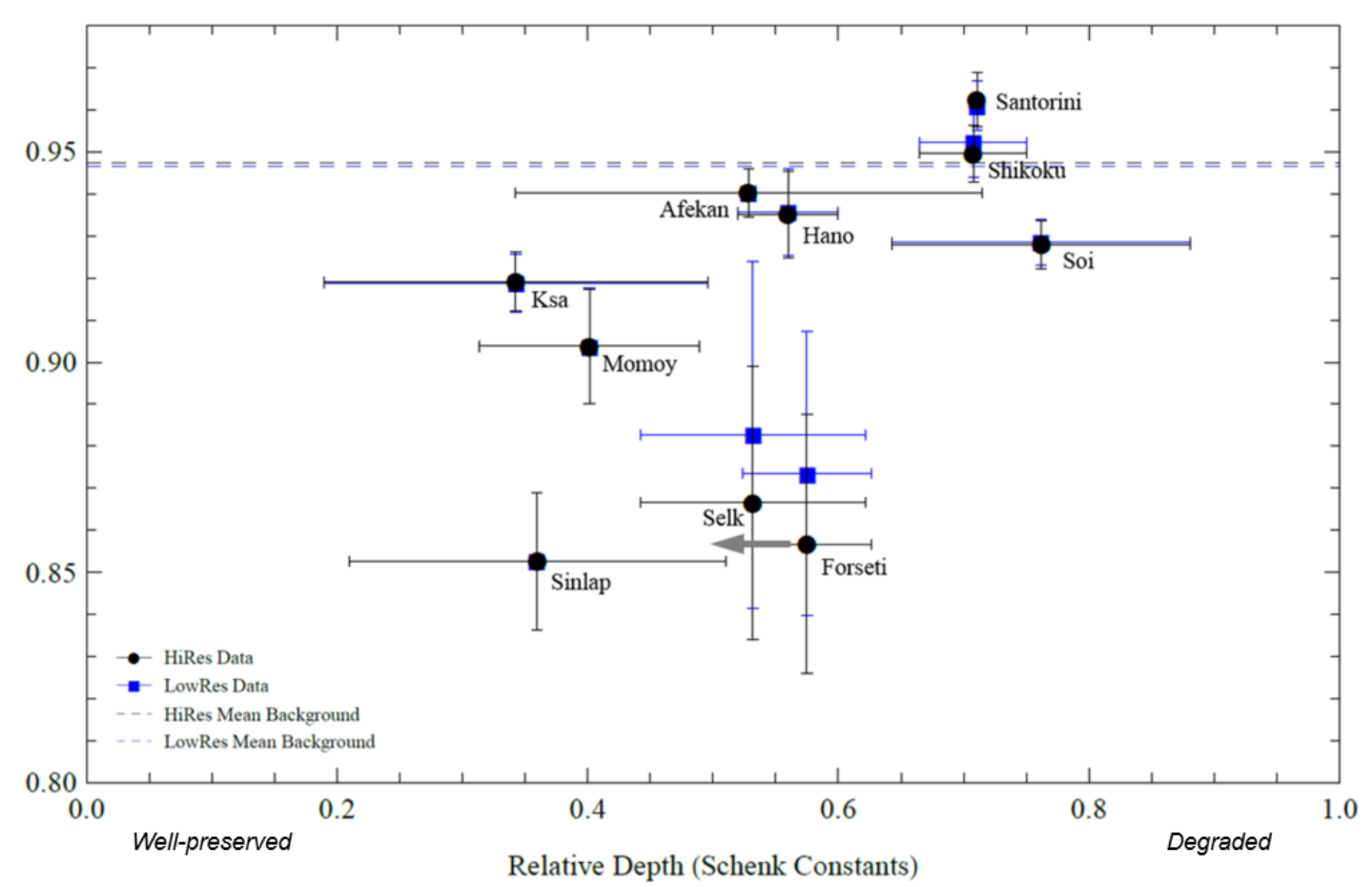

Figure 34: Mean emissivity for crater rim and ejecta blankets on Titan versus relative crater depth. Craters with larger relative depths (more degraded) have higher emissivity than craters with smaller relative depths (less degraded). However, composition also depends on location. Here we see Santorini and Shikoku (dunes craters) with higher emissivities than Soi, the most degraded crater. This will be discussed further in section 3.3.2. The arrow indicates that this is an upper limit to Forseti's relative depth. 
In general, craters with small relative depths (less degraded) have lower emissivities than craters with high relative depths (more degraded). A statistical analysis was performed on the data and an $\mathrm{R}^{2}$ value of 0.355 was found. After weighting the fit based on the $\mathrm{X}$ and $\mathrm{Y}$ error bars following the procedures outlined in Thirumalai et al. (2011), the $\mathrm{R}^{2}$ value improved to 0.480 which more effectively shows a linear relationship between the compositions and degradation state. This relationship is consistent with an enhancement in water-ice in the rims and ejecta blankets of well-preserved craters on Titan, and a more organic-rich composition in the rims and ejecta blankets of more degraded craters. This suggests that weathering and erosion on Titan plays a large role in the observed composition of its craters.

\subsubsection{Filling factor emissivity of Titan's impact craters}

The results from the filling factor technique confirm what we observed from the average emissivity values (Figure 35). We observe that less degraded craters, such as Sinlap and Forseti, typically have lower emissivities indicative of water-ice, whereas more degraded craters such as Soi, Shikoku, or Santorini have higher emissivity values indicative of an enrichment in organics. However, we also note that geologic context and location also plays a role: as with the average emissivity values, we see that craters in the dunes regions have higher emissivity values in comparison to craters in the plains regions. Moreover, all of the crater interiors (with the exception of Sinlap) have higher emissivities than their ejecta blankets + rims, suggestive of an enrichment in organic material in this region, likely by infilling of organic sediment. It is expected that if the crater interior has a smaller emissivity value than the crater rim + ejecta blanket, it is extremely youthful. As time goes on, it is expected that the difference in emissivity values between crater interior and exterior will increase as organic material is deposited within the crater. As the crater rims and ejecta blankets erode away, it is likely that older, more degraded craters will see a decrease in this difference in emissivity, but with the interior still having a higher value. The difference in emissivity for craters with their respective relative depth measurements are shown in Figure 36. 


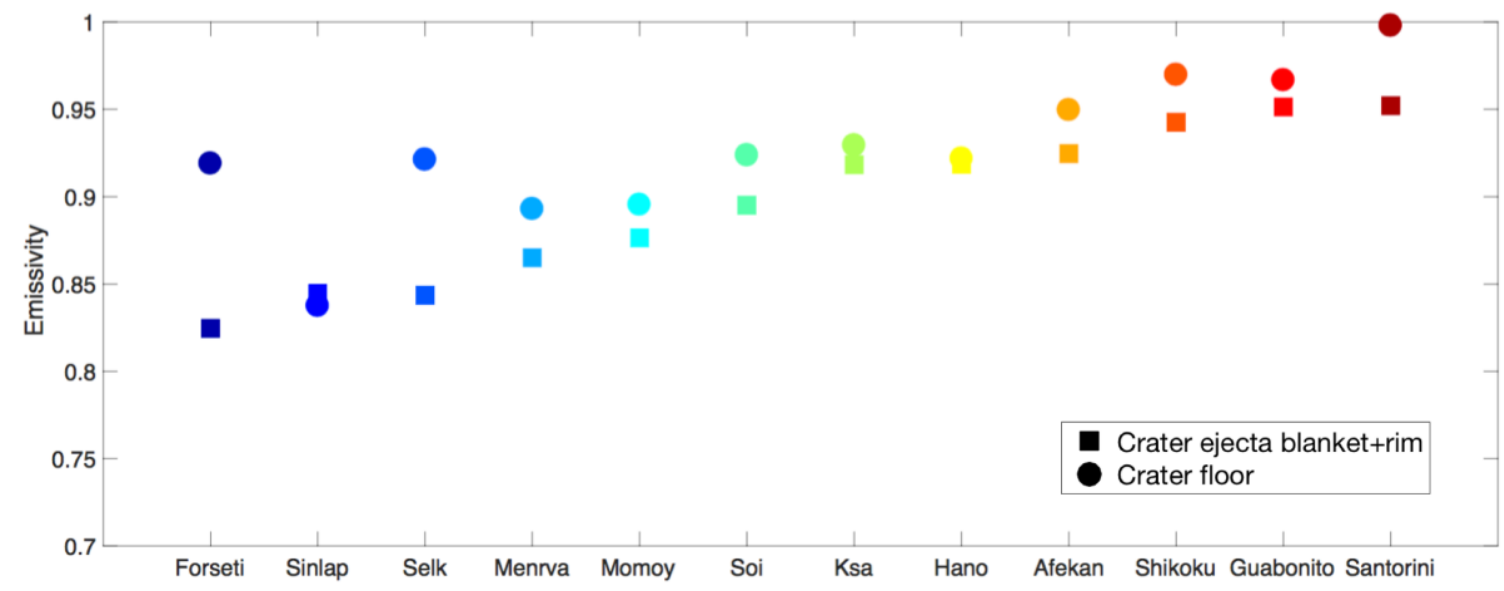

Figure 35: Filling factor emissivity of the ejecta blanket + rim and the floor of 12 craters on Titan. Cooler colors correspond with lower emissivities and warmer colors represent higher emissivities. The crater ejecta blanket + rim and floor emissivities were obtained by extrapolation of the emissivity for a filling factor of $100 \%$ (see section 3.2.2). There is a larger uncertainty on the emissivity of the crater floors of Sinlap, Momoy, Soi, Afekan and Santorini which have been observed with radiometry footprints including more than $50 \%$ of other terrains. Note that, except for Sinlap, the crater floors are always more emissive than the crater ejecta blankets + rims, most likely because these are sinks for organics. 


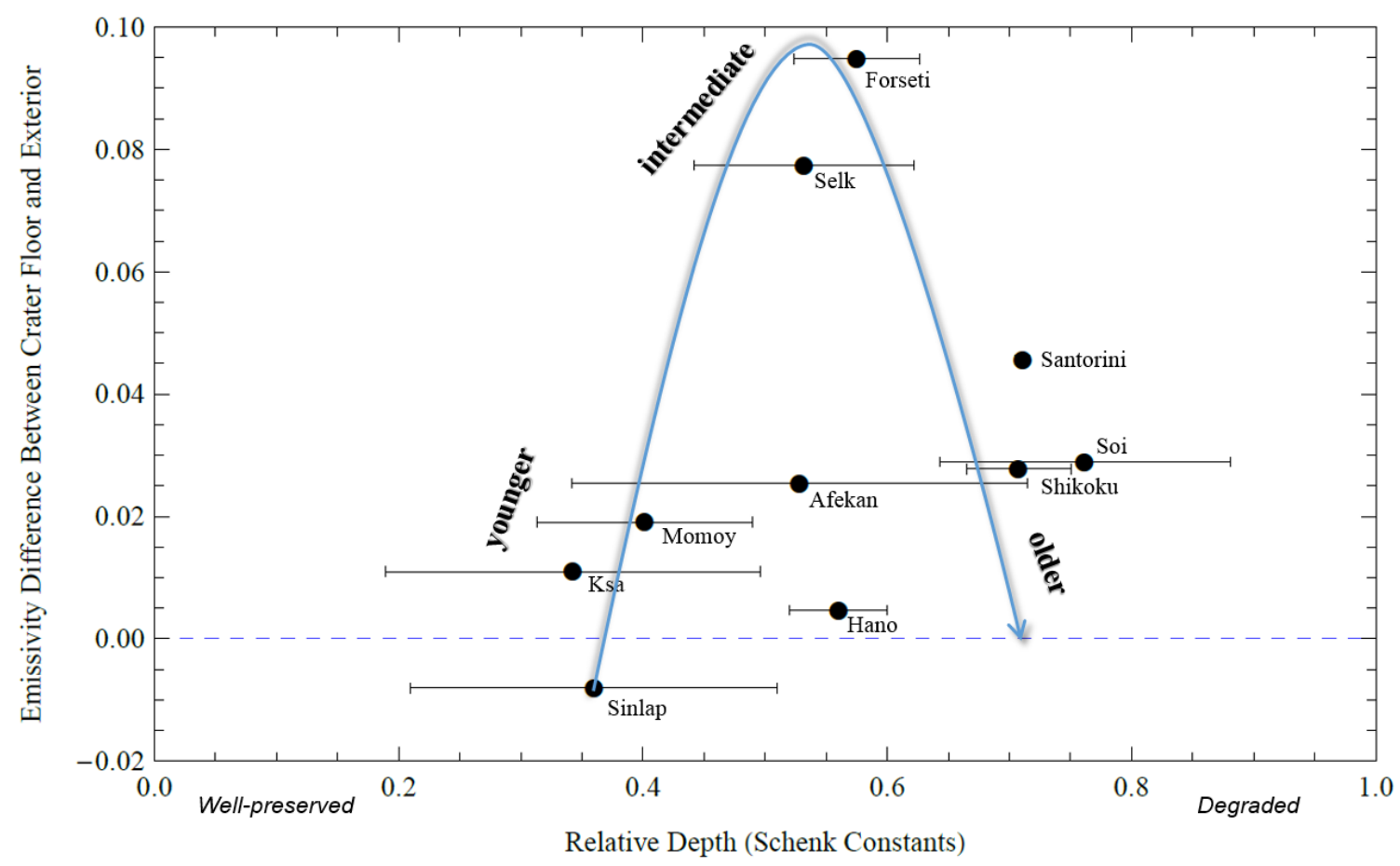

Figure 36: Emissivity difference between crater floor and crater ejecta blanket + rim versus relative depth. The dashed line represents an equivalent emissivity for the crater interior and exterior. The solid blue line shows the general trend of the craters. Sinlap is the only crater with a lower emissivity value in the interior, implying extreme youth. As craters degrade toward intermediate ages, this difference increases. As craters become heavily degraded, this difference becomes minimal again. 
The small difference in emissivity between the crater floor and ejecta for Ksa may be due to its extreme youth, while the small difference for Guabonito may be due to its extreme state of degradation. Craters such as Forseti and Selk, with large differences in emissivity, are likely intermediate in age. However, as we have been seeing, highly organic-rich does not necessarily mean it will be the oldest or most degraded crater as shown by the relative depth measurement; the geologic context and emissivity difference must also be taken into consideration.

\subsubsection{Infrared spectra of Titan's impact craters}

The emissivity analysis revealed fresher craters to have lower emissivities in their ejecta and rims, indicative of volume scattering caused by water-ice. As time passes and craters become more degraded, the emissivity increases, indicative of a more organic composition. VIMS data, which sees a few microns into the surface instead of tens of centimeters like the emissivity data can, reveals the opposite trend (Figure 37). Fresher craters such as Sinlap typically do not appear VIMS dark blue in their ejecta + rim portions and are mostly VIMS bright green in color. The composition of these bright green units is unknown, but is potentially a mixture of organics and water-ice (Neish et al., 2015). In degraded craters, such as Soi, dark blue VIMS units are observed in the crater rim and ejecta. The dark blue VIMS unit suggests that there is an enrichment of water-ice in the region (Barnes et al., 2007). However, the emissivity data also showed a trend with geologic context. Therefore, the geologic context has to also be taken into consideration here as well. In VIMS, we see that geologic context - not the degradation state - plays a major role in the surficial composition of the crater's ejecta and rim (Table 6). All craters in the dunes region have VIMS bright green ejecta blankets + rims, while all craters in the plains region have VIMS dark blue ejecta blankets + rims. The interior of the dunes craters are typically dark brown, except in the case of the two best preserved craters on Titan, Sinlap and Ksa. These craters are likely so young, their interiors have not had time to fill with sand. In the plains, the interiors are consistently VIMS bright green, similar to the surrounding terrain. 

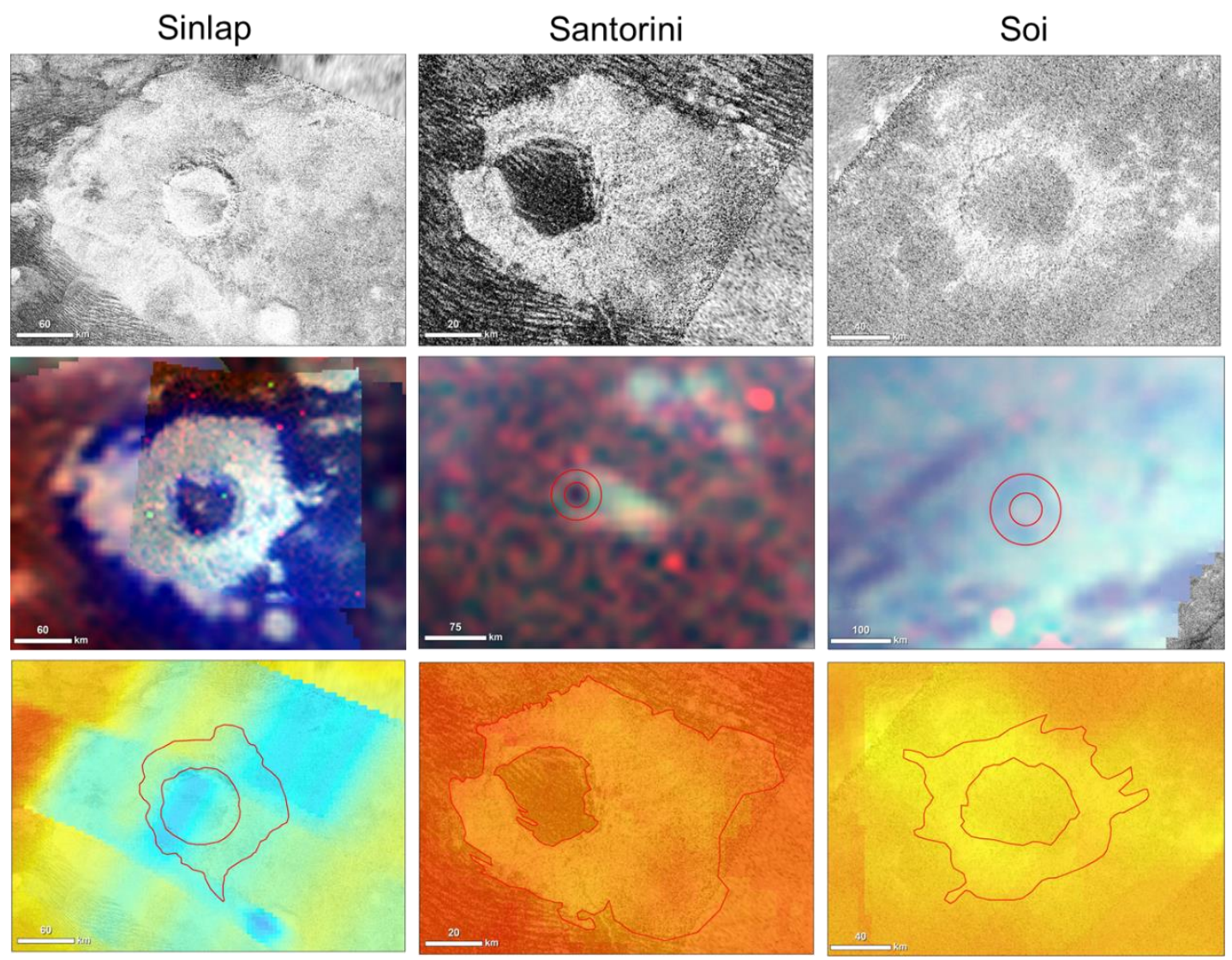

Figure 37: Top images show radar images, center images show VIMS data, bottom images show 2.18-cm emissivity data of Sinlap, Santorini, and Soi. The ejecta of Sinlap, a dunes region crater, exhibits a bright green VIMS spectra, potentially a mix of organics and water-ice. The emissivity data shows a blue signature, indicative of a lower value that is interpreted as water-ice. Santorini, a relatively degraded dunes crater, but less degraded than Soi, shows a VIMS green spectra on its ejecta blanket. The emissivity data shows a heavily organic region, represented by the dark red hue. The ejecta of Soi crater, a degraded plains crater, shows VIMS dark blue unit, suggestive of water-ice. The emissivity data shows a reddish hue, indicating a higher value or an organic-rich composition. 
Table 6: Characteristics of 15 impact craters on Titan

\begin{tabular}{|c|c|c|c|c|c|c|c|}
\hline$\frac{\text { Crater }}{\underline{\text { name }}}$ & $\frac{\text { Diameter }}{(\mathbf{k m})}$ & $\frac{\text { Relative }}{\text { depth }}$ & $\begin{array}{l}\text { Ejecta } \\
\text { emissivity }\end{array}$ & $\frac{\text { VIMS }}{\text { ejecta }}$ & $\underline{\text { VIMS }}$ & Location & Comments \\
\hline Paxsi & 120 & $\mathrm{n} / \mathrm{a}$ & organic & green & brown & dunes & \\
\hline Sinlap & 82 & $0.36 \pm 0.15$ & water-ice & green & blue & dunes & $\begin{array}{l}\text { Very well-preserved } \\
\text { crater }\end{array}$ \\
\hline Selk & 80 & $0.53 \pm 0.09$ & water-ice & green & brown & dunes & \\
\hline Guabonito & 68 & $\mathrm{n} / \mathrm{a}$ & highly organic & green & brown & dunes & $\begin{array}{l}\text { Morphology suggests a } \\
\text { degraded crater infilled } \\
\text { with sediment }\end{array}$ \\
\hline T104 & 57 & $\mathrm{n} / \mathrm{a}$ & organic & green & brown & dunes & \\
\hline Momoy & 40 & $0.40 \pm 0.088$ & transitional & $\mathrm{n} / \mathrm{a}$ & $\mathrm{n} / \mathrm{a}$ & dunes & $\begin{array}{l}\text { Mid-range emissivity } \\
\text { value, likely some water- } \\
\text { ice enrichment and } \\
\text { some organic }\end{array}$ \\
\hline \multirow{2}{*}{ Ksa } & \multirow{2}{*}{39} & $0.34 \pm 0.15$ & \multirow{2}{*}{ transitional } & \multirow{2}{*}{ green } & \multirow{2}{*}{ blue } & \multirow{2}{*}{ dunes } & \multirow{2}{*}{$\begin{array}{l}\text { Mid-range emissivity } \\
\text { value, likely some water- } \\
\text { ice enrichment and } \\
\text { some organic }\end{array}$} \\
\hline & & $0.42 \pm 0.15$ & & & & & \\
\hline Shikoku & 35 & $0.71 \pm 0.043$ & highly organic & green & $\mathrm{n} / \mathrm{a}$ & dunes & \\
\hline Santorini & 33 & $0.70 \pm 0.06$ & highly organic & green & brown & dunes & \\
\hline Menrva & 425 & $\mathrm{n} / \mathrm{a}$ & water-ice & green & blue & plains & $\begin{array}{l}\text { Outlier due to its size; } \\
\text { this is a multi-ring basin } \\
\text { on the boundary of the } \\
\text { plains and dunes } \\
\text { regions }\end{array}$ \\
\hline Forseti & 139 & $<0.55 \pm 0.055$ & water-ice & blue & green & plains & $\begin{array}{l}\text { Morphology suggests } \\
\text { more well-preserved } \\
\text { than the relative depth } \\
\text { measurement shows }\end{array}$ \\
\hline Afekan & 115 & $0.52 \pm 0.19$ & organic & blue & green & plains & \\
\hline Hano & 100 & $0.56 \pm 0.04$ & organic & $\mathrm{n} / \mathrm{a}$ & $\mathrm{n} / \mathrm{a}$ & plains & \\
\hline Soi & 78 & $0.76 \pm 0.12$ & organic & blue & green & plains & \\
\hline Nath & 58 & $\mathrm{n} / \mathrm{a}$ & organic & blue & green & plains & \\
\hline
\end{tabular}

\subsection{Discussion}

Subsurface composition of crater ejecta blankets + rim, shown in emissivity data, reveals a dependency on crater degradation state and geologic context. Older craters have highly emissive, organic subsurface compositions, whereas more well-preserved craters have lower emissivities, indicating a water-ice enrichment. Additionally, craters in the dunes regions have higher emissivity values than plains craters. Surficial composition of crater ejecta blankets + rim, shown in VIMS data, reveals a dependency solely on geologic context. Plains craters have a blue VIMS spectra in their ejecta blankets + rim, indicative of water-ice, and dunes craters have a brown VIMS spectra in their ejecta blankets + rim, indicative of sand dunes and organic material. 
We propose a hypothesis for the discrepancy between the VIMS and emissivity data for different regions on Titan (Figure 38). Since these two data sets sample different depths, there could be compositional changes between these sampling depths, providing clues as to their origin. In the dunes regions pre-impact (e.g., around Shikoku, Santorini) there is a thick, $100 \mathrm{~m}$ layer of sand (Neish et al., 2010) covering the presumably water-ice rich substrate. The presence of dunes would result in a high emissivity and a VIMS brown signature on the surface prior to the impact. During the excavation stage of the impact cratering process, subsurface material would be uplifted and ejected outward, mixing with organic-rich surficial material. This could produce the VIMS bright green spectral signature, as organics mix with water-ice in a "hydrothermal"-like system (Neish et al., 2015). The substrate would also be extensively fractured. This would increase the volume scattering in the region, making the crater appear water-ice rich in the emissivity data (i.e., reducing its emissivity). As time passes and erosion occurs, the subsurface fractures would be filled with organic materials, increasing the emissivity values. However, it is possible the surface would remain unchanged, perhaps as a result of active processes such as wind or rain sweeping the surface 'clean'. This would produce a VIMS spectra that is unchanged. 


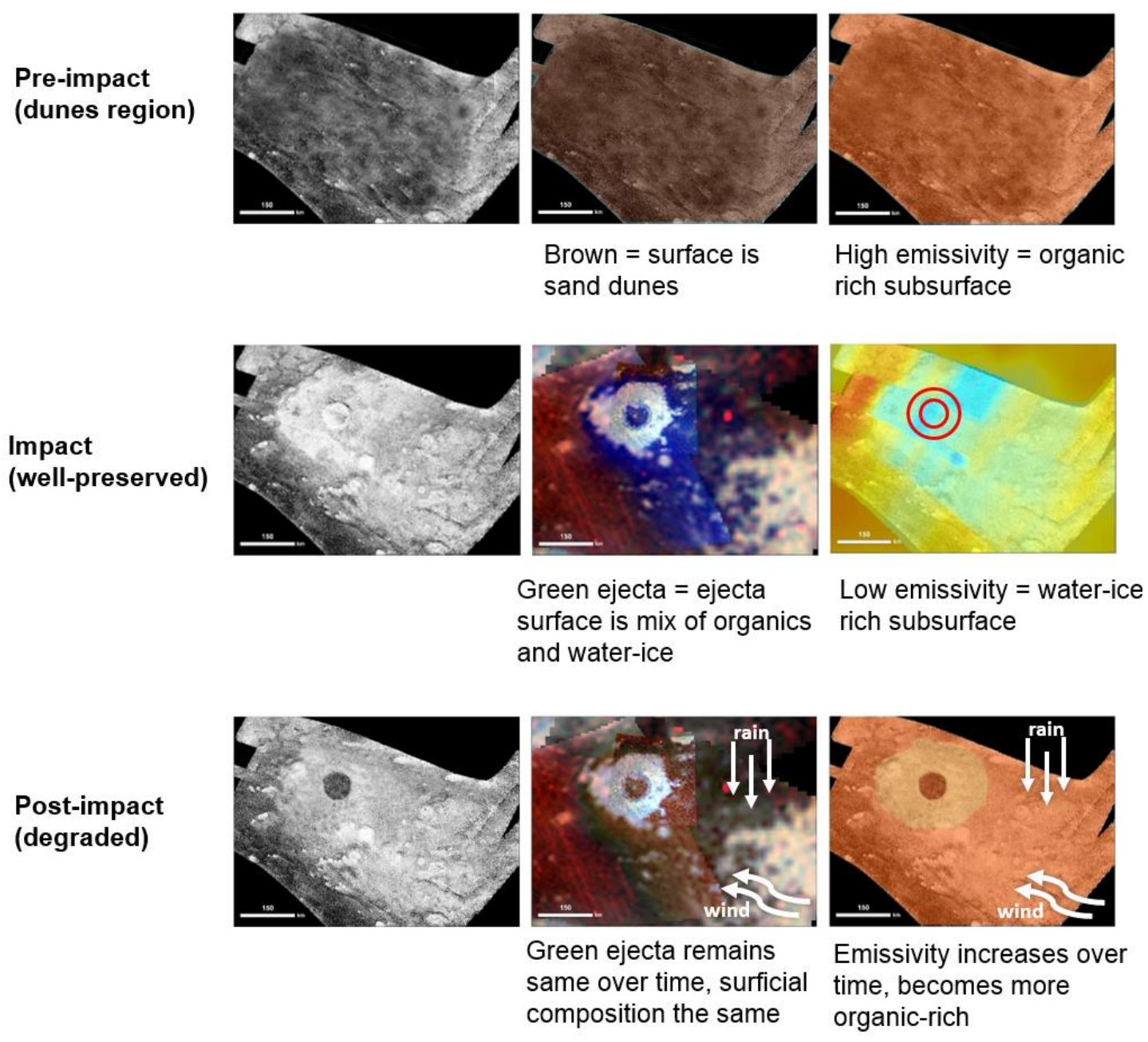

Figure 38: Hypothesis for the evolution of a crater in the dunes region. In the preimpact stage, the surface shows a brown spectra, indicative of sand dunes, and a high emissivity, indicative of an organic-rich substrate. Immediately post-impact, a well-preserved crater is formed. The ejecta blanket and rim shows a surficial VIMS green spectra, likely a mix of organics and water-ice. The ejecta blanket and rim shows a water-ice rich subsurface. Over time, as this crater degrades, the VIMS signature of the ejecta blanket remains the same due to active surface processes, but the subsurface becomes more organic-rich as the fractures are infilled by sediment. A similar process happens in the plains regions: the VIMS spectra remains the same over time, with an increase in the emissivity of the subsurface.

A similar process may occur in the plains regions (e.g, around Soi, Afekan), where we propose there is a thinner layer of organic material lying atop the water-ice substrate. 
Solomonidou et al. (2018) report similar findings of water-ice dominated mid-latitudes with a thin layer of organics. An alternate proposal for the thickness of the overlying material, detailed in Lopes et al. (2016) and Malaska et al. (2014) and (2016), describes local regions of labyrinth terrain within the undifferentiated plains. They propose these regions are much thicker and more elevated (Malaska et al., 2014; Lopes et al., 2016; Malaska et al., 2016). With our proposal, the organic layer would have to be thick enough to produce high emissivity values in the global map (Janssen et al., 2016) and a VIMS bright green spectral signature (Barnes et al., 2007), but thin enough to not contribute substantively to the spectral signature of the final impact crater. With fewer overlying organics to mix into the ejecta blanket during the impact process, the exposed rock appears water-ice enriched in VIMS in the final crater form. Over time, the fractures here too fill in with organic materials, increasing the emissivity as volume scattering decreases, but retaining the original surface composition.

In this scenario, the observed compositional variations are a result of varying amounts of organic materials on the surface of Titan, coupled with active surface processes. It also implies that the dunes have been present on Titan for the time needed to produce the impact craters studied here, at least several hundred million years (Neish et al., 2016). Neish et al. (2015) concluded that the progression of crater composition seen in VIMS was a result of chemical weathering. Our research suggests that chemical weathering is not the primary source, and instead, VIMS spectra of craters tends to be more closely tied to their location on Titan.

\subsection{Conclusions}

This work presents the first detailed analysis of the composition of Titan's impact craters, using microwave emissivity and VIMS hyperspectral data. This compositional data was then compared to crater characteristics such as location, elevation, and erosional state to try to understand why there are compositional variations amongst the impact craters on Titan. Results show fresher, well-preserved craters on Titan have a low emissivity at 2.18-cm, indicative of water-ice enrichment, while more degraded craters have higher emissivities, consistent with an organic-rich composition. In addition to degradation, location is also a factor: dunes craters have higher emissivities than plains regions craters. 
And as craters on Titan erode over time, the VIMS spectra remain the same as their emissivity increases, with different VIMS compositions depending on the location of the crater. Craters in the equatorial dune field are VIMS green while craters in the midlatitude plains are VIMS blue. The differing VIMS signatures suggest more mixing with organics during the cratering event in the organic-rich dunes than in the plains. The changes in emissivity over time, with unchanging VIMS spectra, are consistent with organic infilling of subsurface fractures in both regions, with limited surficial alteration. These results support the idea that compositional variations in Titan's impact craters are related to erosion and infilling, as well as local variations in the overlying organic material of the pre-impact substrate. They also suggest that active processes, such as wind or rain, are presently 'wiping the surface clean', effectively transporting sediments and exposing the underlying bedrock. 


\subsection{References}

Barnes, J. W., Brown, R. H., Soderblom, L., Buratti, B. J., Sotin, C., Rodriguez, S., Le Mouelic, S., Baines, K. H., Clark, R., and Nicholson, P. 2007. Global-scale surface spectral variations on Titan seen from Cassini/VIMS. Icarus 180, 242258.

Bray, V. J., Schenk, P. M., Melosh, H. J., Morgan, J. V., and Collins, G. S. 2012. Ganymede crater dimensions - Implications for central peak and central pit formation and development. Icarus 217, 115-129.

Bonnefay, L. E., Hayes, A. G., Hayne, P. O., Malaska, M. J., Le Gall, A., Solomonidou, A., and Lucas, A. 2016. Compositional and spatial variations in Titan dune and interdune regions from Cassini VIMS and RADAR. Icarus 270, 222-237.

Buratti, B. J., Sotin, C., Lawrence, K., Brown, R. H., Le Mouelic, S., Soderblom, J. M., Barnes, J., Clark, R. N., Baines, K. H., and Nicholson, P. D. 2012. A newly discovered crater in Titan's Senkyo: Cassini VIMS observations and comparison with other impact features. Planetary and Space Science 60, 18-25.

Clark, R. N., Curchin, J. M., Barnes, J. W., Jaumann, R., Soderblom, L., Cruikshank, D. P., Brown, R. H., Rodriguez, S., Lunine, J., Stephan, K., Hoefen, T. M., Le Mouelic, S., Sotin, C., Baines, K. H., Buratti, B. J., and Nicholson, P. D. 2010. Detection and mapping of hydrocarbon deposits on Titan. Journal of Geophysical Research 115, E10005.

Corlies, P., Hayes, A. G., Birch, S. P. D., Lorenz, R. D., Stiles, B. W., Kirk, R. L., Poggiali, V., Zebker, H., and Iess, L. 2017. Titan's topography and shape at the end of the Cassini mission. Geophysical Research Letters 44, 11754-11761.

Dunaeva, A., Kronrod, V., and Kuskov, O., 2014. Models of Titan with water-ice shell, rock-ice mantle, and constraints on the rock-iron component composition. Doklady Earth Sciences 454, 334-339. 
Griffith, C. A., Penteado, P. F., Turner, J., Montiel, N., Schoenfeld, A., Lopes, R. M. C., Soderblom, L. A., Neish, C., and Radebaugh, J. 2016. Spectral trends of Titan's tropical surface. Division of Planetary Science. Abstract 412.03.

Janssen, M. A., Lorenz, R. D., West, R., Paganelli, F., Lopes, R. M. C., Kirk, R. L., Elachi, C., Wall, S. D., Johnson, W. T. K., Anderson, Y., Boehmer, R. A., Callahan, P., Gim, Y., Hamilton, G. A., Kelleher, K. D., Roth, L., Stiles, B., Le Gall, A., and the Cassini RADAR team. 2009. Titan's surface at 2.2-cm wavelength imaged by the Cassini RADAR radiometer: Calibration and first results. Icarus 200, 222-239.

Janssen, M. A., Le Gall, A., Lopes, R. M. C., Lorenz, R. D., Malaska, M. J., Hayes, A. G., Neish, C. D., Solomonidou, A., Mitchell, K. L., Radebaugh, J., Keihm, S. J., Choukroun, M., Leyrat, C., Encrenaz, P. J., and Mastrogiuseppe, M. 2016. Titan's surface at $2.18-\mathrm{cm}$ wavelength imaged by the Cassini RADAR radiometer: Results and interpretations through the first ten years of observation. Icarus 270, 443-459.

Le Gall, A., Malaska, M. J., Lorenz, R. D., Janssen, M. A., Tokano, T., Hayes, A. G., Mastrogiuseppe, M., Lunine, J. I., Veyssiere, G., Encrenaz, P., and Karatekin, O. 2016. Composition, seasonal change, and bathymetry of Ligeia Mare, Titan, derived from its microwave thermal emission. Journal of Geophysical Research: Planets 121, 233-251.

Le Mouélic, S., Paillou, P., Janssen, M. A., Barnes, J. W., Rodriguez, S., Sotin, C., Brown, R. H., Baines, K. H., Buratti, B. J., Clark, R. N., Crapeau, M., Encrenaz, P. J., Jaumann, R., Geudtner, D., Paganelli, F., Soderblom, L., Tobie, G., and Wall, S. 2008. Mapping and interpretation of Sinlap crater on Titan using Cassini VIMS and RADAR data. Journal of Geophysical Research 113, E04003.

Lopes, R. M. C., Malaska, M. J., Solomonidou, A., Le Gall, A., Janssen, M. A., Neish, C. D., Turtle, E. P., Birch, S. P. D., Hayes, A. G., Radebaugh, J., Coustenis, A., Schoenfeld, A., Stiles, B. W., Kirk, R. L., Mitchell, K. L., Stofan, E. R., 
Lawrence, K. J., and the Cassini RADAR team. 2016. Nature, distribution, and origin of Titan's undifferentiated plains. Icarus 270, 162-182.

Lorenz, R. D., Wood, C. A., Lunine, J. I., Wall, S. D., Lopes, R. M. C., Mitchell, K. L., Paganelli, F., Anderson, Y. Z., Wye, L., Tsai, C., Zebker, H., and Stofan, E. R. 2007. Titan's young surface: Initial impact crater survey by Cassini RADAR and model comparison. Geophysical Research Letters 34, L07204.

Lorenz, R. D., Stiles, B. W., Aharonson, O., Lucas, A., Hayes, A. G., Kirk, R. L., Zebker, H. A., Turtle, E. P., Neish, C. D., Stofan, E. R., Barnes, J. W., and the Cassini RADAR team. 2013. A global topographic map of Titan. Icarus 225, 367-377.

Lunine, J. I. and Lorenz, R. D., 2009. Rivers, lakes, dunes, and rain: Crustal processes in Titan's methane cycle. The Annual Review of Earth and Planetary Sciences 37, 299-320.

MacKenzie, S. M., Barnes, J. W., Sotin, C., Soderblom, J. M., Le Mouelic, S., Rodriguez, S., Baines, K. H., Buratti, B. J., Clark, R. N., Nicholson, P. D., and McCord, T. B. 2014. Evidence of Titan's climate history from evaporite distribution. Icarus 243, 191-207.

Malaska, M. J., Radebaugh, J., Lopes, R. M. C., Mitchell, K. L., Hayes, A. G., Le Gall, A., Turtle, E., Solomonidou, A., and Lorenz, R. 2014. Labyrinth terrain on Titan. 2014 Annual Meeting of the Geological Society of America, Vancouver. Abstract \#T227.

Malaska, M. J., Lopes, R. M. C., Williams, D. A., Neish, C. D., Solomonidou, A., Soderblom, J. M., Schoenfeld, A. M., Birch, S. P. D., Hayes, A. G., Le Gall, A., Janssen, M. A., Farr, T. G., Lorenz, R. D., Radebaugh, J., and Turtle, E. P. 2016. Geomorphological map of the Afekan crater region, Titan: Terrain relationships in the equatorial and mid-latitude regions. Icarus 270, 130-161.

McCord, T. B., Hansen, G. B., Buratti, B. J., Clark, R. N., Cruikshank, D. P., D’Aversa, E., Griffith, C. A., Baines, E. K. H., Brown, R. H., Dalle Ore, C. M., Filacchione, 
G., Formisano, V., Hibbitts, C. A., Jaumann, R., Lunine, J. I., Nelson, R. M., Sotin, C., and the Cassini VIMS Team. 2006. Composition of Titan's surface from Cassini VIMS. Planetary and Space Science 54, 1524-1539.

Neish, C. D., Lorenz, R. D., Kirk, R. L., and Wye, L. C., 2010. Radarclinometry of the sand seas of Africa's Namibia and Saturn's moon Titan. Icarus 208, 385-394.

Neish, C. D. and Lorenz, R. D., 2012. Titan's global crater population: A new assessment. Planetary and Space Science 60, 26-33.

Neish, C. D., Kirk, R. L., Lorenz, R. D., Bray, V. J., Schenk, P., Stiles, B. W., Turtle, E, Mitchell, K., Hayes, A., and the Cassini RADAR team. 2013. Crater topography on Titan: Implications for landscape evolution. Icarus 223, 82-90.

Neish, C. D. and Lorenz, R. D. 2014. Elevation distribution of Titan's craters suggests extensive wetlands. Icarus 228, 27-34.

Neish, C. D., Barnes, J. W., Sotin, C., MacKenzie, S., Soderblom, J. M., Le Mouelic, S., Kirk, R. L., Stiles, B. W., Malaska, M. J., Le Gall, A., Brown, R. H., Baines, K. H., Buratti, B., Clark, R. N., and Nicholson, P. D. 2015. Spectral properties of Titan's impact craters imply chemical weathering of its surface. Geophysical Research Letters 42, 3746-3754.

Neish, C. D., Molaro, J. L., Lora, J. M., Howard, A. D., Kirk, R. L., Schenk, P., Bray, V. J., and Lorenz, R. D. 2016. Fluvial erosion as a mechanism for crater modification on Titan. Icarus 270, 114-129.

Neish, C. D., Lorenz, R. D., Turtle, E., Barnes, J. W., Trainer, M., Stiles, B. W., Kirk, R. L., Hibbitts, C., and Malaska, M. 2018. Strategies for detecting biological molecules on Titan. Astrobiology, submitted.

Radebaugh, J., Lorenz, R. D., Lunine, J. I., Wall, S. D., Boubin, G., Reffet, E., Kirk, R. L., Lopes, R. M. C., Stofan, E. R., Soderblom, L., Allison, M., Janssen, M. A., Paillou, P., Callahan, P., Spencer, C., and the Cassini RADAR team. 2008. Dunes on Titan observed by Cassini Radar. Icarus 194, 690-703. 
Rodriguez, S., Le Mouelic, S., Sotin, C., Clenet, H., Clark, R. N., Buratti, B., Brown, R. H., McCord, T. B., Nicholson, P. D., Baines, K. H., and the VIMS Science Team. 2006. Cassini/VIMS hyperspectral observations of the Huygens landing site on Titan. Planetary and Space Science 54, 1510-1523.

Schenk, P. M., 2002. Thickness constraints on the icy shells of the Galilean satellites from a comparison of crater shapes. Nature 417, 419-421.

Soderblom, L. A., Kirk, R. L., Lunine, J. I., Anderson, J. A., Baines, K. H., Barnes, J. W., Barrett, J. M., Brown, R. H., Buratti, B. J., Clark, R. N., Cruikshank, D. P., Elachi, C., Janssen, M. A., Jaumann, R., Karkoschka, E., Le Mouelic, S., Lopes, R. M. C., Lorenz, R. D., McCord, T. B., Nicholson, P. D., Radebaugh, J., Rizk, B., Sotin, C., Stofan, E. R., Sucharski, T. L., Tomasko, M. G., and Wall, S. D. 2007. Correlations between Cassini VIMS spectra and RADAR SAR images: Implications for Titan's surface composition and the character of the Huygens Probe Landing Site. Planetary and Space Science 55, 2025-2036.

Solomonidou, A., Coustenis, A., Lopes, R. M. C., Malaska, M. J., Rodriguez, S., Drossart, P., Elachi, C., Schmitt, B., Philippe, S., Janssen, M., Hirtzig, M., Wall, S., Sotin, C., Lawrence, K, Altobelli, N., Bratsolis, E., Radebaugh, J., Stephan, K., Brown, R. H., Le Mouelic, S., Le Gall, A., Villanueva, E. V., Brossier, J. F., Bloom, A. A., Witasse, O., Matsoukas, C., and Schoenfeld, A. 2018. The spectral nature of Titan's major geomorphological units: constraints on surface composition. Journal of Geophysical Research: Planets 123, 489-507.

Thirumalai, K., Singh, A., and Ramesh, R. A MATLAB code to perform weighted linear regression with (correlated or uncorrelated) errors in bivariate data. 2011. Journal Geological Society of India 77, 377-380.

Tobie, G., Grasset, O., Lunine, J. I., Mocquet, A., and Sotin, C., 2005. Titan's internal structure inferred from a coupled thermal-orbital model. Icarus 175, 496-502.

Vixie, G., Barnes, J. W., Bow, J., Le Mouelic, S., Rodriguez, S., Brown, R. H., Cerroni, P., Tosi, F., Burratti, B., Sotin, C., Filacchione, G.,Capaccioni, F., and Coradini, 
A. 2012. Mapping Titan's surface features within the visible spectrum via Cassini VIMS. Planetary and Space Science 60, 52-61.

Wood, C. A., Lorenz, R., Kirk, R., Lopes, R., Mitchel, K., Stofan, E., and the Cassini RADAR Team, 2010. Impact craters on Titan. Icarus 206, 334-344. 


\section{Chapter 4}

\section{Review and conclusions}

The purpose of this study was to analyze the compositions of Titan's impact features to understand how they vary across the surface and subsequently, understand the various modification processes occurring on Titan. Fifteen large, $>30 \mathrm{~km}$ diameter, craters and their ejecta blankets were included in this research. Remote sensing data at a range of wavelengths was utilized to study these craters. Radar was especially useful in visualizing these craters: rough surfaces (i.e. crater rims and ejecta blankets) appear bright in radar, whereas smooth surfaces (i.e. crater floors) appear dark. This research was primarily focused on the compositions of the ejecta blankets and crater rims because in the crater formation process, these are the crater regions which host excavated subsurface material. Deriving the composition of these regions was completed by using multiple wavelengths and therefore multiple penetrating depths. Emissivity data gathered information at depths of tens of centimeters up to a meter, whereas visible and infrared spectroscopy gathered information from the upper microns of the surface.

Fresh craters were expected to have rims and ejecta blankets enriched in water-ice because water-ice is likely the main constituent of Titan's crust. It was expected that over time, as these craters degraded, the water-ice signature would be replaced with an organic signature because organics cover the surface of Titan. However, it was unknown how the location of these craters would affect their compositions. Our analysis shows that our initial hypothesis was partly correct: in emissivity data, fresh craters show a water-ice signature in their rims and ejecta, and degraded craters have more infilling by organics. However, this was not the case with the VIMS data which sampled the upper microns of the surface. VIMS data was more dependent on the local geologic region and environment. For instance, all dunes craters have similar VIMS spectra, which is different than the plains craters. The VIMS signature of craters in the dunes regions shows an unknown spectra, thought to be a mix of organics and water-ice. These spectra likely comes as a result of the $\sim 100 \mathrm{~m}$ thick layer of organics in these regions (Neish et al., 2010). When the impactor made contact with this organic rich surface and probed the 
subsurface, organics and water-ice were intimately mixed during the excavation. Conversely, in the plains regions, craters show a spectra indicative of water-ice. This again, is likely a result of the geologic context and environment. It is thought that there is a much thinner layer of organics in the plains regions, $\sim 1 \mathrm{~m}$ thick. This would result in a VIMS water-ice signature because there are less organics present for mixing in during excavation; water-ice would dominate the surface. The VIMS and emissivity results for both regions are interpreted to mean that over time, the crater subsurface must be infilling with organics, and the surface remains the same composition. To explain this, we propose that the resulting fractured subsurface produced upon impact is being infilled with sediments over time but some active surface process, such as wind or rain, is effectively sweeping the surface off. If the surface is swept clean, the VIMS spectra would remain the same over time, as seen for dunes craters and plains craters, but if the subsurface fractures are being infilled with organic sediments, the emissivity value would increase over time, as seen in more degraded craters. This would mean that the dunes predate the dunes crater formation. Dunes are thought to be among the youngest surface features on Titan because they are not superimposed or cross cut by any fluvial features, however, it is not clear when they originated (Radebaugh, 2013). This research suggests they are older than the oldest crater found in Titan's sand seas. The overall interpretation of this work is that there are active surface processes on Titan which contribute to the resulting crater compositions.

In summary:

- The emissivity data shows that the subsurface composition of the craters is controlled by their degradation state, with older craters being infilled by more organics than younger craters.

- The surficial composition of the craters, exhibited by VIMS data, is controlled by their local environment. During impact crater formation, water-ice mixes with the organic rich dunes in the sand seas to produce a spectral signature unlike that found in the plains. This implies that the dunes predate crater formation in the sand seas, meaning they are relatively old (several hundred million years old). 
- Old craters in the plains have spectral signatures consistent with water-ice. Thus, there are likely active surface processes on Titan, such as wind or rain, which clear the surface of sediments and infill the subsurface fractures.

\subsection{Limitations}

As with any remote sensing research, there are limitations to this study. The first limiting factor is Titan's dense atmosphere. This is a unique characteristic amongst moons in the solar system: Titan is the only moon restricted to only a handful of wavelengths of the electromagnetic spectrum that can be utilized to sense the surface. Its dense atmosphere absorbs or reflects the majority of the electromagnetic spectrum and only transmits in a few specific windows in the near infrared, namely $0.94,1.08,1.28,1.6,2.0,2.7,2.8$, and 5.0 microns (Barnes et al., 2007), as well as in the microwave and radio portion of the electromagnetic spectrum. These specific atmospheric windows limit the type of information that can be learned about Titan's surface.

In addition to the restrictions Titan's atmosphere imposes upon remote sensing data sets, we are also restricted in the coverage and resolution of the data sets we do have. Four missions have studied Titan in detail: Pioneer, Voyager 1, 2, and Cassini. However, none of these missions were solely dedicated to studying Titan, but rather, the Saturn system as a whole. As a result, there is roughly $25 \%$ of Titan's surface that was not mapped by the Cassini RADAR instrument (Lopes et al., 2018). Moreover, the resolution of these images is at best $\sim 175 \mathrm{~m} /$ pixel (Lopes et al., 2010). Global images of Titan are available from VIMS and ISS, but their resolution is $250 \mathrm{~m} /$ pixel to greater than $50 \mathrm{~km} / \mathrm{pixel}$ (Barnes et al., 2007), and $450 \mathrm{~m} /$ pixel respectively (Archinal et al., 2013). In comparison, the Huygens probe was equipped with a Descent Imager and Spectral Radiometer (DISR) which took the highest resolution images available of the moon. Images were taken as often as possible during descent and had resolutions from 150 $\mathrm{m} /$ pixel to $0.4 \mathrm{~mm} /$ pixel (Karkoschka et al., 2007). Upon studying these, it became evident that some geologic features and details are certainly hidden in lower resolution images. For example, these images confirmed the presence of dendritic channels that were hinted at in the first radar images (Lorenz and Mitton, 2008). Moreover, small 
centimeter scale rounded cobbles were found scattered upon the landing region (Lorenz and Mitton, 2008). These cobbles and their round characteristics are something that is not able to be resolved in low resolution radar images.

There were also resolution issues with the topography data used in this work. The data used to calculate the elevation of each crater feature was from an interpolated global elevation map. This map was created from interpolation because less than $10 \%$ of Titan's surface is covered by topography data (Lorenz et al., 2013; Corlies et al., 2017). This map is the only way to extract global elevation data. Improved resolution of topography data would capture small nuances in elevation. For instance, with digital terrain models (DTMs) from DISR, it is possible to see small scale elevation changes which correlate with small dendritic channels (Soderblom et al., 2007). Furthermore, having improved global topography data would better constrain crater rim heights in relation to crater floors to determine an overall more refined, depth measurement. This improved elevation data could also highlight more circular features as crater candidates which were missed in radar images, providing a greater sample size to study the modification effects on Titan.

Finally, there is the possibility for error in composition interpretation from radiometry data. This was discussed in detail in Chapter 3, but to summarize, the low emissivity material inferred to be water-ice could instead be a brittle organic substance yet to be determined. The radiometry data provides information on a substance's dielectric constant, volume scattering, and emissivity. In Janssen et al. (2009; 2016), it was shown that lower emissivity values were a result of strong volume scattering and suggested the composition for these values to be water-ice. There is still the possibility that other organic substances could also act as equally efficient volume scatterers. This is unlikely though, for several reasons. First, the formation of Titan is thought to have been similar to the other icy moons, which leads to the likely conclusion that they have similar interior structures. In Chapter 1, the interiors of the icy Galilean moons were discussed, and it was noted that all are hypothesized to have an icy crust and subsurface (Sotin et al., 2009). Moreover, in general, organics are incapable of exceeding depths of 100s of meters (e.g. Yung et al., 1984), and impact craters excavate deeper than 100s of meters, 
implying that there would be more evidence of organics on the surface than currently seen. Additionally, the current inventory of organics requires approximately $135 \mathrm{Myr}$ to accumulate, which implies that these organic depositions from the atmosphere have not existed for long enough to form an organic crust (Lorenz et al., 2008; Nixon et al., 2012).

\subsection{Future work}

With the conclusion of the Cassini mission in September 2017, all high-resolution images of Titan's surface have been received. Additional high-resolution imagery may be acquired if a new mission to Titan is funded. In the meantime, studies utilizing the existing Cassini data are still underway. One such study by Hedgepeth et al. (2018) has used radar and topographic data to provide an up-to-date catalog of all the potential craters on Titan. With this, they have found about 30 more potential craters for a total of 90 craters on Titan's surface. This thesis work did include 3 of the newly discovered 30 craters; these were all suitable in diameter and likelihood of impact origin, whereas the remaining craters were either too small or too degraded, thus making it more uncertain as to their origin. If more craters were to be discovered, or if more were to be upgraded to a 'certain' ranking for impact origin, this thesis work could be expanded by analyzing these craters.

Auxiliary future work that would supplement this research would be experiments to further understand the nature of the different VIMS spectra. For instance, if the green VIMS spectra was able to be replicated experimentally, this would either confirm or deny the hypothesis that this spectrum represents a unit mixed with organics and water-ice. This would be beneficial to this study because the VIMS green signature is evident in dunes craters. Experimental work is currently being conducted at the University of Arkansas. Czaplinski et al. (2018) and Farnsworth et al. (2017, 2018) utilize a Titan surface simulation chamber for multiple experiments involving various hydrocarbons. Their overall goal is to learn how hydrocarbons, such as ethylene and benzene evaporites, or methane-ethane mixtures, react to surface conditions (Farnsworth et al., 2017; Czaplinski et al., 2018; Farnsworth et al., 2018). Specifically relevant to VIMS, Czaplinski et al. (2018) is working to understand 5-micron bright regions in the north polar lakes. Completing any experimental study which can simulate Titan conditions and 
narrow down the candidates for VIMS spectra is beneficial to deepen the knowledge of the interplay between different geologic units, compounds, and overall processes on Titan.

As with any study purely based in remote sensing, a ground truth component would be tremendously beneficial. NASA has selected two finalists for the New Frontiers program to launch in the 2020s, one of which would send a relocatable rotorcraft called Dragonfly to Titan (Lorenz et al., 2018; Turtle et al., 2018). Though this potential mission is still in development, it would have the capability of using Titan's atmosphere to its advantage. The drone-like rotorcraft would be able to travel long distances in a single hop, imaging a very large portion of Titan at high resolution, including sites possibly several hundred kilometers away from the initial landing site. It would carry a five instrument suite: a mass spectrometer, a gamma-ray and neutron spectrometer, a geophysics and meteorology package, a camera suite, and engineering systems (Lorenz et al., 2018). The mass spectrometer, geophysics and meteorology package, and camera suite would be particularly useful in ground truthing the results from this thesis (Lorenz et al., 2018). The mass spectrometer would have the capability to process high molecular weight samples (Lorenz et al., 2018), which, as described in Chapter 1, the INMS aboard Cassini could only measure compounds up to 100 Daltons. The geophysics and meteorology package will measure the dielectric constant and thermal properties of the ground surface (Lorenz et al., 2018). These two instrument suites would be able to confirm or refute the crater compositions derived from emissivity and VIMS data. The camera suite is equipped with multiple cameras: one for forward imaging, downward imaging, and a microscopic imager to study surface material on a fine-grain scale (Lorenz et al., 2008). Images taken by the drone, both in flight and on the surface, would prove exponentially helpful to resolve more detail of geologic features found in lower resolution Cassini RADAR images. This would be advantageous for the mapping of crater rims, ejecta blankets, and overall geologic context. Dragonfly, or a similar mission, would prove extraordinarily beneficial towards ground truthing this research and confirming the notion of active surface processes altering crater compositions on Titan. 


\subsection{References}

Archinal, B., Becker, T., Lee, E., and Edmundson, K. 2013. Initial global control network and mosaicking of ISS images of Titan. 44th Lunar and Planetary Science Conference, Houston. Abstract \# 2957.

Barnes, J. W., Brown, R. H., Soderblom, L., Buratti, B. J., Sotin, C., Rodriguez, S., Le Mouelic, S., Baines, K. H., Clark, R., and Nicholson, P. 2007. Global-scale surface spectral variations on Titan seen from Cassini/VIMS. Icarus 180, 242258.

Corlies, P., Hayes, A. G., Birch, S. P. D., Lorenz, R. D., Stiles, B. W., Kirk, R. L., Poggiali, V., Zebker, H., and Iess, L. 2017. Titan's topography and shape at the end of the Cassini mission. Geophysical Research Letters 44, 11754-11761.

Czaplinski, E., Farnsworth, K., Gilbertson, W., and Chevrier, V. 2018. Experimental studies of ethylene and benzene evaporites on Titan. 49th Lunar and Planetary Science Conference, Houston. Abstract \#1480.

Farnsworth, K., McMahon, Z., Laxton, D., Czaplinski, E., Chevrier, V., Luspay-Kuti, A., and Singh, S. 2017. Experimental study of nitrogen dissolution in methaneethane mixtures under Titan surface conditions. 48th Lunar and Planetary Science Conference, Houston. Abstract \#1932.

Farnsworth, K., McMahon, Z., Laxton, D., Chevrier, V., and Soderblom, J. M. 2018. Experimental study of the effects of freezing on liquid hydrocarbons on the surface of Titan. 49th Lunar and Planetary Science Conference, Houston. Abstract \#1974.

Hedgepeth, J. E., Neish, C. D., Turtle, E. P., and Stiles, B. W. 2018. Impact craters on Titan: Finalizing Titan's crater population. 49th Lunar and Planetary Science Conference, Houston. Abstract \#2105.

Janssen, M. A., Lorenz, R. D., West, R., Paganelli, F., Lopes, R. M. C., Kirk, R. L., Elachi, C., Wall, S. D., Johnson, W. T. K., Anderson, Y., Boehmer, R. A., 
Callahan, P., Gim, Y., Hamilton, G. A., Kelleher, K. D., Roth, L., Stiles, B., Le Gall, A., and the Cassini RADAR team. 2009. Titan's surface at 2.2-cm wavelength imaged by the Cassini RADAR radiometer: Calibration and first results. Icarus 200, 222-239.

Janssen, M. A., Le Gall, A., Lopes, R. M. C., Lorenz, R. D., Malaska, M. J., Hayes, A. G., Neish, C. D., Solomonidou, A., Mitchell, K. L., Radebaugh, J., Keihm, S. J., Choukroun, M., Leyrat, C., Encrenaz, P. J., and Mastrogiuseppe, M. 2016. Titan's surface at $2.18-\mathrm{cm}$ wavelength imaged by the Cassini RADAR radiometer: Results and interpretations through the first ten years of observation. Icarus 270, 443-459.

Karkoschka, E., Tomasko, M. G., Doose, L. R., See, C., McFarlane, E. A., Schroder, S. E., and Rizk, B. 2007. DISR imaging and the geometry of the descent of the Huygens probe within Titan's atmosphere. Planetary and Space Science 55, 1896-1935.

Lopes, R. M. C., Stofan, E. R., Peckyno, R., Radebaugh, J., Mitchell, K. L., Mitri, G., Wood, C. A., Kirk, R. L., Wall, S. D., Lunine, J. I., Hayes, A., Lorenz, R. D., Farr, T., Wye, L., Craig, J., Ollerenshaw, R. J., Janssen, M. A., Le Gall, A., Paganelli, F., West, R., Stiles, B., Callahan, P., Anderson, Y., Valora, P., Soderblom, L., and the Cassini RADAR Team. 2010. Distribution and interplay of geologic processes on Titan from Cassini radar data. Icarus 205, 540-558.

Lopes, R. M. C. et al., 2018. Titan as revealed by the Cassini RADAR. Space and Science Reviews, submitted.

Lorenz, R. D., Mitchell, K. L., Kirk, R. L., Hayes, A. G., Aharonson, O., Zebker, H. A., Paillou, P., Radebaugh, J., Lunine, J. I., Janssen, M. A., Wall, S. D., Lopes, R. M. C., Stiles, B., Ostro, S., Mitri, G., and Stofan, E. R. 2008. Titan's inventory of organic surface materials. Geophysical Research Letters 35, L02206.

Lorenz, R. D., and Mitton, J. 2008. Titan unveiled. Princeton, NJ: Princeton University Press. 
Lorenz, R. D., Stiles, B. W., Aharonson, O., Lucas, A., Hayes, A. G., Kirk, R. L., Zebker, H. A., Turtle, E. P., Neish, C. D., Stofan, E. R., Barnes, J. W., and the Cassini RADAR team. 2013. A global topographic map of Titan. Icarus 225, 367-377.

Lorenz, R. D., Turtle, E. P., Barnes, J. W., Trainer, M. G., Adams, D. S., Hibbard, K. E., Sheldon, C. Z., Zacny, K., Peplowski, P. N., Lawrence, D. J., Ravine, M. A., McGee, T. G., Sotzen, K. S., MacKenzie, S. M., Langelaan, J. W., Schmitz, S., Wolfarth, L. S., and Bedini, P. D. 2017. Dragonfly: A rotorcraft lander concept for scientific exploration at Titan. John Hopkins APL Technical Digest, submitted.

Neish, C. D., Lorenz, R. D., Kirk, R. L., and Wye, L. C., 2010. Radarclinometry of the sand seas of Africa's Namibia and Saturn's moon Titan. Icarus 208, 385-394.

Nixon, C. A., Temelso, B., Vinatier, S., Teanby, N. A., Bezard, B., Achterberg, R. K., Mandt, K. E., Sherrill, C. D., Irwin, P. G. J., Jennings, D. E., Romani, P. N., Coustenis, A., and Flasar, F. M. 2012. Isotopic ratios in Titan's methane: Measurements and modeling. The Astrophysical Journal 749, 159.

Radebaugh, J. 2013. Dunes on Saturn's moon Titan as revealed by the Cassini mission. Aeolian Research 11, 23-41.

Soderblom, L. A., Tomasko, M. G., Archinal, B. A., Becker, T. L., Bushroe, M. W., Cook, D. A., Doose, L. R., Galuszka, D. M., Hare, T. M., Howington-Kraus, E., Karkoschka, E., Kirk, R. L., Lunine, J. I., McFarlane, E. A., Redding, B. L., Rizk, B., Rosiek, M. R., See, C., Smith, and P. H. 2007. Topography and geomorphology of the Huygens landing site on Titan. Planetary and Space Science 55, 2015-2024.

Sotin, C., Mitri, G., Rappaport, N., Schubert, G., and Stevenson, D. 2009. Titan's interior structure. In Brown, R. H., Lebreton, J., and Waite, J. H (Eds)., Titan from Cassini-Huygens, New York, NY, Springer, 61-74. 
Turtle, E. P., Barnes, J. W., Trainer, M. G., Lorenz, R. D., Hibbard, K. E., Adams, D. S., Bedini, P., Brinckerhoff, B., Cable, M. L., Ernst, C., Freissinet, C., Hand, K., Hayes, A. G., Horst, S. M., Johnson, J. R., Karkoschka, E., Langelaan, J. W., Lawrence, D. J., Le Gall, A., Lora, J. M., MacKenzie, S. M., McKay, C. P., Neish, C. D., Newman, C. E., Palacios, J., Panning, M. P., Parsons, A. M., Peplowski, P. N., Radebaugh, J., Rafkin, S. C. R., Ravine, M. A., Schmitz, S., Soderblom, J. M., Sotzen, K. S., Stickle, A. M., Stofan, E. R., Tokano, T., Wilson, C., Yingst, R. A., and Zacny, K. 2018. Dragonfly: In situ exploration of Titan's organic chemistry and habitability. 49th Lunar and Planetary Science Conference, Houston. Abstract \#2083.

Yung, Y. L., Allen, M., and Pinto, J. P. 1984. Photochemistry of the atmosphere of Titan: comparison between model and observations. Astrophysical Journal Supplement Series 55, 465-506. 


\section{Curriculum Vitae}

Name:

Post-secondary Education and Degrees:

\section{Honors and Awards:}

Related Work Experience
Alyssa Werynski

University of Western Ontario

London, Ontario, Canada

2016-2018 M.Sc.

SUNY Geneseo

Geneseo, NY, USA

2011-2015 B.A.

Global Opportunities Award

University of Western Ontario

2018

Technologies for Exo-Planetary Science CREATE Program (TEPS) Scholarship

2017-2018

Dean's List

SUNY Geneseo

2011, 2015

Research and Teaching Assistant University of Western Ontario

2016-2018

Student Intern: GIS and Geology

NASA Langley Research Center

2016

Student Intern: Astrophysics

NASA Marshall Space Flight Center

2015

Research Assistant

SUNY Geneseo

2013-2015

\section{Publications:}

Werynski, A., Neish, C. D., Le Gall, A., Janssen, M. A., and the Cassini RADAR team. (2018). Compositional Variations in Titan's Impact Craters Indicates Active Surface Erosion. Icarus, in preparation. 